UNIVERSIDADE DE SÃO PAULO

FACULDADE DE ZOOTECNIA E ENGENHARIA DE ALIMENTOS

GERMÁN AYALA VALENCIA

Propriedades físicas de filmes à base de biopolímeros reforçados com laponita

Pirassununga

2017

GERMÁN AYALA VALENCIA 


\section{Propriedades físicas de filmes à base de biopolímeros reforçados com laponita}

(Versão corrigida)

Tese apresentada à Faculdade de Zootecnia e Engenharia de Alimentos da Universidade de São Paulo, como parte dos requisitos para a obtenção do Título de Doutor em Ciências do programa de pósgraduação em Engenharia de Alimentos.

Área de Concentração: Ciências da Engenharia de Alimentos

Orientador: Prof. Dr. Paulo José do Amaral Sobral

\section{Pirassununga}


Ficha catalográfica elaborada pelo

Serviço de Biblioteca e Informação, FZEA/USP, com os dados fornecidos pelo(a) autor(a)

A152p Ayala Valencia, Germán

Propriedades físicas de filmes à base de

biopolímeros reforçados com laponita / Germán Ayala

Valencia ; orientador Paulo José do Amaral Sobral.

- Pirassununga, 2017.

$125 \mathrm{f}$.

Tese (Doutorado - Programa de Pós-Graduação em Engenharia de Alimentos) - - Faculdade de Zootecnia e Engenharia de Alimentos, Universidade de São Paulo.

1. gelatina. 2. colágeno. 3. fécula de mandioca. 4. nanopartículas. 5. propriedades funcionais. I. do Amaral Sobral, Paulo José, orient. II. Título. 
Dedico a minha familia. 


\section{AGRADECIMENTOS}

Ao Prof. Paulo José do Amaral Sobral pela orientação e confiança durante os quatro anos de doutorado.

À Profa. Madeleine Djabourov pela orientação e confiança durante meu estágio de doutorado na França.

À FAPESP pela concessão da bolsa de doutorado no país (2012/24047-3), e ao CNPq pela concessão da bolsa no exterior SWE (200247/2015-8), as quais permitiram a dedicação exclusiva a este trabalho de doutorado.

Aos técnicos de laboratório Rodrigo Vinicius Lourenço e Ana Mônica Quinta Barbosa Bittante, assim como à Profa. Isabel Cristina Freita Moraes, pela ajuda e sugestões durante estes quatro anos.

À Faculdade de Zootecnia e Engenharia de Alimentos pela oportunidade de realização deste trabalho.

À Profa. Ana Cecilia Agudelo Henao pela amizade.

A Talita Ribeiro Gagliardi pelo seu amor, ajuda, apoio e compreensão.

Aos meus amigos e todos aqueles que de alguma forma contribuíram para a realização deste trabalho.

Muito obrigado. 


\section{RESUMO}

\section{VALENCIA, G. A. Propriedades físicas de filmes à base de biopolímeros}

reforçados com laponita. 2017. 125 f. Tese (Doutorado) - Faculdade de Zootecnia e Engenharia de Alimentos, Universidade de São Paulo, Pirassununga, 2017.

Os problemas ambientais provocados pelas embalagens à base de materiais sintéticos não biodegradáveis têm provocado um importante aumento nos estudos sobre filmes à base de biopolímeros. Entretanto, esses filmes têm limitações em suas propriedades, devido, sobretudo à sensibilidade a umidade relativa ambiente. Dentre as alternativas estudadas para melhorar as características desses materiais está o uso de nanopartículas, com destaque para a montmorilonita, que tem problemas de dispersão em água. Outra nanopartícula pouco usada em estudos à base de biopolímeros é a laponita, que é uma nanoargila sintética. Assim, o objetivo geral desta tese foi o desenvolvimento de filmes à base de biopolímeros (colágeno, gelatina e fécula de mandioca), reforçados com uma nanoargila (laponita). Foi estudado o efeito da concentração do biopolímero e da laponita, assim como o método de produção dos filmes (casting e espalhamento mecânico), além da qualidade da dispersão da nanopartícula, sobre as principais propriedades físicas dos filmes nanocompósitos, com especial interesse nas propriedades de superfície. Os filmes foram preparados pela desidratação de soluções formadoras de filmes (SFF), com 2,4 ou $8 \mathrm{~g}$ de biopolímero/100 g SFF; 25 ou 30 g glicerol/100 g de biopolímero; e 0, 1,5; 3; 4,5 e 6 g laponita/100 g de biopolímero. A laponita foi dispersa em água destilada, utilizando-se ultraturrax com velocidade de agitação de $20.000 \mathrm{rpm}$, por 30 minutos. As partículas de laponita em água tiveram tamanhos menores que $50 \mathrm{~nm}$. Não houve efeito da concentração do biopolímero, nem do método de produção (casting ou espalhamento mecânico) sob as propriedades de topografia superficial e físico-químicas estudadas nos filmes nanocompósitos. As análises de raios X e espectroscopia de infravermelho por transformada de Fourier revelaram que as plaquetas de laponita estiveram esfoliadas e/ou intercaladas nos filmes, e que não houve nenhuma formação de ligação química entre as plaquetas de laponita e os biopolímeros em estudo. A presença de laponita incrementou a irregularidade superficial dos filmes, especialmente naqueles produzidos com colágeno e fécula de mandioca. Outras propriedades dos filmes nanocompósitos, tais como densidade, umidade, cor, opacidade, propriedades térmicas, propriedades 
mecânicas, solubilidade em água, ângulo de contato à água, isotermas de sorção e permeabilidade ao vapor de água não sofreram alterações com a presença de laponita.

Palavras-chave: gelatina, colágeno, fécula de mandioca, nanopartículas, propriedades funcionais, dispersão. 


\begin{abstract}
VALENCIA, G. A. Physical properties of films based in biopolymers reinforced with laponite. 2017. 125 f. PhD Thesis - Faculdade de Zootecnia e Engenharia de Alimentos, Universidade de São Paulo, Pirassununga, 2017.
\end{abstract}

The environmental problems caused by packaging based on non-biodegradable synthetic materials have lead to a significant increase in studies about biopolymer films. However, these films have limited physicochemical properties due mainly to its sensitivity to ambient relative humidity. Among the alternatives studied to improve the physicochemical properties of these materials is the use of nanoparticles, especially the montmorillonite, which has problems of dispersion in water. Another nanoparticle no so much studied in films based on biopolymers is laponite, which is a synthetic nanoparticle. Thus, this these aims to development and characterize films based on biopolymers (collagen, gelatin and cassava starch), with a nanoparticle (laponite). The effects of biopolymer and laponite concentrations were studied, as well as, the film production method (casting and spreading), besides the quality of laponite dispersion and its relationship with the physicochemical properties of the films were investigated, with special interest on the surface properties. The films were produced by the dehydration of filmogenic-forming solutions (FFS), with 2, 4 or $8 \mathrm{~g}$ of biopolymer/100 $\mathrm{g}$ FFS; 25 or $30 \mathrm{~g}$ glycerol/100g of biopolymer; and $0,1.5,3,4.5$ and $6 \mathrm{~g}$ of laponite/100g of biopolymer. The laponite was dispersed in water using ultraturrax, at $20,000 \mathrm{rpm}$, for 30 minutes. The laponite particles in water had sizes smaller than 50 $\mathrm{nm}$. There was not effect of biopolymer concentration and film production method (casting or spreading) on the surface and physicochemical properties studied in the nanocomposite films. X-ray analysis and Fourier transform infrared spectroscopy revealed that laponite platelets were exfoliated and/or intercalated in the films, and that there were no formed chemical bonds between laponite platelets and the biopolymers studied. The presence of laponite increased the surface irregularity of the films, especially in those produced with collagen and cassava starch. Other properties in the nanocomposite films, such density, moisture content, color, opacity, thermal properties, mechanical properties, water solubility, water contact angle, sorption isotherms and water vapor permeability were not altered by the presence of laponite. 
Keywords: gelatin, collagen, cassava starch, nanoparticles, functional properties, dispersion. 


\section{LISTA DE ILUSTRAÇÕES}

Figura 1 - Representação de um fragmento de cadeia de amilose e amilopectina........ 23

Figura 2 - Estrutura idealizada da laponita................................................................ 24

Figura 3 - Exemplos de micrografias da laponita obtidas por microscopia eletrônica de varredura: 1000x (a) e 2000x (b).

Figura 4 - Elementos químicos detectados por espectroscopia de energia dispersiva na laponita.

Figura 5 - Exemplos de espectros obtidos por difração de raios X (a) e espectroscopia de infravermelho por transformada de Fourier (b) da laponita. 42

Figura 6 - Imagens representativas do ultraturrax e da dispersão de laponita em água obtida a $20.000 \mathrm{rpm}$ por 30 minutos.

Figura 7 - Exemplos de distribuição de tamanho das partículas nas dispersões de laponita, preparadas usando-se ultraturrax, com velocidade de agitação de $10.000 \mathrm{e}$ $15.000 \mathrm{rpm}$, durante 30 minutos (a), e 60 minutos (b); ou 20.000 e $23.000 \mathrm{rpm}$, durante 30 minutos (c), e 60 minutos (d).

Figura 8 - Imagem representativa de uma amostra de laponita obtida por microscopia de força atômica (a), perfil de altura (b), obtido no mesmo equipamento. Amostra preparada usando-se ultraturrax (20.000 rpm, durante 30 minutos), e diluída 1:150 em água destilada. 45

Figura 9 - Exemplos de curvas de fluxo das dispersões de laponita em água, preparadas usando-se ultraturrax. 46

Figura 10 - Exemplos de curvas de fluxo das soluções com $8 \mathrm{~g}$ de gelatina/100 g SFF (a), e das soluções com $4 \mathrm{~g}$ de fécula de mandioca/100 g SFF (b), ambas com laponita $\left(\mathrm{C}_{\text {lap }}\right)$

Figura 11 - Exemplos de curvas de varredura de deformação das soluções com $4 \mathrm{~g}$ de gelatina/100 g SFF, em função da concentração de laponita $\left(\mathrm{C}_{\text {lap }}\right.$ ), a $50^{\circ} \mathrm{C}$ (a), e $10{ }^{\circ} \mathrm{C}$ (b).

Figura 12 - Exemplos de curvas de varredura de temperatura das soluções com $4 \mathrm{~g}$ de gelatina/100 g SFF, em função da concentração de laponita $\left(\mathrm{C}_{\text {lap }}\right): 0 \%$ (a), e 6\% (b); e das soluções com $8 \mathrm{~g}$ de gelatina/100 g SFF, em função da concentração de laponita $\left(\mathrm{C}_{\text {lap }}\right): 0 \%(\mathrm{c})$, e $6 \%(\mathrm{~d})$.

Figura 13 - Imagens representativas dos filmes de colágeno $\left(\mathrm{C}_{\mathrm{col}}=4 \%\right)$, com laponita $\left(\mathrm{C}_{\text {lap }}=6 \%\right)$, produzidos por: casting (a) e espalhamento mecânico (b).

Figura 14 - Imagens representativas dos filmes de gelatina $\left(\mathrm{C}_{\text {gel }}=4 \%\right)$, com laponita $\left(\mathrm{C}_{\text {lap }}=6 \%\right)$, produzidos por: casting (a) e espalhamento mecânico (b).

Figura 15 - Imagens representativas dos filmes de fécula de mandioca $\left(\mathrm{C}_{\text {féc }}=4 \%\right)$, com laponita $\left(\mathrm{C}_{\text {lap }}=6 \%\right)$, produzidos por: casting (a) e espalhamento mecânico (b).......... 51 Figura 16 - Exemplos de espectros obtidos por difração de raios $\mathrm{X}$ dos filmes nanocompósitos de colágeno (a), gelatina (b) e fécula de mandioca (c), em função da concentração de colágeno $\left(\mathrm{C}_{\mathrm{col}}\right)$, gelatina $\left(\mathrm{C}_{\mathrm{gel}}\right)$, fécula de mandioca $\left(\mathrm{C}_{\text {féc }}\right)$ e laponita $\left(\mathrm{C}_{\text {lap }}\right)$, produzidos por espalhamento mecânico. 55 
Figura 17 - Exemplos de espectros obtidos por difração de raios $\mathrm{X}$ dos filmes de colágeno (a), gelatina (b) e fécula de mandioca (c), em função da concentração de

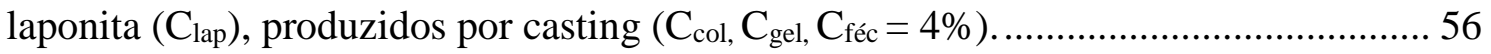

Figura 18 - Exemplos de espectros obtidos por difração de raios $\mathrm{X}$ dos filmes de fécula de mandioca, na região de: $2 \theta=2^{\circ}$ e $13^{\circ}$, em função da concentração de laponita $\left(\mathrm{C}_{\text {lap }}\right)$,

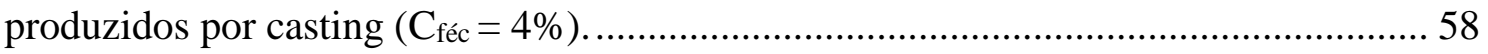

Figura 19 - Exemplos de espectros obtidos por espectroscopia de infravermelho por transformada de Fourier dos filmes de colágeno (a), gelatina (b) e fécula de mandioca (c), em função da concentração de laponita $\left(\mathrm{C}_{\text {lap }}\right)$, produzidos por espalhamento mecânico $\left(\mathrm{C}_{\mathrm{col}}, \mathrm{C}_{\mathrm{gel}}, \mathrm{C}_{\mathrm{féc}}=4 \%\right)$.

Figura 20 - Imagens representativas das micrografias de superfície dos filmes de colágeno, com concentrações de laponita de: $0 \%$ (a), 1,5\% (b), 3\% (c), $4,5 \%$ (d) e $6 \%$ (e), produzidos por casting $\left(\mathrm{C}_{\mathrm{col}}=4 \%\right)$.

Figura 21 - Imagens representativas das micrografias de seção transversal após criofratura dos filmes de colágeno, com concentrações de laponita de: 0\% (a), 1,5\% (b), $3 \%$ (c), $4,5 \%$ (d) e $6 \%$ (e), produzidos por casting $\left(\mathrm{C}_{\mathrm{col}}=4 \%\right)$.

Figura 22 - Imagens representativas das micrografias de superfície dos filmes de gelatina, com concentrações de laponita de: $0 \%$ (a), 1,5\% (b), 3\% (c), 4,5\% (d) e $6 \%$ (e), produzidos por espalhamento mecânico $\left(\mathrm{C}_{\text {gel }}=4 \%\right)$.

Figura 23 - Imagens representativas das micrografias de seção transversal após criofratura dos filmes de gelatina, com concentrações de laponita de: 0\% (a), 1,5\% (b), $3 \%$ (c), $4,5 \%$ (d) e $6 \%$ (e), produzidos por espalhamento mecânico $\left(\mathrm{C}_{\text {gel }}=4 \%\right)$.

Figura 24 - Imagens representativas das micrografias de superfície dos filmes de fécula de mandioca, com concentrações de laponita de: $0 \%$ (a), 1,5\% (b), 3\% (c), 4,5\% (d) e $6 \%$ (e), produzidos por espalhamento mecânico $\left(\mathrm{C}_{\text {féc }}=4 \%\right)$.

Figura 25 - Imagens representativas das micrografias de seção transversal após criofratura dos filmes de fécula de mandioca, com concentrações de laponita de: $0 \%$ (a), $1,5 \%$ (b), $3 \%$ (c), $4,5 \%$ (d) e $6 \%$ (e), produzidos por espalhamento mecânico $\left(\mathrm{C}_{\text {féc }}=\right.$ $4 \%)$.

Figura 26 - Imagens representativas das micrografias dos filmes de colágeno, com concentrações de laponita de: $0 \%$ (a), 1,5\% (b), 3\% (c), 4,5\% (d) e 6\% (e), produzidos por casting $\left(\mathrm{C}_{\mathrm{col}}=4 \%\right)$.

Figura 27 - Imagens representativas das micrografias dos filmes de gelatina, com concentrações de laponita de: $0 \%$ (a), 1,5\% (b), 3\% (c), 4,5\% (d) e 6\% (e), produzidos por espalhamento mecânico $\left(\mathrm{C}_{\mathrm{gel}}=4 \%\right)$.

Figura 28 - Imagens representativas das micrografias dos filmes de fécula de mandioca, com concentrações de laponita de: $0 \%$ (a), 1,5\% (b), 3\% (c), 4,5\% (d) e $6 \%$ (e), produzidos por casting $\left(\mathrm{C}_{\text {féc }}=4 \%\right)$.

Figura 29 - Exemplos de termogramas dos filmes de colágeno (a), gelatina (b) e fécula de mandioca (c), em função da concentração de laponita $\left(\mathrm{C}_{\text {lap }}\right)$, produzidos por casting $\left(\mathrm{C}_{\mathrm{col}}, \mathrm{C}_{\mathrm{gel}}, \mathrm{C}_{\text {féc }}=4 \%\right)$.

Figura 30 - Exemplos de isotermas de sorção dos filmes nanocompósitos de colágeno (a), gelatina (b) e fécula de mandioca (c), em função da concentração de laponita $\left(\mathrm{C}_{\text {lap }}\right)$, produzidos por casting $\left(\mathrm{C}_{\mathrm{col}}, \mathrm{C}_{\mathrm{gel}}, \mathrm{C}_{\text {féc }}=4 \%\right)$. 


\section{LISTA DE TABELAS}

Tabela 1 - Valores de potencial $\zeta(\mathrm{mV})$ das dispersões de laponita em água, preparadas usando-se ultraturrax*.

Tabela 2 - Composição das soluções formadoras de filmes (SFF) de proteínas e dos filmes de proteínas após secagem.

Tabela 3 - Composição das soluções formadoras de filmes (SFF) de fécula de mandioca e dos filmes de fécula de mandioca após secagem.

Tabela 4 - Valores de rugosidade média $R a$ e dimensão fractal $D F$ dos filmes de colágeno, gelatina e fécula de mandioca $\left(\mathrm{C}_{\mathrm{col}}, \mathrm{C}_{\mathrm{gel}}, \mathrm{C}_{\text {féc }}=4 \%\right)$, em função da concentração de laponita $\left(\mathrm{C}_{\text {lap }}\right)^{*}$......

Tabela 5 - Valores dos parâmetros de cor dos filmes de colágeno, gelatina e fécula de mandioca $\left(\mathrm{C}_{\text {col, }}, \mathrm{C}_{\text {gel, }}, \mathrm{C}_{\text {féc }}=4 \%\right)$, em função da concentração de laponita $\left(\mathrm{C}_{\text {lap }}\right)^{*} \ldots \ldots \ldots . . . .73$

Tabela 6 - Valores de brilho a $60^{\circ}$ dos filmes de colágeno, gelatina e fécula de mandioca $\left(\mathrm{C}_{\text {col, }}, \mathrm{C}_{\text {gel }}, \mathrm{C}_{\text {féc }}=4 \%\right)$, em função da concentração de laponita $\left(\mathrm{C}_{\text {lap }}\right)^{*} \ldots \ldots \ldots . . . .75$

Tabela 7 - Temperatura de transição vítrea $\left(\mathrm{T}_{\mathrm{g}}\right)$ dos filmes de colágeno, gelatina e fécula de mandioca $\left(\mathrm{C}_{\text {col, }}, \mathrm{C}_{\text {gel, }}, \mathrm{C}_{\text {féc }}=4 \%\right)$, em função da concentração de laponita $\left(\mathrm{C}_{\text {lap }}\right)$, para as duas varreduras de temperaturas*.

Tabela 8 - Valores de temperatura $\left(\mathrm{T}_{\mathrm{m}}\right)$ e entalpia $(\Delta \mathrm{H})$ de fusão dos filmes de colágeno e gelatina $\left(\mathrm{C}_{\mathrm{col}}, \mathrm{C}_{\mathrm{gel}}=4 \%\right)$., em função da concentração de laponita $\left(\mathrm{C}_{\mathrm{lap}}\right)^{*}$.

Tabela 9 - Valores das propriedades mecânicas determinados por testes de tração dos filmes de colágeno, gelatina e fécula de mandioca $\left(\mathrm{C}_{\text {col, }} \mathrm{C}_{\mathrm{gel}}, \mathrm{C}_{\text {féc }}=4 \%\right)$, em função da concentração de laponita $\left(\mathrm{C}_{\text {lap }}\right)^{*}$.

Tabela 10 - Valores das propriedades mecânicas determinadas por testes de perfuração dos filmes de colágeno, gelatina e fécula de mandioca $\left(\mathrm{C}_{\mathrm{col}}, \mathrm{C}_{\mathrm{gel}}, \mathrm{C}_{\text {féc }}=4 \%\right)$, em função da concentração de laponita $\left(\mathrm{C}_{\text {lap }}\right)^{*}$.

Tabela 11 - Valores de solubilidade dos filmes de colágeno, gelatina e fécula de mandioca $\left(\mathrm{C}_{\mathrm{col}}, \mathrm{C}_{\mathrm{gel}}, \mathrm{C}_{\text {féc }}=4 \%\right)$, em função da concentração de laponita $\left(\mathrm{C}_{\text {lap }}\right)^{*}$.

Tabela 12 - Valores de ângulo de contato $\left(^{\circ}\right)$ dos filmes de colágeno, gelatina e fécula de mandioca $\left(\mathrm{C}_{\text {col, }}, \mathrm{C}_{\text {gel, }}, \mathrm{C}_{\text {féc }}=4 \%\right)$, em função da concentração de laponita $\left(\mathrm{C}_{\text {lap }}\right)^{*} \ldots . . . .87$

Tabela 13 - Valores de permeabilidade ao vapor de água $\left(\mathrm{g} \cdot \mathrm{mm} / \mathrm{m}^{2} \cdot \mathrm{h} \cdot \mathrm{kPa}\right)$ dos filmes de colágeno, gelatina e fécula de mandioca $\left(\mathrm{C}_{\mathrm{col}}, \mathrm{C}_{\mathrm{gel}}, \mathrm{C}_{\text {féc }}=4 \%\right)$, em função da concentração de laponita $\left(\mathrm{C}_{\text {lap }}\right)^{*}$ 


\section{SUMÁRIO}

1. INTRODUÇÃ

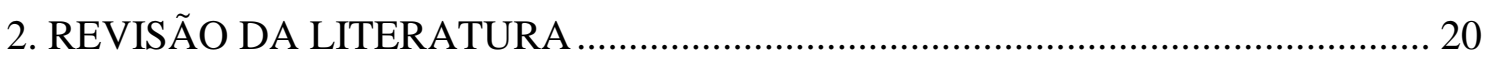

2.1. Nanotecnologia e nanocompósitos à base de biopolímeros ................................ 20

2.2. Principais biopolímeros utilizados para a produção de filmes nanocompósitos . 21

2.3. Principais nanoargilas utilizadas para a produção de filmes nanocompósitos .... 23

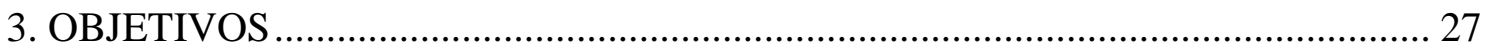

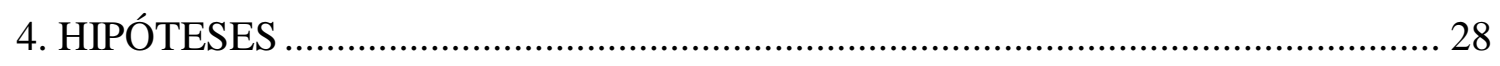

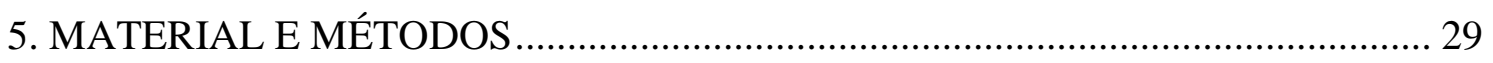

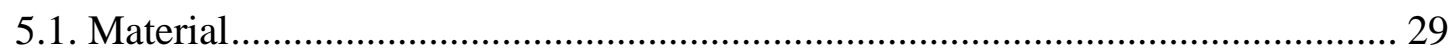

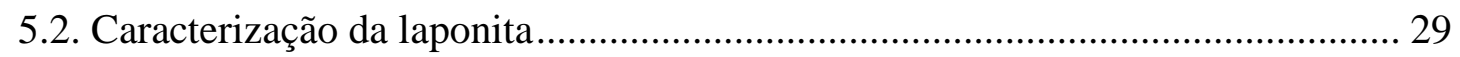

5.2.1. Microscopia eletrônica de varredura ....................................................... 29

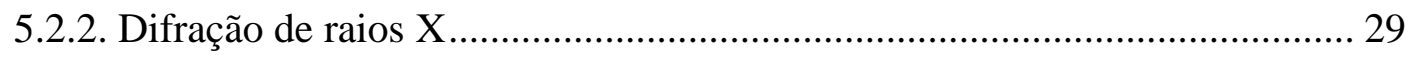

5.2.3. Espectroscopia de infravermelho por transformada de Fourier.................... 30

5.3. Produção e caracterização das dispersões de laponita......................................... 30

5.3.1. Tamanho de partícula, potencial $\zeta$ e pH ................................................... 30

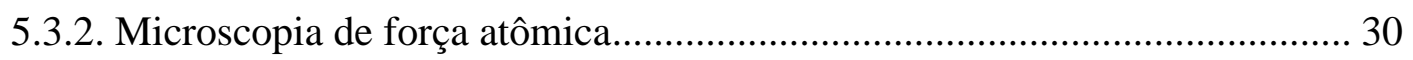

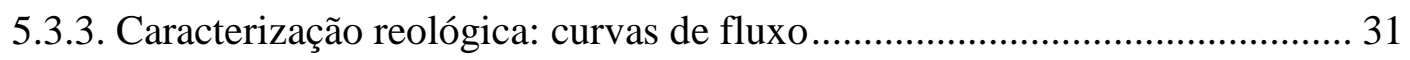

5.4. Produção das soluções formadoras de filmes (SFF) à base de biopolímeros com

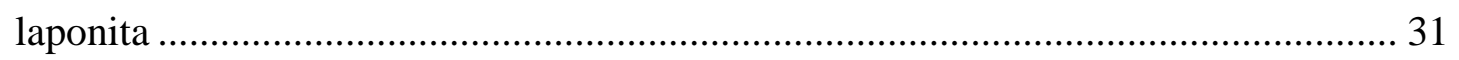

5.5. Caracterização reológica das soluções formadoras de filmes (SFF) à base de

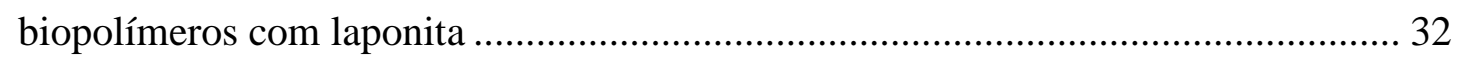

5.6. Produção de filmes nanocompósitos à base de biopolímeros com laponita......... 33

5.7. Caracterização dos filmes nanocompósitos à base de biopolímeros com laponita 34

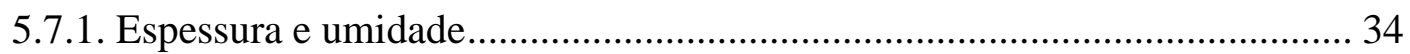

5.7.2. Difração de raios X e Espectroscopia de infravermelho por transformada de

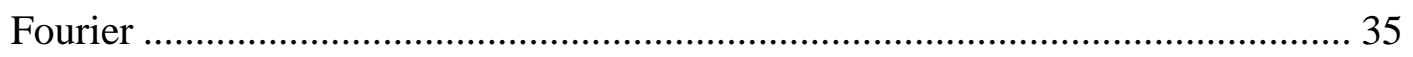

5.7.3. Microscopia eletrônica de varredura ...................................................... 35

5.7.4. Microscopia de força atômica.................................................................... 35

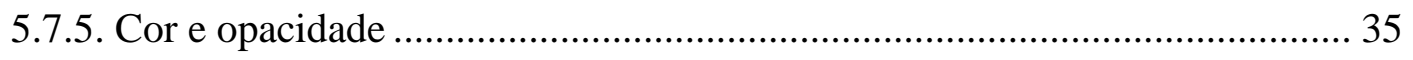

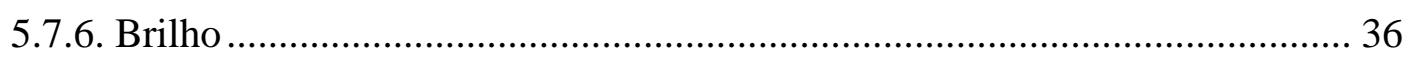

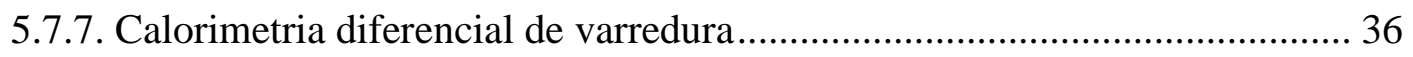


5.7.8. Propriedades mecânicas: ensaios de tração uniaxial e de perfuração 37

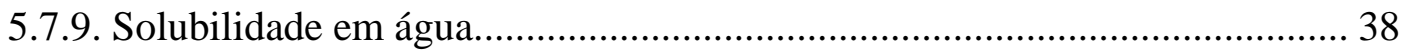

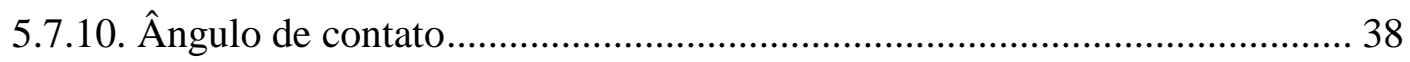

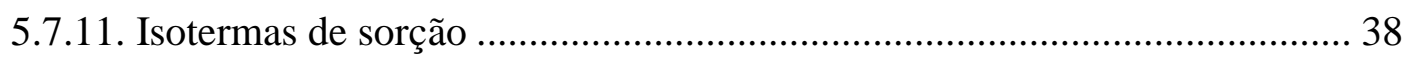

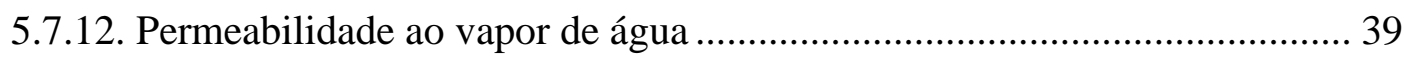

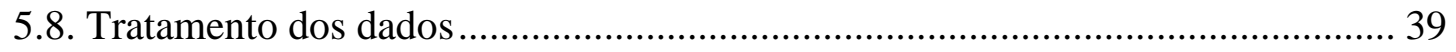

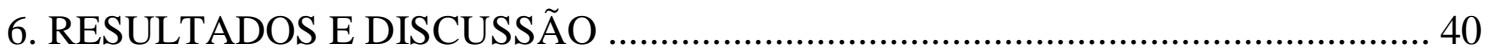

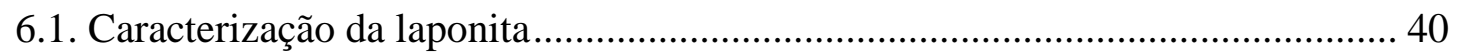

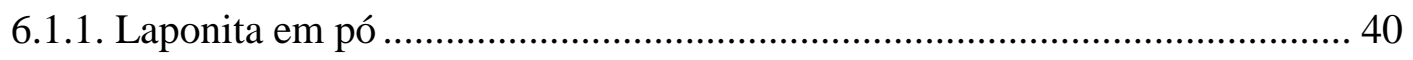

6.1.1.1. Microscopia eletrônica de varredura .................................................... 40

6.1.1.2. Difração de raios X e Espectroscopia de infravermelho por transformada

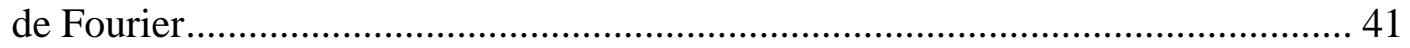

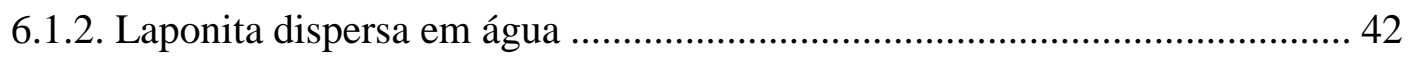

6.1.2.1. Tamanho de partícula, potencial $\zeta$ e $\mathrm{pH}$............................................... 42

6.1.2.2. Microestrutura da laponita por microscopia de força atômica .................. 45

6.1.2.3. Reologia das dispersões de laponita em água.......................................... 45

6.2. Caracterização reológica das SFF à base de biopolímeros com laponita ............ 46

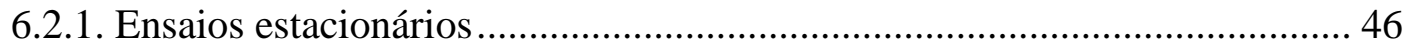

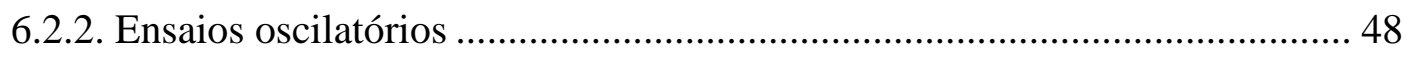

6.3. Caracterização dos filmes nanocompósitos ...................................................... 50

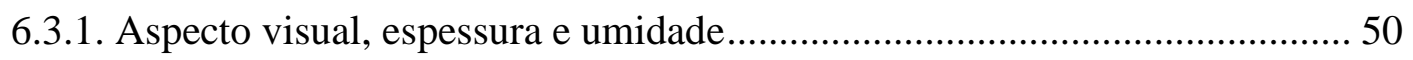

6.3.2. Difração de raios $\mathrm{X}$ e espectroscopia de infravermelho por transformada de

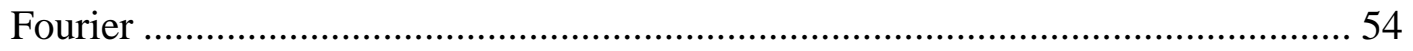

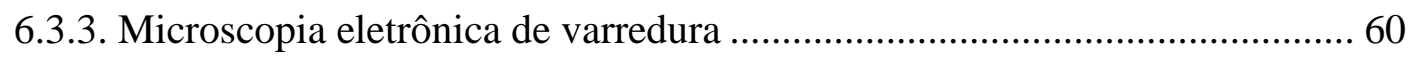

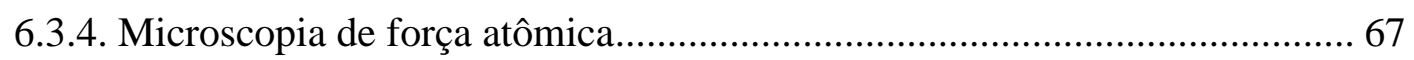

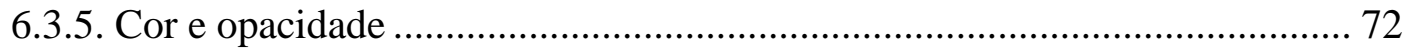

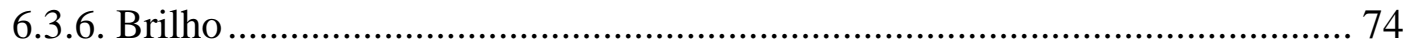

6.3.7. Calorimetria diferencial de varredura......................................................... 75

6.3.8. Propriedades mecânicas: ensaios de tração uniaxial e de perfuração............ 80

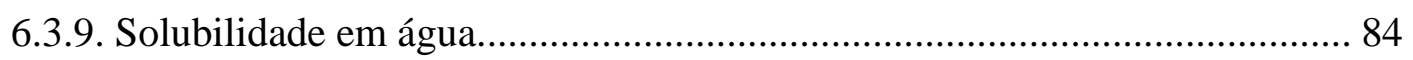

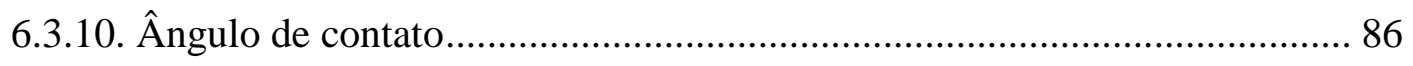

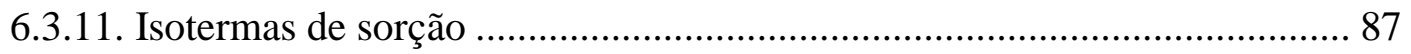

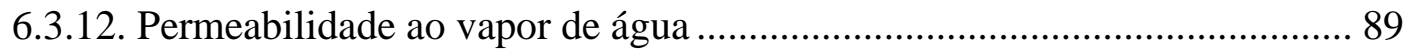

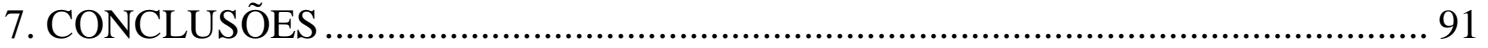


8. SUGESTÕES PARA TRABALHOS FUTUROS................................................. 93

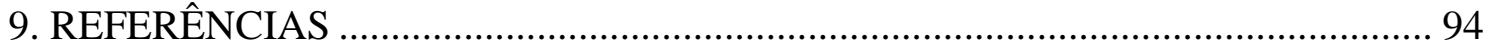

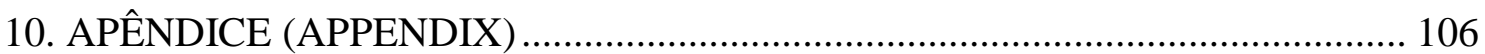




\section{INTRODUÇÃO}

$\mathrm{O}$ crescente aumento na demanda por produtos naturais, como embalagens potencialmente biodegradáveis, assim como o aumento na conscientização ambiental por produtos que gerem um menor impacto negativo ao meio ambiente, tem motivado fortemente o estudo de materiais biológicos para o desenvolvimento de novas embalagens (BODINI et al., 2013).

Diferentes materiais de origem biológica, como celulose, amido, colágeno, gomas e seus derivados, têm sido empregados na produção de filmes comestíveis e/ou biodegradáveis (BERTUZZI; ARMADA; GOTTIFREDI, 2007; GENNADIOS et al., 1994; TAPIA-BLACIDO et al., 2007; THARANATHAN, 2003). De acordo com Sothornvit e Krochta (2001), o uso de filmes biodegradáveis na indústria de alimentos apresenta um grande potencial para garantir ótima qualidade e vida de prateleira. Estes materiais têm sido utilizados como embalagens em diversos alimentos, tais como: vegetais, frutas frescas e minimamente processadas, entre as quais se destacam o tomate, a papaia, o pepino, a maçã, a manga, a couve-flor, os pimentões verde e vermelho (AYRANCI e TUNC, 2003; 2004; MALI e GROSSMANN, 2003; PEREZGAGO; SERRA; RIO, 2006; TAPIA et al., 2008); carnes bovina e de búfala (CHIDANANDAIAH e SANYAL, 2009; OUSSALAH et al., 2004); produtos processados à base de peixe e sardinha defumada (GÓMEZ-ESTACA et al., 2007; LOPEZ-CABALLERO et al., 2005); manteiga e gorduras derivadas do porco (OU et al., 2005; PONCE et al., 2008); cogumelos (AYRANCY e TUNC, 2003); amendoins e nozes (BALDWIN e WOOD, 2006; LEE et al., 2002).

Algumas macromoléculas de origem biológica têm sido extensamente estudadas para produção de filmes biodegradáveis, com destaque para o colágeno, que é uma proteína extraída da pele e dos ossos de bovinos ou suínos; a gelatina, que deriva do fracionamento das cadeias peptídicas do colágeno; e o amido, que é conhecido como um dos biopolímeros mais abundantes na natureza, depois da celulose (MARIA et al., 2008; VALENCIA; HENAO; ZAPATA, 2012).

De forma geral, os filmes biodegradáveis se caracterizam por serem materiais higroscópicos, ou seja, sensíveis à umidade do ar, o que afeta suas propriedades mecânicas, limitando suas aplicações comerciais (ANDREUCCETTI; CARVALHO; GROSSO, 2010; DIAS et al., 2013; GENNADIOS et al., 1994). Em busca de melhorar as propriedades físicas dos filmes biodegradáveis, diferentes alternativas têm sido 
estudadas, tais como a utilização de novos plastificantes, hidrofílicos (ex.: manitol e xilitol) (NAVARRO-TARAZAGA; SOTHORNVIT; PEREZ-GAGO, 2008; ZHANG; HAN, 2006), ou hidrofóbicos (ex.: citrato de acetil tributila, citrato de tributila e acetil citrato de trietilo) (ANDREUCCETTI; CARVALHO; GROSSO, 2010); a adição na formulação de compostos apolares, como óleos vegetais (ex.: óleo de girassol) (GARCIA; MARTINO; ZARITZKI, 2000), ácidos graxos (ex.: ácido palmítico, láurico e esteárico) (POMMET et al., 2010); assim como aminoácidos (ex.: glicina e isoleucina) (STEIN; GORDON; GREENE, 1999); o uso de ureia (GALDEANO et al., 2009); o uso de cargas, como fibras vegetais (TEXEIRA et al., 2009; WU et al., 2016; YUAN et al., 2014) e bagaço de cana (SHAIKH et al., 2009); e uso de blendas de biopolímeros (WANG et al., 2017), ou de biopolímeros com polímeros sintéticos biodegradáveis, como o poli(vinil álcool) (BONILLA et al., 2014). Contudo, estas alternativas não têm melhorado suficientemente as propriedades dos filmes biodegradáveis (BAE et al., 2009).

Novas alternativas para melhorar as propriedades dos filmes biodegradáveis vêm sendo propostas, dentre as quais destaca-se a utilização de carga de materiais em escala nanométrica, conhecidos como nanopartículas, com destaque para a montmorilonita, que é uma nanoargila de origem natural (CHIOU et al., 2007; CYRAS et al., 2008; FLAKER et al., 2015; KAMPEERAPAPPUN et al., 2007; SOUZA et al., 2012).

Com exceção da montmorilonita, poucos estudos são encontrados na literatura sobre a utilização de nanoargilas em filmes biodegradáveis. Dessa forma, outras nanoargilas similares merecem atenção, como é o caso da laponita (PEROTTI et al., 2011), que tem sido amplamente usada na tecnologia de filmes à base de polímeros sintéticos e no desenvolvimento de sensores e biossensores (BESOMBES et al., 1995; LIU, 2007; NELSON e COSGROVE, 2004; SHAN et al., 2010).

Recentemente, a laponita tem sido aplicada em filmes à base de amido de milho, fécula de mandioca e gelatina, contribuindo para certa melhora das propriedades mecânicas, como módulo elástico e tensão na ruptura (CHUNG et al., 2010; TANG e ALAVI, 2012; PEROTTI et al., 2014; LI et al., 2015). 
Esta tese é composta de sete seções:

$\checkmark$ Seção 1. Corresponde à Introdução, onde se apresenta uma breve introdução à tese, para contextualização do trabalho realizado.

$\checkmark$ Seção 2. Correspondendo à Revisão Bibliográfica, onde estão apresentados alguns conceitos de nanotecnologia, nanopartícula, compósitos e nanocompósitos, assim como os biopolímeros (colágeno, gelatina e fécula de mandioca), e nanoargila (laponita), utilizados na parte experimental desta tese. Também se apresentam as pesquisas mais importantes e atuais, na área dos nanocompósitos à base de biopolímeros com laponita. Este capítulo serviu, inclusive, para justificar a escolha dos biopolímeros estudados.

$\checkmark$ Seções 3 e 4. Correspondem aos Objetivos e à Hipótese desta tese.

$\checkmark$ Seção 5. As descrições dos experimentos e das análises realizadas para as caracterizações da lapontita, das soluções filmogênicas e dos filmes nanocompósitos estão apresentadas nesta parte, correspondendo a Material e Métodos.

$\checkmark$ Seção 6. Resultados e discussão. Nesta seção, se apresentam e discutem os resultados referentes a caracterização da laponota, da dispersão da laponita em água, e das propriedades das soluções filmogênicas e dos filmes à base de colágeno, gelatina ou fécula de mandioca, contendo laponita.

$\checkmark$ Seção 7. As Conclusões desta tese de doutorado estão devidamente descritas nesta seção.

$\checkmark$ APÊNDICE. Para terminar esta tese, dois apêndices (A1 e A2) estão descritos na forma de manuscritos para publicação em revistas científicas, sendo que esses dados foram obtidos na Ecole Supérieure de Physique et Chimie Industrielle de la Ville de Paris (ESPCI), durante estágio de tese sanduíche, com bolsa do Programa Ciências sem Fronteira.

O primeiro apêndice (A1), trata de um estudo bastante detalhado e criterioso sobre propriedades térmicas da fécula de mandioca, estudada principalmente com o emprego da técnica TGA (análise termogravimétrica), onde se determinou os vários tipos de água 
absorvida e as energias envolvidas. Este material está publicado na revista Carbohydrate Polymers.

O segundo apêndice (A2), trata sobre a higroscopicidade da laponita em pó, onde se correlacionou sua cristalinidade com os diversos níveis de umidade absorvida. 


\section{REVISÃO DA LITERATURA}

\subsection{Nanotecnologia e nanocompósitos à base de biopolímeros}

O estudo da matéria na escala nanométrica foi proposto pela primeira vez pelo físico Richard Feynman no ano de 1959, quem sugeriu a possibilidade de construir novos materiais a partir da manipulação dos átomos, permitindo assim o controle da matéria desde sua escala atômica (TOUMEY, 2008). O termo nanotecnologia se refere à manipulação da matéria, onde as partículas em estudo possuem um tamanho entre 0,1 e 100 nm (BOUWMEESTER et al., 2009; MAZUR, 2012).

Os primeiros estudos na área da nanotecnologia foram orientados por Lianos e Thomas (1986; 1987), assim como por Lisieki e Pileni (1993), os quais produziram partículas de cádmio, cobre e chumbo com tamanhos inferiores que $30 \mathrm{~nm}$. Nestas pesquisas foi concluído que o processo de sínteses alterou o tamanho e a forma das nanopartículas, levando a alterações nas propriedades físicas das mesmas. Em outros estudos, Kojima et al. (1993) e (1994) dispersaram montmorilonita no nylon, obtendo materiais nanocompósitos com melhores propriedades térmicas e mecânicas.

O grande interesse no estudo dos nanomateriais deve-se a sua aplicação em diversas áreas do conhecimento, tais como física, química, ciência dos materiais, medicina, entre outras. Estas aplicações derivam das propriedades térmicas, óticas, magnéticas, eletrônicas, elétricas, mecânicas, microbiológicas, entre outras, que as nanopartículas apresentam (FILIPPO et al., 2010; WEI e QUIAN, 2008). As modificações das propriedades físicas, químicas e magnéticas dos materiais na nanoescala, quando comparados com os mesmo materiais na macroescala, se deve principalmente a dois fatores: o primeiro faz referência à manifestação dos efeitos quânticos, que são mais visíveis na nanoescala, assim como aumento da área superficial como consequência do aumento na proporção entre a área e o volume (MAZUR, 2012).

O incremento da área superficial pode ser entendido ao analisar a fração de área presente na superfície (A) e o volume (V). A relação A/V em materiais macroscópicos, microscópicos e nanoscópicos é de aproximadamente $10^{2} \mathrm{~m}^{-1}, 10^{6} \mathrm{~m}^{-1}$ e $10^{9} \mathrm{~m}^{-1}$, respectivamente. Portanto, a relação A/V em materiais nanoscópicos é $10^{7}$ vezes maior quando comparado com os materiais macroscópicos (CAO e WANG, 2011).

Uma parte da nanotecnologia se dedica ao estudo de nanocompósitos, ou seja, de compósitos com pelo menos uma fase em escala nanométrica. Os compósitos são sistemas constituídos por pelo menos dois materiais (fases), os quais podem ser da mesma natureza, ou não. Estes materiais compósitos apresentam uma significante 
proporção de propriedades das fases constituintes, obtendo assim uma melhor combinação de propriedades em um material só, quando comparado com suas fases constituintes por separado (BARROSO, 2009; MAZUR, 2012). Na maioria dos casos, os compósitos são formados unicamente por duas fases: a fase contínua, constituída geralmente pelo material mais dúctil, sendo a que se apresenta em maior proporção no compósito; e a fase dispersa, constituída geralmente por um material mais rígido do que na fase contínua, apresentando-se em menor proporção no compósito (BARROSO, 2009; MAZUR, 2012).

No material compósito, a fase dispersa também é conhecida como carga, que pode ser adicionada no sistema com a finalidade de reduzir o custo do material ou de melhorar as propriedades do material compósito. No primeiro caso, a fase dispersa será chamada de carga de enchimento ou carga inerte; no segundo caso, a fase dispersa será chamada de carga de reforço (PAOLI, 2008).

Os nanocompósitos, similarmente aos compósitos estão constituídos por pelo menos dois materiais (fases), havendo igualmente uma fase contínua e uma fase dispersa. A diferença é que no nanocompósito, o material da fase dispersa deve possuir pelo menos uma das suas dimensões na escala nanométrica (MAZUR, 2012). Exemplos de materiais nanocompósitos são os filmes à base de biopolímeros reforçados com nanoargilas, os quais foram objeto de estudo desta tese.

\subsection{Principais biopolímeros utilizados para a produção de filmes nanocompósitos}

Segundo Vieira et al. (2011), os biopolímeros são macromoléculas sintetizadas por seres vivos, sendo classificados em quatro grupos, de acordo com suas fontes:

- Polímeros obtidos da biomassa: podem ser polissacarídeos, tais como: o amido, a lignocelulose, as pectinas, a quitina, o quitosana e algumas gomas; ou proteínas, tais como: a caseína, a proteína do soro do leite, o colágeno e a gelatina, de origem animal; ou a zeína, a soja e o glúten, de origem vegetal.

- Polímeros obtidos por vias microbianas: os mais comuns são os polihidroxialcanoatos (PHA), como o polihidroxibutirato $(\mathrm{PHB})$ e $\mathrm{o}$ polihidroxibutirato-co-hidroxivalerato $(\mathrm{PHBv})$.

- Polímeros sintetizados quimicamente a partir de monômeros da biomassa: o mais comum é o poli(ácido lático) (PLA). 
- Polímeros cujos monômeros e polímeros são obtidos pela síntese química de fontes fósseis, sendo os mais comuns: as policaprolactonas (PCL), poliestereamidas (PEA), poliésteres alifáticos e aromáticos, dentre outros.

Devido a sua alta aplicabilidade no setor alimentar (VIEIRA et al., 2011), na presente tese foram escolhidos três biopolímeros obtidos da biomassa: o colágeno, a gelatina e a fécula de mandioca. Estes foram utilizados como a fase contínua na elaboração dos filmes nanocompósitos.

O colágeno é uma proteína, podendo ser classificada como tipo I, II, III e IV. O colágeno tipo I é o mais abundante, sendo encontrado na pele, tendões, ligamentos e ossos, principalmente de mamíferos (PRESTES, 2012). A unidade básica do colágeno tipo I é o tropocolágeno, constituído pela interação paralela de três cadeias de polipeptídios, duas $\alpha_{1}$ e uma $\alpha_{2}$, que se entrelaçam em formato helicoidal, formando uma molécula linear com comprimento entre 180 e $280 \mathrm{~nm}$, largura entre 1,4 a 1,5 nm e massa molecular entre 345.000 e 360.000 Da (PRESTES, 2012; VIEIRA et al., 2011). O colágeno é extraído a partir de diversas matérias primas, como o couro de bovino, sendo obtido fibras de colágeno e pó de colágeno, ambos insolúveis em água (WOLF; SOBRAL; TELIS, 2009).

A gelatina é obtida a partir da hidrólise do tropocolágeno, que pode ser:

- Hidrólise parcial ácida: tratamento realizado em meio ácido, em temperaturas entre 65 e $68{ }^{\circ} \mathrm{C}$. A gelatina obtida por este processo é do tipo “ A", caracterizada por ter uma ampla faixa de massa molecular, entre 30.000 a $300.000 \mathrm{Da}$ (PRESTES, 2012).

- Hidrólise parcial alcalina: tratamento realizado em meio alcalino, em temperaturas entre 65 e $68{ }^{\circ} \mathrm{C}$. A gelatina obtida por este processo é do tipo “'B', caracterizada por ter uma massa molecular de aproximadamente 100.000 Da (PRESTES, 2012).

Os dois tipos de gelatina são solúveis em água quente e possuem diferentes valores de $\mathrm{pH}$ em solução aquosa. Para a gelatina tipo “A”, o pH esta na faixa de 7 e 9 , e na gelatina tipo “'B', na faixa de 4,7 a 5,5. A mudança no $\mathrm{pH}$ da gelatina, assim como a diferença da massa molecular geram propriedades funcionais diferentes nas gelatinas (PRESTES, 2012).

A fécula de mandioca é o amido da mandioca. O amido é um polissacarídeo de origem vegetal, constituído de amilose (20 - 35\%), e amilopectina (80 - 65\%) (TESTER; KARKALAS; QI, 2004). Tanto a amilose como a amilopectina estão 
constituídos de alfa glucanos, conectados por ligações $\alpha-1,4$, e $\alpha-1,6$ (Figura 1). A porcentagem de ligações $\alpha-1,6$ na amilose e na amilopectina é de aproximadamente $1 \%$ e $5 \%$, respectivamente. As ligações $\alpha-1,4$ formam estruturas lineares, enquanto que as ligações $\alpha-1,6$, geram estruturas ramificadas; portanto, a amilose se caracteriza por ser um biopolímero linear, enquanto que a amilopectina é ramificado (Figura 1) (TESTER; KARKALAS; QI, 2004).

Figura 1 - Representação de um fragmento de cadeia de amilose e amilopectina.
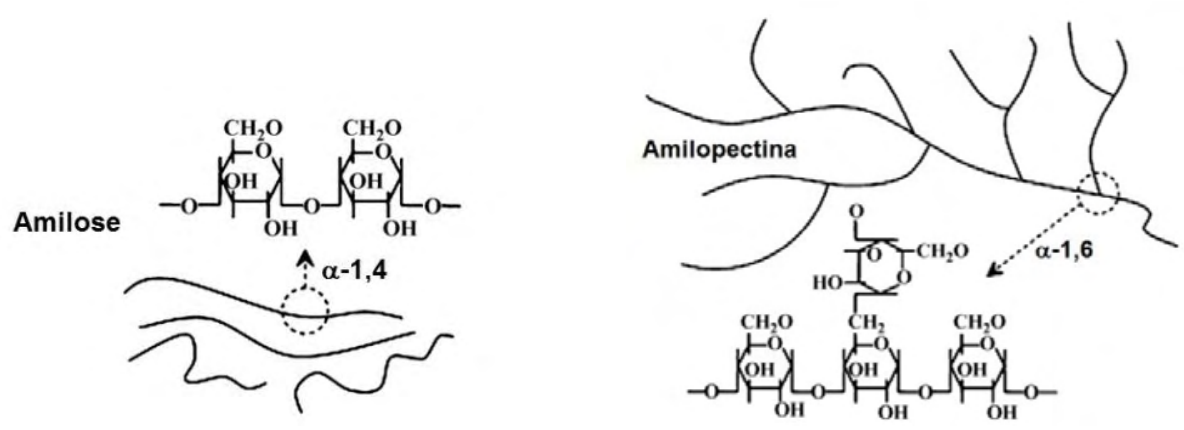

Fonte: Liu et al. (2009).

Na natureza, o amido é encontrado em forma de grânulos, os quais são insolúveis em água fria, porém, o aquecimento da água leva à sua solubilização, processo conhecido como gelatinização (TESTER; KARKALAS; QI, 2004). No caso da fécula de mandioca (ou amido de mandioca), os grânulos têm forma lenticular e/ou esférica, com tamanhos de partícula entre 5 - $45 \mu \mathrm{m}$, relação de amilose/amilopectina de 17/83 e temperatura de gelatinização entre 65 - $70 \quad{ }^{\circ} \mathrm{C}$ (BREUNINGER; PIYACHOMKMAN; SRIROTH, 2009; TESTER; KARKALAS; QI, 2004).

\subsection{Principais nanoargilas utilizadas para a produção de filmes nanocompósitos}

As nanoargilas se conformam pela combinação de camadas de sílica $\left(\mathrm{Si}_{2} \mathrm{O}_{5}\right)_{\mathrm{n}}$ com configuração tetraédrica $(\mathrm{T})$, e camadas de alumina $\mathrm{AlO}(\mathrm{OH})_{2}$ com configuração octaédrica (O) (ANDERSON et al., 2010; COELHO e SANTOS, 2007). Quando uma camada $\mathrm{T}$ interage com uma camada $\mathrm{O}$, a nanoargila formada tem uma proporção 1:1, conhecida como nanoargila T-O. Outra opção é a formação de nanoargilas T-O-T, produto da interação de duas camadas de $\mathrm{T}$ com uma camada $\mathrm{O}$, sendo que, a camada $\mathrm{O}$ esta no meio em forma de sanduíche. Tanto as argilas T-O como as T-O-T podem chegar a ter tamanho entre 1 e $100 \mathrm{~nm}$, sendo classificadas como nanoargilas 
(ANDERSON et al., 2010; COELHO e SANTOS, 2007). A maioria das nanoargilas são de origem natural, exemplo a montmorilonita, mas também podem ser sintéticas como a laponita (CUMMINS, 2007). As propriedades das nanoargilas dependem da estrutura cristalina e da composição química dos seus constituintes (ANDERSON et al., 2010).

Entre os diferentes grupos de nanoargilas, o grupo da esmectita (T-O-T) tem sido privilegiado nas pesquisas. Exemplos de nanoargilas deste grupo são a montmorilonita e a nontronita. A montmorilonita tem sido a nanoargila mais estudada no desenvolvimento de materiais nanocompósitos, desde a década dos 90 e até a atualidade, sendo utilizada como material reforçador de diferentes polímeros sintéticos e biodegradáveis, incluindo os biopolímeros (JORGE et al., 2014; FLAKER et al., 2015; RAY et al., 2006).

A laponita é uma nanoargila do grupo da esmectita, pouco aplicada no desenvolvimento de filmes à base de biopolímeros. A fórmula química da laponita é $\left(\mathrm{Si}_{8}\left[\mathrm{Mg}_{5.5} \mathrm{Li}_{0.4} \mathrm{H}_{4.0} \mathrm{O}_{24.0}\right]^{0.7-}\left[\mathrm{Na}_{0.7}\right]^{0.7+}\right)$ (TAWARI; KOCH; COHEN, 2001). A laponita tem forma de placa com comprimento de aproximadamente $25 \mathrm{~nm}$, e espessura de aproximadamente $1 \mathrm{~nm}$ (Figura 2) (CUMMINS, 2007; RUZICKA e ZACARELLI, 2011). As placas de laponita apresentam uma densidade de carga negativa na superfície, de $1,4 \times 10^{-2} \mathrm{e}^{-} / \AA^{2}$, o que permite a sua estabilização e formação de suspensões em água (HERRERA et al., 2004; NICOLAI e COCARD, 2000).

Figura 2 - Estrutura idealizada da laponita.

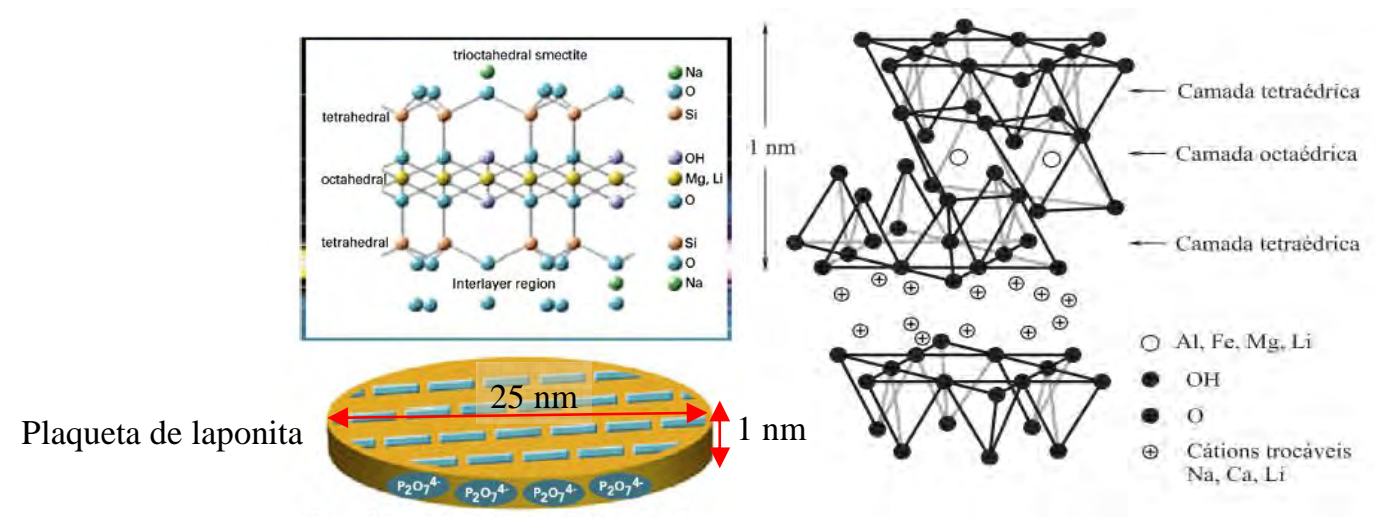

Fonte: Cummins (2007); Paiva, Morales, Guimarães (2006).

A laponita tem sido amplamente utilizada como aditivo para modificar o comportamento reológico em produtos usados na agricultura, construção, saúde, assim como na indústria do papel, de pinturas, adesivos e de polímeros. Muitas das aplicações 
desta nanoargila são em forma de suspensão ou gel, contendo altas concentrações de laponita (CUMMINS, 2007; HERRERA et al., 2004; KUMAR; MURALIDHAR; JOSHI, 2008).

Em diversas áreas de pesquisa onde a laponita tem aplicações tecnológicas é importante conhecer o mecânismo de dispersão desta nanoargila em água, sendo que, a laponita pode estar dispersa na sua unidade elementar (plaqueta), ou como agregados de plaquetas (PEROTTI et al., 2014). Avery e Ramsay (1986) estudaram a dimensão da laponita em água a uma concentração de $10 \%$ (p/v) e observaram tamanho de partículas de $30 \mathrm{~nm}$, que foram associados ao diâmetro das plaquetas de laponita (Figura 2). Esses autores não informaram as condições de dispersão, nem o método usado.

Nicolai e Cocard (2000) caracterizaram dispersões de laponita em concentrações de $1 \times 10^{-3}$ e $2 \times 10^{-3} \%(\mathrm{p} / \mathrm{v})$. Não foram informadas as condições de dispersão, nem o método usado. Esses autores observaram que o tamanho final das partículas esteve entre 1 e 100 nm. Balnois, Vidal, Levitz (2003) dispersaram laponita em água a uma concentração de $0,1 \%(\mathrm{p} / \mathrm{v})$ e observaram tamanho de partículas entre 5 e $42 \mathrm{~nm}$, que foram associados com a presença de plaquetas de laponita, assim como agregados de plaquetas. Esses autores não informaram as condições de dispersão, nem o método usado.

Wang et al. (2009) dispersaram laponita em água e observaram por microscopia de força atômica a presença de plaquetas de laponita com tamanho de partículas de 30 nm, e agregados de partículas, com tamanho de partículas entre 200 e $400 \mathrm{~nm}$. Esses autores não informaram as condições de dispersão, nem o método usado.

Bippus, Jaber, Lebeau (2009) estudaram a dispersão da laponita em água destilada, utilizando agitação mecânica (velocidade de agitação não informada), durante 24 horas à temperatura ambiente. Eles observaram tamanho de partículas entre 3 e 10 $\mathrm{nm}, 10$ e $100 \mathrm{~nm}, 90$ e $400 \mathrm{~nm}$. O tamanho de partículas maiores que $10 \mathrm{~nm}$ foram associados à presença de agregados de plaquetas. Estes resultados concordam com aqueles observados por Pignon et al. (1997) e Daniel, Frost, Zhu (2007), trabalhando em dispersões de laponita em água.

Segundo Cummins (2007), a dispersão da laponita em água e sua posterior estabilidade poderiam ser alteradas por três fatores: $\mathrm{pH}$ da solução, concentração da laponita e filtração da solução. Esse autor dispersou a laponita utilizando agitação mecânica (velocidade de agitação não informada) e observou que as dispersões de laponita foram mais estáveis quando o $\mathrm{pH} \geq 10$, e com concentração da laponita não 
maior a $1 \%$ (p/p). Segundo Cummins (2007), a filtração das suspensões de laponita não alterou o tamanho nem a estabilidade das partículas de laponita, embora algumas pesquisas sugiram o uso de filtros (KUMAR; MURALIDHAR; JOSHI, 2008; NICOLAI e COCARD, 2000).

$\mathrm{Na}$ área de filmes nanocompósitos, poucas são as aplicações da laponita. Chung et al. (2010) produziram filmes pelo método de casting à base de amido de milho, contendo laponita. Esse autores observaram que a adição da laponita, em até $5 \%(\mathrm{p} / \mathrm{p})$ $\left(C_{l a p}\right)$, levou a uma melhora nas propriedades mecânicas, como o módulo elástico e a tensão na ruptura, sendo que a laponita reforçou a matriz biopolimérica. Eles também observaram que as propriedades mecânicas dos filmes não incrementaram para $C_{\text {lap }}>$ $5 \%$, sendo atribuido à presença de agregados de laponita nos filmes.

Aouada, Mattoso, Longo (2011) também produziram filmes pelo método de casting à base de amido de milho, contendo laponita. Esses autores observaram que os valores de módulo elástico, tensão e deformação na ruptura incrementaram em até 44\%, $18 \%$ e $21 \%$, respectivamente, com $C_{\text {lap }}=5 \%$. Esses mesmos autores correlacioram o aumento das propriedades mecânicas nos filmes com a exfoliação da laponita.

Tang e Alavi (2012) produziram filmes pelo método de casting à base de blendas de amido de milho e poli(vinil álcool), contendo laponita. Esses autores observaram que o módulo elástico nos filmes incrementou em até $175 \%$, e que os valores de permeabilidade ao vapor de água diminuíram em até $37 \%$, ambos com $C_{\text {lap }}=$ $20 \%$.

Perotti et al. (2014) produziram filmes pelo método de casting à base de fécula de mandioca, contendo laponita. Esses autores observaram que as plaquetas de laponita foram esfoliadas ou intercaladas na matriz do biopolímero, para $C_{\text {lap }} \leq 10 \%$. Entretanto, para $C_{\text {lap }}>10 \%$ foi observada a formação de agregados desta nanoargila nos filmes.

Li et al. (2015) produziram filmes pelo método de casting à base de gelatina bovina tipo "A", contendo laponita. Esses autores observaram que a permeabilidade ao vapor de água e a solubilidade em água incrementaram, enquanto as propriedades mecânicas decresceram (tensão e elongação na ruptura), ambas com $C_{l a p} \leq 20 \%$.

Dessa forma, fica clara a necessidade de mais pesquisas sobre o efeito da carga de laponita nas propriedades físicas de filmes nanocompósitos à base de biopolímeros, uma vez que não existe um comportamento único observado nos estudos descritos acima. 


\section{OBJETIVOS}

O objetivo geral desta tese foi o desenvolvimento de filmes à base de biopolímeros (colágeno, gelatina e fécula de mandioca), reforçados com uma nanoargila (laponita). Estudou-se o efeito da concentração do biopolímero, da laponita e de dois métodos de produção dos filmes (casting e espalhamento mecânico) sobre algumas propriedades físicas do material.

Os objetivos específicos desta tese foram os seguintes:

- Compreender o mecanismo de dispersão das nanopartículas (laponita) em água.

- Estudar os filmes em relação a suas propriedades físicas e de topografia superficial.

- Correlacionar o efeito da carga da laponita e do método de produção dos filmes sob possíveis mudanças na microestrutura dos filmes e nas suas propriedades. 


\section{HIPÓTESES}

A hipótese relacionada com esta tese é que a carga da laponita, desde que se garanta sua perfeita dispersão na matriz biopolimérica (colágeno, gelatina e fécula de mandioca), pode afetar positivamente as principais propriedades físicas dos filmes nanocompósitos. 


\section{MATERIAL E MÉTODOS}

\subsection{Material}

Para o desenvolvimento de filmes nanocompósitos foram utilizados como biopolímeros: colágeno em pó (Novaprom Food Ingredients Ltda., Brasil), gelatina suína tipo "A” (Gelita Ltda, São Paulo, Brasil) e fécula de mandioca (Yoki Food Industry, Brasil). O plastificante foi o glicerol (Synth, Brasil), e a nanopartícula foi a laponita RD (Southerm Clay Products Inc, EUA). Os biopolímeros, o glicerol e a laponita foram utilizados sem nenhum tipo de tratamento prévio.

\subsection{Caracterização da laponita}

Com o intuito de compreender as principais características da laponita, foram feitas algumas análises da laponita em pó e em dispersão de laponita em água.

\subsubsection{Microscopia eletrônica de varredura}

A morfologia da laponita em pó foi estudada usando um microscópio eletrônico de varredura (TM-3000, HITACHI, Japão), empregando uma voltagem de 15 kV. A laponita foi espalhada sobre fita de carbono e analisada sem nenhum preparo (FLAKER et al., 2015). Também foram realizadas análises de espectroscopia de raios $\mathrm{X}$ por dispersão de energia no mesmo equipamento, visando a caracterização química da nanoargila.

\subsubsection{Difração de raios $X$}

$\mathrm{O}$ espectro de raios $\mathrm{X}$ da laponita foi obtido utilizando-se um difractômetro de raios X (Rigaku Miniflex 600, Japão), operando a $40 \mathrm{kV}$ e $15 \mathrm{~mA}$ (radiação $\mathrm{CuK}_{\beta}, \lambda=$ $0,15405 \mathrm{~nm})$. O espectro foi obtido a uma temperatura de $25{ }^{\circ} \mathrm{C}$, e para uma faixa de ângulos entre $2 \theta=2^{\circ}$ até $70^{\circ}$, com velocidade de varredura de $2^{\circ} / \mathrm{min}$. O espaçamento interplanar $[d(\mathrm{~nm})]$ foi determinado pela lei de Bragg, como:

$$
n \lambda=2 d \operatorname{sen} \theta
$$

na qual $\lambda$, é o comprimento de onda e $n$, a ordem de reflexão $(n=1)$. 


\subsubsection{Espectroscopia de infravermelho por transformada de Fourier}

A espectroscopia de infravermelho por transformada de Fourier foi obtida usando um espectrofotômetro (Spectrum-One, Perkin-Elmer, EUA), e com um acessório UATR (“Universal Attenuator Total Reflectance”), que permitiu a análise do material em pó sem nenhum preparo (BERGO; MORAES; SOBRAL, 2012). Foram

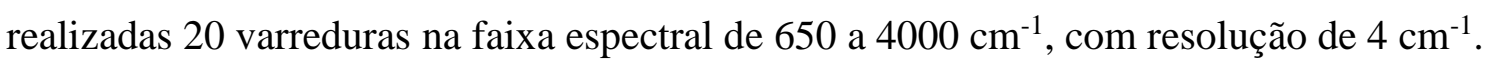
Os espectros de varredura foram coletados e analisados com o programa FTIR Spectrum Software (Perkin-Elmer).

\subsection{Produção e caracterização das dispersões de laponita}

De acordo com Cummins (2007), as dispersões de laponita com uma concentração maior que $1 \%(\mathrm{p} / \mathrm{p})$ são instáveis. Portanto, na presente tese foram produzidas dispersões de laponita a uma concentração de $1 \%$ (p/p), em água destilada. Estas dispersões foram obtidas utilizando um ultraturrax (IKA ® T25 digital, MERSE, Brasil), a diferentes velocidades de agitação (10.000, 15.000, 20.000 e 23.000 rpm), e tempos de dispersão (30 e 60 minutos). Finalmente, as dispersões foram armazenadas em frascos de vidro de cor âmbar e disposta na geladeira a $4{ }^{\circ} \mathrm{C}$, até sua caracterização.

\subsubsection{Tamanho de partícula, potencial $\zeta$ e pH}

O tamanho de partícula das dispersões de laponita, assim como o potencial $\zeta$, foram analisados usando um medidor de tamanho de partícula por espalhamento de luz quase-elástico e de potencial $\zeta$ “Zeta Plus” (Brookhaven Instruments Company, EUA).

$\mathrm{O} \mathrm{pH}$ das dispersões de laponita foi determinado por triplicata, usando um $\mathrm{pH}$ metro portátil (PG1400 Gehaka, Brasil).

\subsubsection{Microscopia de força atômica}

As dispersões de laponita foram diluídas em água destilada numa proporção de 1:150. Em seguida, dez microlitros foram dispersos em discos de mica e colocados a secar dentro de uma placa de Petri livre de impurezas por $24 \mathrm{~h}$, em condições ambientais (temperatura de $20 \pm 2{ }^{\circ} \mathrm{C}$ e umidade relativa, UR de $40 \pm 3 \%$ ) (BALNOIS; VIDAL; LEVITZ, 2003). As análises foram realizadas usando um microscópio de força atômica (NT-MDT, Rússia). As nanopartículas foram caracterizadas usando o modo de semi-contato no MFA, com uma frequência de ressonância de $240 \mathrm{kHz}$, força de contato de $11,8 \mathrm{~N} / \mathrm{m}$, e velocidade de varredura de $0,3 \mathrm{~Hz}$. 


\subsubsection{Caracterização reológica: curvas de fluxo}

As curvas de fluxo das dispersões de laponita foram obtidas para uma temperatura de $25{ }^{\circ} \mathrm{C}$, usando um reômetro de tensão controlada (AR2000 Advanced Rheomeer, TA Instruments, New Castle DE, EUA), equipado com uma geometria de cilindros concêntricos de folga dupla (raio interno $=16,0 \mathrm{~mm}$, raio externo $=17,5 \mathrm{~mm}$, e "gap" = $2000 \mu \mathrm{m}$ ). Para cada ensaio foram usadas aproximadamente $12 \mathrm{~mL}$ das dispersões de laponita, sendo analisadas taxas de cisalhamento ascendente e descendente, entre 0 e $200 \mathrm{~s}^{-1}$, com duração de 2 minutos para cada rampa (JORGE et al., 2014; MORAES et al., 2009). Todos os resultados foram analisados no software “'Rheology Advantage Data Analysis V.5.3.1” (TA Instrument).

\subsection{Produção das soluções formadoras de filmes (SFF) à base de biopolímeros com laponita}

Como solvente da gelatina e da fécula de mandioca foi utilizada água destilada. O colágeno foi dissolvido utilizando uma solução de ácido acético $(0,5 \mathrm{M})$, que foi preparada com ácido acético glacial (99,7\%, Synth, Brasil).

A melhor dispersão de laponita foi misturada com glicerol e submetida a agitação mecânica durante 15 minutos. Esta dispersão foi misturada com as SFF à base de biopolímeros.

As SFF foram produzidas com as seguintes concentrações:

- Concentração de colágeno $\left(C_{c o l}\right): 2$ e 4 g/100 g SFF (MAKISHI, 2016; WOLF; SOBRAL; TELIS, 2009).

- Concentração de gelatina $\left(C_{g e l}\right): 4$ e 8 g/100 g SFF (FLAKER, 2014; JORGE, 2012; MAKISHI, 2016).

- Concentração de fécula de mandioca $\left(C_{f e ́ c}\right): 2$ e 4 g/100 g SFF (CANO et al., 2015; SOUZA et al., 2012).

- Concentração de glicerol $\left(C_{g l i}\right): 30 \mathrm{~g} / 100 \mathrm{~g}$ de colágeno ou gelatina, $25 \mathrm{~g} / 100 \mathrm{~g}$ de fécula de mandioca (CANO et al., 2015; FLAKER, 2014; MAKISHI, 2016; WOLF; SOBRAL; TELIS, 2009).

- Concentração da laponita $\left(C_{\text {lap }}\right): 0,1,5,3,4,5$ e 6 g/100 g de biopolímero (AOUADA, MATTOSO, LONGO, 2011; FLAKER, 2014). 
Para a produção da SFF à base de colágeno, o biopolímero foi disperso em ácido acético $(0,5 \mathrm{M})$, sob agitação mecânica durante 10 minutos, a temperatura ambiente (20 $\pm 2{ }^{\circ} \mathrm{C}$ ). Em seguida, a dispersão de colágeno foi armazenada a uma temperatura de 4 ${ }^{\circ} \mathrm{C}$, durante $24 \mathrm{~h}$, permitindo a hidratação do colágeno (STILIANOU et al., 2011). Posteriormente, a dispersão foi levada ao ultrassom, na temperatura ambiente, durante 10 minutos. A dispersão foi aquecida em banho maria com temperatura controlada (81 ${ }^{\circ} \mathrm{C}$ ), durante 6 minutos (WOLF; SOBRAL; TELIS, 2009). A dispersão foi resfriada até temperatura ambiente e misturada com a dispersão de laponita contendo glicerol. A dispersão final foi submetida a agitação mecânica por 15 minutos, para garantir a completa homogeneização dos componentes.

Para a produção da SFF à base de gelatina, o biopolímero foi hidratado durante 30 minutos a temperatura ambiente $\left(20 \pm 2{ }^{\circ} \mathrm{C}\right)$. Em seguida, foi solubilizado a $70{ }^{\circ} \mathrm{C}$, durante 15 minutos, sob agitação mecânica, utilizando-se um banho maria com temperatura controlada (JORGE et al., 2014; VANIN et al., 2014; SOBRAL et al., 2001). Posteriormente, foi adicionada a dispersão de laponita contendo glicerol e mantendo em agitação por mais 15 minutos.

Para a produção da SFF à base de fécula de mandioca, o biopolímero foi disperso em água e posteriormente aquecido em banho maria com temperatura controlada $\left(90^{\circ} \mathrm{C}\right)$, durante 30 minutos (CHEN; KUO; LAI, 2009). Em seguida, foi adicionada a dispersão de laponita contendo glicerol e mantendo em agitação por mais 15 minutos.

\subsection{Caracterização reológica das soluções formadoras de filmes (SFF) à base de biopolímeros com laponita}

A caracterização reológica das SFF à base de colágeno não foi realizada devido à presença de aglomerados nas SFF, não sendo possível a reprodução de resultados nas análises. Makishi (2016) encontrou os mesmos problemas para caracterizar SFF à base de colágeno.

As SFF à base de gelatina e fécula de mandioca foram analisadas reologicamente utilizando o mesmo reômetro empregado na seção 5.3.3. As curvas de fluxo foram feitas nas SFF à base de gelatina e fécula de mandioca. No caso das SFF à base de gelatina foi utilizada a geometria de cone e placa (ângulo do cone $4^{\circ}$, diâmetro da geometria $60 \mathrm{~mm}$ ). Para as SFF de fécula de mandioca foi utilizada a geometria de cilindros concêntricos (raio interno de $14 \mathrm{~mm}$, raio externo de $15 \mathrm{~mm}$, altura de $42 \mathrm{~mm}$ 
e "gap" de $1000 \mu \mathrm{m})$. As SFF à base de gelatina e fécula de mandioca foram analisadas com taxas de cisalhamento ascendente e descendente, entre 0 e $200 \mathrm{~s}^{-1}$, com duração de 2 minutos para cada rampa (JORGE et al., 2014; MORAES et al., 2009).

Com o intuito de conhecer a temperatura ideal de resfriamento das SFF à base de gelatina (temperatura para verter as SFF nas placas de Petri ou de acrílico), foram realizados testes de varredura de deformação e oscilatório de varredura de temperatura. Os ensaios oscilatórios foram feitos nas SFF à base de gelatina, utilizando-se uma geometria de cone e placa (ângulo do cone $4^{\circ}$, diâmetro da geometria, $60 \mathrm{~mm}$ ). A temperatura foi controlada usando um sistema "Peltier" de aquecimento termostático, e a perda de água foi controlada aplicando óleo mineral na geometria (JORGE et al., 2014). O teste de varredura de deformação foi realizado com deformações variando entre 0,01 e 100\%, e mantendo constante a frequência em 1 Hz (MORAES et al., 2009). De acordo com os resultados apresentados na seção 6.2, foi fixado um valor de tensão de $10 \%$, valor dentro da região linear, que foi utilizado no teste de varredura de temperatura.

No teste de varredura de temperatura, as SFF à base de gelatina foram resfriadas, e em seguida aquecidas entre 50 e $10^{\circ} \mathrm{C}$, e 10 e $50{ }^{\circ} \mathrm{C}$, sempre a uma taxa de $1^{\circ} \mathrm{C} / \mathrm{min}$. Foram determinadas as temperaturas de gelificação (temperatura sol-gel), e de fusão (temperatura gel-sol), como a temperatura onde o modulo elástico (G') mudou drasticamente (GÓMEZ-ESTACA et al., 2009).

Segundo Chiou et al. (2005), as SFF à base de fécula de mandioca contendo nanoargilas não apresentam nenhuma transição térmica entre 25 e $50^{\circ} \mathrm{C}$. Portanto, na presente tese não foram realizados testes reológicos oscilatórios nas SFF à base de fécula de mandioca.

\subsection{Produção de filmes nanocompósitos à base de biopolímeros com laponita}

Para a produção de filmes nanocompósitos, todas as SFF foram resfriadas até 27 ${ }^{\circ} \mathrm{C}$. Esta temperatura foi determinada por testes reológicos de varredura de temperatura, apresentados na seção 6.2.

Os filmes nanocompósitos foram preparados pela desidratação das SFF, sendo aplicados em placas de Petri ou de acrílico para a produção de filmes por casting ou por espalhamento mecânico, respectivamente, e seguindo a seguintes especificações: 
- Casting: espalhamento da SFF em placas de Petri de $14 \mathrm{~cm}$ de diâmetro. A quantidade da SFF vertida na placa foi fixado para um valor de matéria seca de $8 \mathrm{mg} / \mathrm{cm}^{2}$.

- Espalhamento mecânico: espalhamento da SFF em placas de acrílico de $26 \mathrm{~cm}$ x $30 \mathrm{~cm}$ x $0,5 \mathrm{~cm}$. A quantidade da SFF espalhada na placa foi fixada para um valor de matéria seca de $8 \mathrm{mg} / \mathrm{cm}^{2}$. Foi utilizado um aplicador automático de filmes (TKB Erichesen, modelo Speed II), acoplado a um banho ultratermostatizado (Marconi, modelo MA 184/20), para controle da temperatura da superfície de espalhamento, a qual foi mantida a $20{ }^{\circ} \mathrm{C}$ (JORGE, 2012; FLAKER, 2014). A velocidade de espalhamento foi fixada em 35 mm/segundo (FLAKER, 2014; JORGE, 2012), e a altura do dispositivo do aplicador foi mantida em 4, 3 e $2 \mathrm{~mm}$, para as SFF com 2, 4 e $8 \mathrm{~g}$ de biopolímero/100 g de SFF, respectivamente.

As SFF devidamente aplicadas nos suportes foram submetidas a secagem em estufa com circulação de ar forçado (Marconi, modelo MA 035), a $25^{\circ} \mathrm{C}$, durante 18 24 horas. Em seguida, os filmes foram condicionados em dessecadores contendo $\mathrm{NaBr}$, $58 \%$ UR (filmes de colágeno e gelatina), e em $\mathrm{Mg}\left(\mathrm{NO}_{3}\right)_{2}, 52 \%$ UR (filmes de fécula de mandioca), bem como em sílica gel, 0\% UR (todos os filmes), no caso dos filmes utilizados nas técnicas de caracterização de difração de raios $\mathrm{X}$, espectroscopia de infravermelho por transformada de Fourier, microscopia eletrônica de varredura e de força atômica. Os filmes condicionados em $\mathrm{NaBr}$ e $\mathrm{Mg}\left(\mathrm{NO}_{3}\right)_{2}$ foram utilizados para a caracterização das técnicas restantes. Os filmes de fécula de mandioca não foram condicionados em UR $=58 \%$, porque, para esta umidade, os filmes se tornaram pegajosos. Todas as caracterizações foram realizadas, ao menos, três vezes. O condicionamento foi do mínimo sete dias.

\subsection{Caracterização dos filmes nanocompósitos à base de biopolímeros com laponita}

\subsubsection{Espessura e umidade}

A espessura de todos os filmes nanocompósitos foi medida em dez pontos aleatórios, e usando um micrômetro digital (0,001 mm, Mitutoyo).

A umidade nos filmes nanocompósitos foi determinada gravimetricamente por secagem dos filmes a uma temperatura de $105^{\circ} \mathrm{C}$, durante $24 \mathrm{~h}$ (SOBRAL et al., 2001). 
5.7.2. Difração de raios $X$ e Espectroscopia de infravermelho por transformada de Fourier

Os espectros de raios $\mathrm{X}$ dos filmes nanocompósitos foram obtidos utilizando o mesmo difractômetro descrito na seção 5.2.2, seguindo o mesmo protocolo para a análise das amostras.

As análises por espectroscopia de infravermelho por transformada de Fourier nos filmes nanocompósitos foram realizadas usando o mesmo espectrofotômetro descrito na seção $\mathbf{5 . 2 . 3}$, seguindo o mesmo protocolo para a análise das amostras.

\subsubsection{Microscopia eletrônica de varredura}

A microestrutura superficial dos filmes nanocompósitos (superfície de secagem) foi analisada no mesmo microscópio eletrônico de varredura utilizado na seção 5.2.1, com a mesma voltagem para análise. As amostras também foram criofraturadas em nitrogênio líquido, para observação da estrutura interna. As micrografias foram feitas em posições aleatórias com amplificação de 1000x, empregando uma voltagem de 15 $\mathrm{kV}$.

\subsubsection{Microscopia de força atômica}

Os filmes nanocompósitos (superfície de secagem) foram analisados no modo semi-contato, usando o mesmo microscópio de força atômica utilizado na seção 5.3.2, com uma frequência de ressonância de $240 \mathrm{kHz}$, força de contato de 11,8 N/m, e velocidade de varredura de $0,3 \mathrm{~Hz}$. Os filmes nanocompósitos foram analisados em posições aleatórias com áreas de $50 \mu \mathrm{m}$ x $50 \mu \mathrm{m}$. A rugosidade média $\left(R_{a}\right.$, em nm) foi determinada diretamente no software do equipamento (Nova Px 3.2.5 Rev 1266 software). A dimensão fractal $(D F)$ foi determinada nas micrografias obtidas por microscopia de força atômica, na escala de cinza, e aplicando o método "Standard Box Count method" (ARZATE-VÁZQUEZ et al., 2012). Para esta análise foi utilizado o software ImageJ v 1.39.

\subsubsection{Cor e opacidade}

A cor dos filmes nanocompósitos foi determinada conforme a norma ASTM D2244 (SOBRAL et al., 2001), utilizando um colorímetro Hunter Lab (Miniscan XE), com iluminante de D65, ângulo de $10^{\circ}$, e célula de medida com abertura de $3 \mathrm{~cm}$. Para 
esta análise foram utilizados os parâmetros de cor da escala CIELab, sendo $L^{*}$, a variação de luminosidade (variando do preto ao branco), $a^{*}$, é variação de cor, indo do verde (-) ao vermelho (+) e $b^{*}$, a variação de cor, indo do azul (-) para o amarelo (+) (GENNADIOS et al., 1996; KUNTE; GENNADIOS; CUPPETT, 1997). Os filmes nanocompósitos foram colocados numa placa branca padrão para análise. A diferença de cor $\left(\Delta E^{*}\right)$ foi então calculada como:

$\Delta E^{*}=\sqrt{\left(\Delta L^{*}\right)^{2}+\left(\Delta a^{*}\right)^{2}+\left(\Delta b^{*}\right)^{2}}$

sendo $\Delta L^{*}=L^{*}$ da amostra $-L^{*}$ do standard $(92,58 \pm 0,92) ; \Delta a^{*}=a^{*}$ da amostra $-a^{*}$ do standard $(-0,88 \pm 0,06)$; e $\Delta b^{*}=b^{*}$ da amostra $-b^{*}$ do standard $(1,26 \pm 0,02)$.

A opacidade $(Y)$ foi determinada no mesmo equipamento, de acordo com Sobral (2000). O valor de $Y$, foi calculado como a relação da opacidade da amostra ao ser colocada sobre uma superfície padrão negra $\left(Y_{p}\right)$, e padrão branca $\left(Y_{b}\right)$, respectivamente.

\subsubsection{Brilho}

O brilho dos filmes nanocompósitos foi determinado nos ângulos de $20^{\circ}$ e $60^{\circ}$, usando um Glossimetro NGL 20/60, segundo a ASTM D2457. Foram realizadas 10 medições em lugares aleatórios na superfície de secagem dos filmes nanocompósitos, sendo registrado como unidades de brilho GU (VILLALOBOS et al., 2005).

\subsubsection{Calorimetria diferencial de varredura}

As propriedades térmicas dos filmes nanocompósitos foram determinadas com um calorímetro (DSC TA2010, TA Instruments). Os filmes foram colocados em cápsulas de alumínio que foram seladas hermeticamente. As curvas calorimétricas foram obtidas em uma faixa de temperatura entre -150 e $120{ }^{\circ} \mathrm{C}$, com taxa de aquecimento de $5^{\circ} \mathrm{C} / \mathrm{min}$ (filmes à base de colágeno e gelatina,) e $10^{\circ} \mathrm{C} / \mathrm{min}$ (filmes à base de fécula de mandioca), e em corrida dupla, sempre após resfriamento usando nitrogênio liquido, e em atmosfera inerte (45 mL/minuto de $\mathrm{N}_{2}$ ) (SOBRAL e HABITANTE, 2001; GONTARD e RING, 1996). Os parâmetros térmicos: temperatura de transição vítrea $\left(T_{g}\right)$, temperatura de fusão $\left(T_{m}\right.$, temperatura do pico endotérmico), e a entalpia de fusão ( $\Delta H$, área sob a curva do pico de fusão) foram obtidos diretamente 
das curvas térmicas, usando o programa "Universal Analysis V1.7F" (TA Instruments).

\subsubsection{Propriedades mecânicas: ensaios de tração uniaxial e de perfuração}

O ensaio de tração uniaxial nos filmes nanocompósitos foi determinado usando um texturômetro TA.XT2i (TA Instruments, NC, EUA), de acordo com ASTM D88202. Os filmes nanocompósitos foram cortados com um comprimento útil de $5 \mathrm{~cm}$, e largura de $1,5 \mathrm{~cm}$. A espessura de todos os filmes foi medida em 10 pontos aleatórios usando um micrômetro digital (0,001 mm, Mitutoyo). Em seguida, o teste de tração uniaxial foi realizado com uma velocidade de separação de $1 \mathrm{~mm} / \mathrm{s}$. A tensão na ruptura (TR, em MPa), e a deformação na ruptura (DR, em \%) foram obtidas diretamente das curvas de tensão versus deformação (Equação 3). O módulo elástico (ME, em MPa) foi obtido pelo cálculo da inclinação da proporção linear da curva.

$D R(\%)=\frac{\Delta L}{L} * 100$

sendo $\Delta L$, o alongamento do filme nanocompósito (m), e $L$ o comprimento original (m) do mesmo.

Os testes de perfuração dos filmes nanocompósitos foram realizados de acordo com a norma ASTM F1306. As amostras foram fixadas em uma célula e perfuradas por uma sonda de $3 \mathrm{~mm}$ de diâmetro, com uma velocidade de $1 \mathrm{~mm} / \mathrm{s}$ (GONTARD; GUILBERT; CUQ, 1992).

A força na perfuração (FP, em $\mathrm{N}$ ) foi determinada diretamente das curvas força versus deslocamento da sonda, usando-se o software do equipamento (Exponent Lite Express, v 4,0,13,0). A deformação na perfuração (DP, em \%) foi calculada como:

$D P(\%)=\frac{\sqrt{\left(D^{2}+l_{o}^{2}\right)-l_{o}}}{l_{o}} * 100$

sendo $l_{o}$, o comprimento inicial do filme, igual ao raio da célula de medida $(26,3 \mathrm{~mm})$, e $D$, o deslocamento da sonda cilíndrica na perfuração $(\mathrm{mm})$. 


\subsubsection{Solubilidade em água}

Os filmes nanocompósitos foram cortados em círculos de diâmetro de $2 \mathrm{~cm}$, adicionados em $50 \mathrm{~mL}$ de água destilada e colocados para agitação em mesa agitadora orbital (MA-141, Marconi), a $25^{\circ} \mathrm{C}$, durante 24 horas. Após o tempo de agitação, a parte dos filmes nanocompósitos não solubilizada foi seca em estufa a $105{ }^{\circ} \mathrm{C}$, durante 24 h, para a determinação da umidade (GONTARD; GUILBERT; CUQ, 1992). A solubilidade dos filmes nanocompósitos em água foi calculada como:

Solubilidade $(\%)=\frac{m_{s i}-m_{s f}}{m_{s i}} * 100$

sendo $m_{s i}$ e $m_{s f}$, o peso inicial e final do filme (em matéria seca), respectivamente.

\subsubsection{0. Ângulo de contato}

O ângulo de contato da água nos filmes nanocompósitos foi determinado utilizando-se um tensiômetro ótico (Optical tensiometer, Finlândia). Os filmes nanocompósitos foram fixados no suporte do equipamento. Uma gota de água mili-Q foi colocada sobre a superfície de secagem de cada amostra, utilizando uma seringa de precisão. As imagens foram obtidas a cada segundo, por um período de 30 segundos. $\mathrm{O}$ ângulo formado entre a superfície e a tangente da gota da água foi determinado utilizando o software do equipamento.

\subsubsection{Isotermas de sorção}

Para as análises de isotermas de sorção, os filmes nanocompósitos foram inicialmente condicionados em pentóxido de fósforo $\left(\mathrm{P}_{2} \mathrm{O}_{5}\right)$, durante 14 dias. Em seguida, os filmes foram armazenados em dessecadores contendo diferentes soluções saturadas de sais: $\mathrm{LiCl}$ (11,3\% UR), $\mathrm{MgCl}_{2}$ (32,8\% UR), $\mathrm{K}_{2} \mathrm{CO}_{3}$ (43,2\% UR), $\mathrm{Mg}\left(\mathrm{NO}_{3}\right)_{2}$ (52,3\% UR), $\mathrm{NaBr}\left(58 \%\right.$ UR), $\mathrm{NaNO}_{2}(65,4 \% \mathrm{UR}), \mathrm{KCl}(84,3 \% \mathrm{UR})$ e $\mathrm{BaCl}_{2}(90,3 \%$ UR). Para uma UR $\geq 84,3 \%$ foi utilizado timol em pó dentro dos dessecadores, evitando a proliferação de fungos.

A absorção de umidade nos filmes nanocompósitos foi realizada a $25{ }^{\circ} \mathrm{C}$, durante 14 dias, tempo no qual não houve alteração da quantidade de água absorvida nos filmes nanocompósitos. 
A absorção de água nos filmes nanocompósitos foi determinada gravimetricamente, e expressa como g de água/g de matéria seca.

\subsubsection{Permeabilidade ao vapor de água}

A permeabilidade ao vapor de água nos filmes nanocompósitos foi determinada de acordo com ASTM E96. Amostras circulares foram fixadas em células de permeação de alumínio, contendo $60 \mathrm{~g}$ de sílica gel (UR $=0 \%$; pressão de vapor de $0 \mathrm{~Pa}$ ). As células de permeação foram colocadas dentro de dessecadores contendo água destilada (UR $=100 \%$; pressão de vapor de $3,1691 \mathrm{kPa}$ ). As análises foram realizadas mantendo a temperatura constante $\left(25^{\circ} \mathrm{C}\right)$. O ganho de peso nas células de permeação foi registrado por intervalos de $24 \mathrm{~h}$, durante 7 dias. A permeabilidade ao vapor de água (PVA) nos filmes nanocompósitos foi calculada como:

$\mathrm{PVA}=\frac{\Delta G}{\Delta T}\left(\frac{d}{A \Delta P}\right)$

sendo $\Delta G / \Delta T$, a taxa de ganho de água na célula de permeação, no tempo (g/h), $A$, é a área de permeação $\left(32,17 \mathrm{~cm}^{2}\right), d$, é a espessura do filme nanocompósito $(\mathrm{mm})$, e $\Delta P$, a diferença de pressão de vapor entre as superfícies do filme nanocompósito (3,1691 kPa).

\subsection{Tratamento dos dados}

Os resultados obtidos na caracterização das dispersões de laponita e dos filmes nanocompósitos foram submetidos à análise de variância (ANOVA), e teste de Tukey (duas vias), com nível de significância de 5\%. Foi avaliado o efeito da concentração de biopolímero (colágeno, gelatina e fécula de mandioca) e de laponita nos sistemas em estudo. Todas as análises estatísticas foram realizadas com o programa SAS V9.0. 


\section{RESULTADOS E DISCUSSÃO}

\subsection{Caracterização da laponita}

Nesta seção serão apresentados e discutidos os resultados da caracterização da laponita em pó, e dispersa em água.

\subsubsection{Laponita em pó}

\subsubsection{Microscopia eletrônica de varredura}

As micrografias obtidas por microscopia eletrônica de varredura permitiram observar grandes agregados de laponita, com tamanhos irregulares, entre 4 e $70 \mu \mathrm{m}$ (Figura 3a). Com um maior aumento (2000x), observou-se que os agregados de laponita estiveram conformados de unidades de tamanho menor (Figura 3b). Estes resultados foram similares aos observados por Bippus, Jaber, Lebeau (2009), trabalhando com laponita em pó. Esses autores concluíram que as plaquetas de laponita agregam-se de forma adjacente entre si, formando estruturas de tamanho micrométrico.

A presença de íons de $\mathrm{O}, \mathrm{Na}, \mathrm{Mg}$ e Si na laponita foram detectados por análises de espectroscopia de energia dispersiva (Figura 4). Estes resultados concordam com a fórmula química da laponita $\left(\mathrm{Si}_{8}\left[\mathrm{Mg}_{5.5} \mathrm{Li}_{0.4} \mathrm{H}_{4.0} \mathrm{O}_{24.0}\right]^{0.7-}\left[\mathrm{Na}_{0.7}\right]^{0.7+}\right)$, informada por Tawari, Koch, Cohen (2001). A presença de berílio (Be) pode ser devido à janela do detector do equipamento.

A análise quantitativa dos elementos químicos presentes nos aglomerados de laponita foram: $\mathrm{SiO}_{2}, 68,58 \%$; $\mathrm{MgO}, 28,93 \%$; e $\mathrm{Na}_{2} \mathrm{O}, 2,50 \%$. Esses valores foram comparáveis aos encontrados por Levitz et al. (2000), trabalhando com laponita em pó.

Figura 3 - Exemplos de micrografias da laponita obtidas por microscopia eletrônica de varredura: 1000x (a) e 2000x (b).
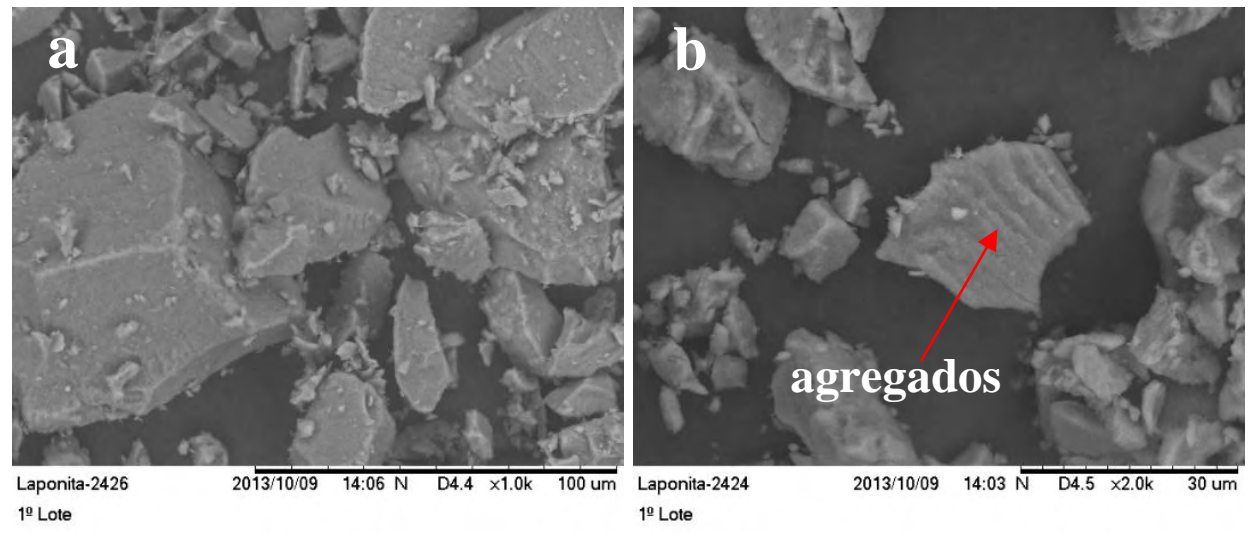

Fonte: própria autoria. 
Figura 4 - Elementos químicos detectados por espectroscopia de energia dispersiva na laponita.

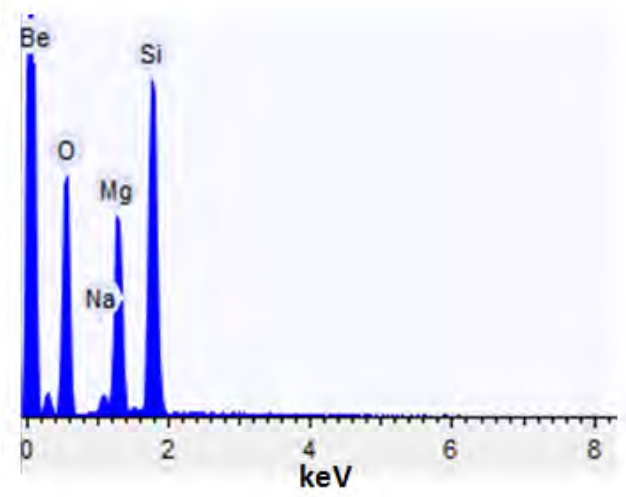

Fonte: própria autoria.

\subsubsection{Difração de raios $X$ e Espectroscopia de infravermelho por transformada de} Fourier

O espectro da laponita foi típico de material cristalino (Figura 5a), apresentando um pico em $2 \theta=6,5^{\circ}$, referente à reflexão basal, típico de plaquetas de laponita agregadas (TRONTO et al., 2007). O pico em $2 \theta=60,9^{\circ}$ indicou a presença de uma estrutura trioctaédrica, típica da laponita (FRAILE et al., 1998; BIPPUS; JABER; LEBEAU, 2009). Os outros picos em $2 \theta=19,5^{\circ}, 27,8^{\circ}, 34,9^{\circ}$ e 55, $6^{\circ}$ também têm sido observados na laponita (BIPPUS; JABER; LEBEAU, 2009), mas não têm sido associados com sua estrutura cristalina. Esses valores dos picos, em graus, foram utilizados para calcular o espaçamento interplanar ( $d$, em $\AA$ ), utilizando a Equação (1). $\mathrm{O}$ valor $d=13,6 \AA\left(2 \theta=6,5^{\circ}\right.$; Figura 5a) esta relacionado à separação mínima entre duas plaquetas de laponita (TRONTO et al., 2007).

Em relação à análise de espectroscopia de infravermelho por transformada de Fourier (FTIR) (Figura 5b), observou-se que a laponita apresentou cinco bandas características. As vibrações em 3674 e $994 \mathrm{~cm}^{-1}$ foram atribuídas ao estiramento dos grupos $\mathrm{Mg}_{3} \mathrm{OH}$ e Si-O, respectivamente. Segundo Pálková et al. (2010), as vibrações dos grupos $\mathrm{Si}-\mathrm{O}$ na laponita estão associadas à presença de grupos oxigênio, na forma basal (O-Si-O), localizados entre as placas tetraédrica e octaédrica na laponita. Os picos em 3431, 1637 e $652 \mathrm{~cm}^{-1}$ foram atribuidos à vibração dos grupos -OH (HERRERA et al., 2004; PÁLKOVÁ et al., 2010). 
Figura 5 - Exemplos de espectros obtidos por difração de raios X (a) e espectroscopia de infravermelho por transformada de Fourier (b) da laponita.
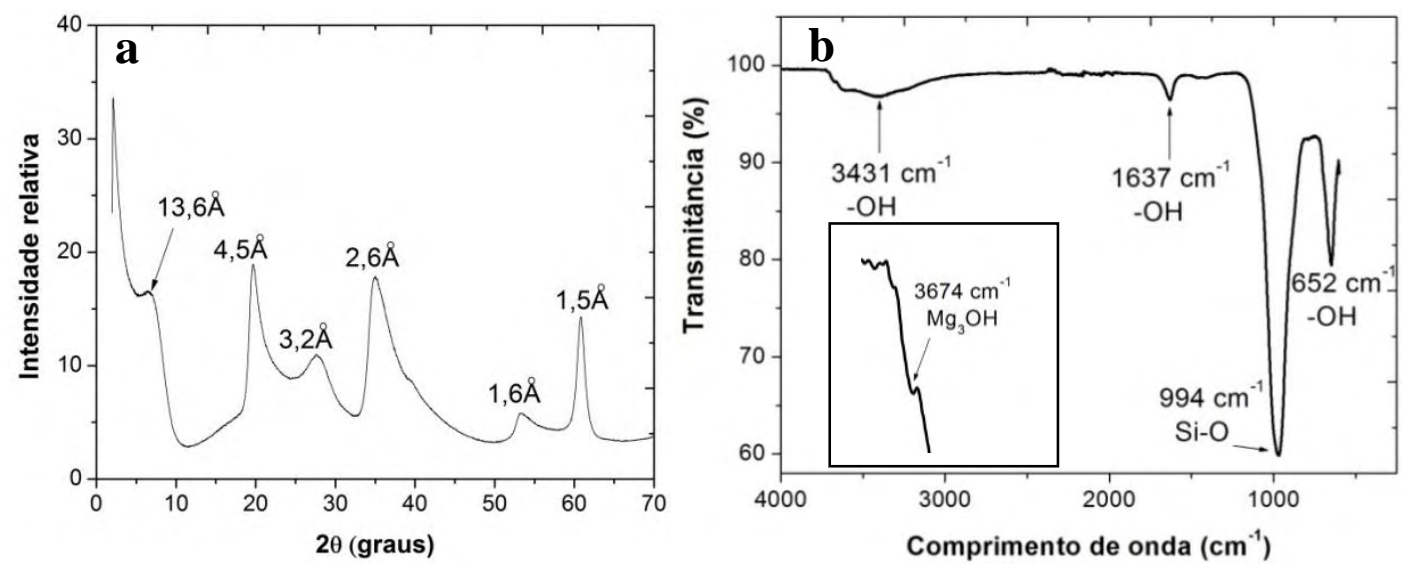

Fonte: própria autoria.

\subsubsection{Laponita dispersa em água}

\subsubsection{Tamanho de partícula, potencial $\zeta$ e pH}

Após ao processo de dispersão da laponita em água, foram obtidos sistemas transparentes e sem nenhuma presença de precipitados (Figura 6). Observou-se que os tratamentos utilizados no ultraturrax (velocidade e tempo de agitação) geraram distribuições de tamanho das partículas bimodais (Figura 7). Conforme mencionado anteriormente, as plaquetas de laponita tem comprimento de aproximadamente $25 \mathrm{~nm}$, e espessura de aproximadamente $1 \mathrm{~nm}$ (CUMMINS, 2007; RUZICKA e ZACARELLI, 2011). Portanto, na presente tese, as dispersões de laponita com tamanho das partículas maiores que $25 \mathrm{~nm}$ foram associados com a presença de agregados de plaquetas de laponita (BIPPUS; JABER; LEBEAU, 2009).

Figura 6 - Imagens representativas do ultraturrax e da dispersão de laponita em água obtida a $20.000 \mathrm{rpm}$ por 30 minutos.
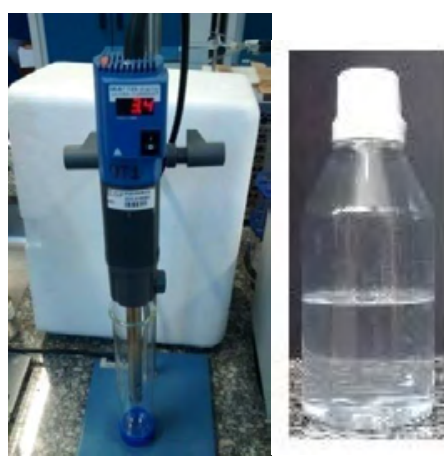

Fonte: própria autoria. 
Não foram observadas diferenças entre as distribuições de tamanho das partículas nos tratamentos que empregaram 10.000 ou $15.000 \mathrm{rpm}$, durante 30 minutos (Figura 7a). Contudo, o aumento no tempo de agitação (60 minutos), mantendo constante a velocidade de agitação (10.000 ou 15.000 rpm), deslocou a distribuição de tamanho das partículas à esquerda (Figura 7b). Nos tratamentos que empregaram 20.000 ou $23.000 \mathrm{rpm}$, durante 30 ou 60 minutos, não foi observada nenhuma alteração da distribuição de tamanho das partículas (Figuras 7c e 7d). As distribuições de tamanho das partículas de laponita obtidas com diferentes velocidades e tempos de agitação foram comparáveis as observadas por Daniel, Frost, Zhu (2007) e Bippus, Jaber, Lebeau (2009), trabalhando em dispersões de laponita em água.

Figura 7 - Exemplos de distribuição de tamanho das partículas nas dispersões de laponita, preparadas usando-se ultraturrax, com velocidade de agitação de 10.000 e $15.000 \mathrm{rpm}$, durante 30 minutos (a), e 60 minutos (b); ou 20.000 e $23.000 \mathrm{rpm}$, durante 30 minutos (c), e 60 minutos (d).
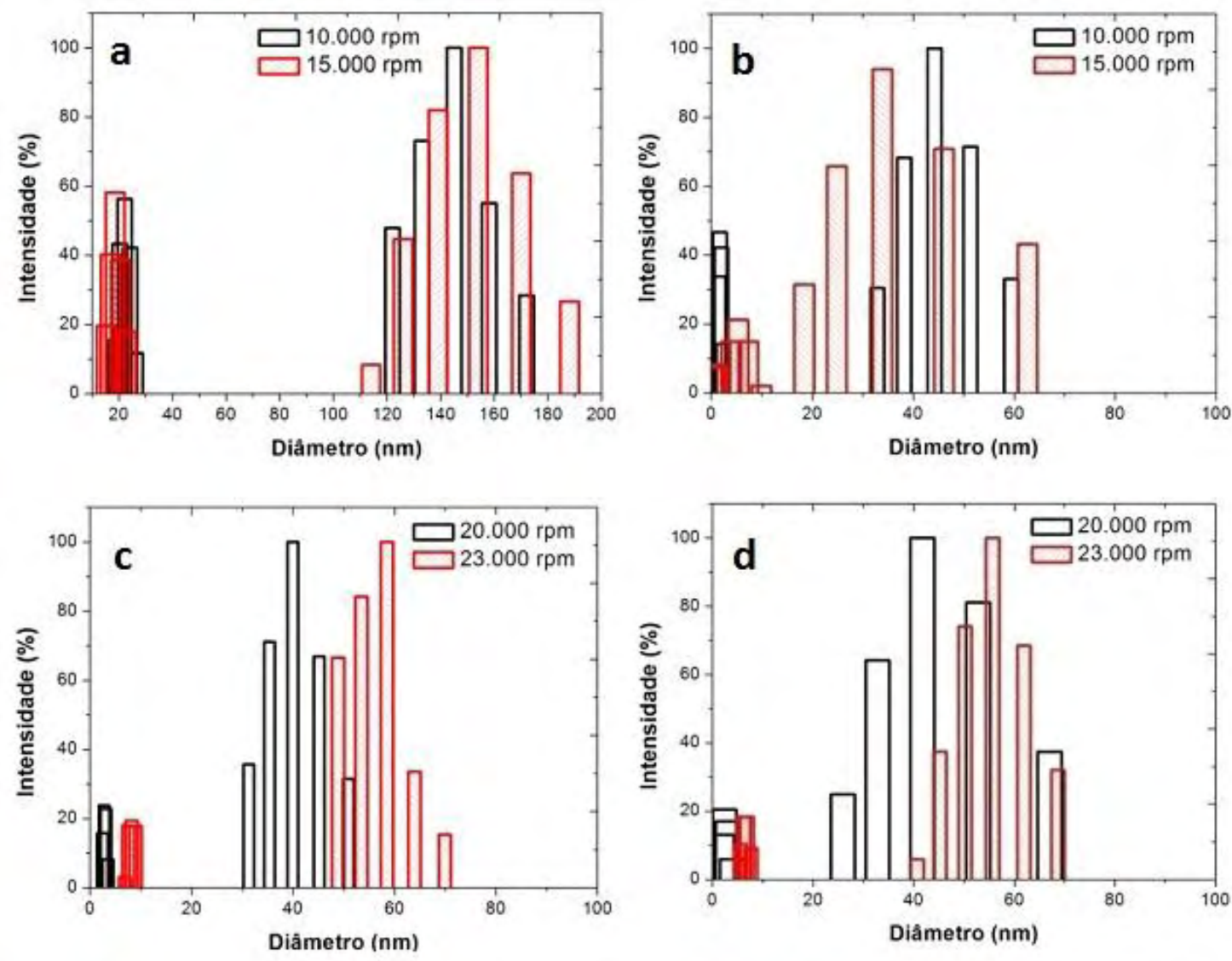

Fonte: própria autoria. 
Em relação à estabilidade das dispersões de laponita em água, observou-se que os valores de potencial $\zeta$ nos sistemas estiveram entre -34 e $-48 \mathrm{mV}$ (Tabela 1). Valores de potencial $\zeta \geq|30| \mathrm{mV}$ são típicos de sistemas estáveis (ZETASIZER NANO SERIES USER MANUAL, 2004).

Uma outra medida da estabilidade das dispersões de laponita foi o $\mathrm{pH}$ (CUMMINS, 2007). No presente trabalho, o pH das dispersões de laponita esteve entre 10,2 e 10,6. Segundo Cummins (2007), valores de $\mathrm{pH} \geq 10$ são típicos de dispersões de laponita estáveis.

Tabela 1 - Valores de potencial $\zeta(\mathrm{mV})$ das dispersões de laponita em água, preparadas usando-se ultraturrax*.

\begin{tabular}{ccc}
\hline & \multicolumn{2}{c}{ Tempo de dispersão (min) } \\
Velocidade de agitação $(\mathbf{r p m})\left(\mathbf{x 1 0}^{-3}\right)$ & $\mathbf{3 0}$ & $\mathbf{6 0}$ \\
\hline 10 & $-34,9 \pm 1,9^{\mathrm{B}, \mathrm{b}}$ & $-44,2 \pm 1,4^{\mathrm{B}, \mathrm{a}}$ \\
15 & $-35,5 \pm 0,0^{\mathrm{B}, \mathrm{b}}$ & $-43,5 \pm 1,4^{\mathrm{B}, \mathrm{a}}$ \\
20 & $-39,9 \pm 4,5^{\mathrm{BB}, \mathrm{a}}$ & $-43,8 \pm 1,2^{\mathrm{B}, \mathrm{a}}$ \\
23 & $-45,7 \pm 5,3^{\mathrm{A}, \mathrm{a}}$ & $-48,0 \pm 2,2^{\mathrm{A}, \mathrm{a}}$ \\
\hline
\end{tabular}

Fonte: própria autoria.

*Os valores são apresentados como média \pm desvio padrão de ao menos seis medições.

Médias numa mesma coluna, seguidas por uma mesma letra maiúscula, não diferem entre si pelo teste de Tukey $(p<0,05)$.

Médias numa mesma linha, seguidas por uma mesma letra minúscula, não diferem entre si pelo teste de Tukey $(p<0,05)$.

De acordo com os resultados apresentados nesta seção (distribuição de tamanho das partículas, potencial $\zeta$ e pH), o tratamento que empregou uma velocidade de agitação de $20.000 \mathrm{rpm}$, durante 30 minutos, foi o melhor entre os tratamentos avalidos, permitindo obter distribuições de tamanho das partículas inferiores que $50 \mathrm{~nm}$, estáveis $(\zeta \approx-40 \mathrm{mV}$, e $\mathrm{pH}>10$ ), e em um tempo curto. Assim, para a produção das SFF foram utilizadas as dispersões de laponita em água, usando-se ultraturrax com velocidade de agitação de 20.000 rpm, durante 30 minutos. 


\subsubsection{Microestrutura da laponita por microscopia de força atômica}

Observando-se as micrografias das dispersões de laponita em água, percebeu-se a presença de estruturas com tamanhos de $1 \mathrm{~nm}$ x $25 \mathrm{~nm}$ (Figuras 8a e 8b), dimensões similares as observados por Cummins (2007), e que consideram como sendo da espessura $(1 \mathrm{~nm})$ e diâmetro $(25 \mathrm{~nm})$ da plaqueta de laponita, na sua unidade elementar. Esses resultados demonstraram que os diferentes tratamentos por ultraturrax (velocidade e tempo de agitação) permitiram obter algumas plaquetas de laponita na sua unidade elementar.

Figura 8 - Imagem representativa de uma amostra de laponita obtida por microscopia de força atômica (a), perfil de altura (b), obtido no mesmo equipamento. Amostra preparada usando-se ultraturrax (20.000 rpm, durante 30 minutos), e diluída 1:150 em água destilada.
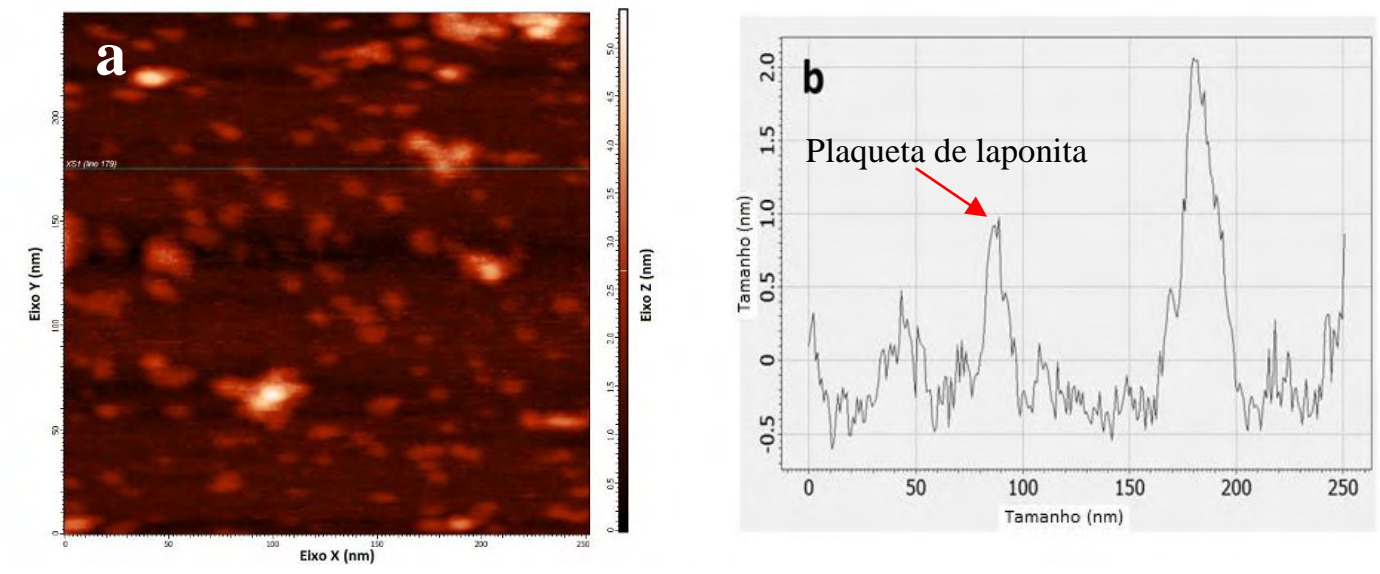

Fonte: própria autoria.

\subsubsection{Reologia das dispersões de laponita em água}

As curvas de fluxo das dispersões de laponita apresentaram um comportamento linear (Figura 9), ou seja, de fluidos Newtoniano (Equação 7), certamente por se tratarem de soluções diluídas.

$\tau=\eta \dot{\gamma}$

sendo $\tau$, a tensão $(\mathrm{Pa}), \dot{\gamma}$, a taxa de cisalhamento (1/s), e $\eta$, a viscosidade $(\mathrm{Pa} \cdot \mathrm{s})$. 
Os valores de viscosidade foram calculados por regressão linear. Observou-se que a viscosidade das dispersões de laponita em água permaneceram constante, em $1.1 \times 10^{-3} \pm 0.0 \mathrm{~Pa} \cdot \mathrm{s}$, não sendo influenciada pela velocidade ou tempo de agitação no ultraturrax. Os valores de viscosidade das dispersões de laponita em água foram praticamente iguais ao da água destilada (amostra controle) $\left(1,0 \times 10^{-3} \pm 0.0 \mathrm{~Pa} \cdot \mathrm{s}\right)$.

Figura 9 - Exemplos de curvas de fluxo das dispersões de laponita em água, preparadas usando-se ultraturrax.

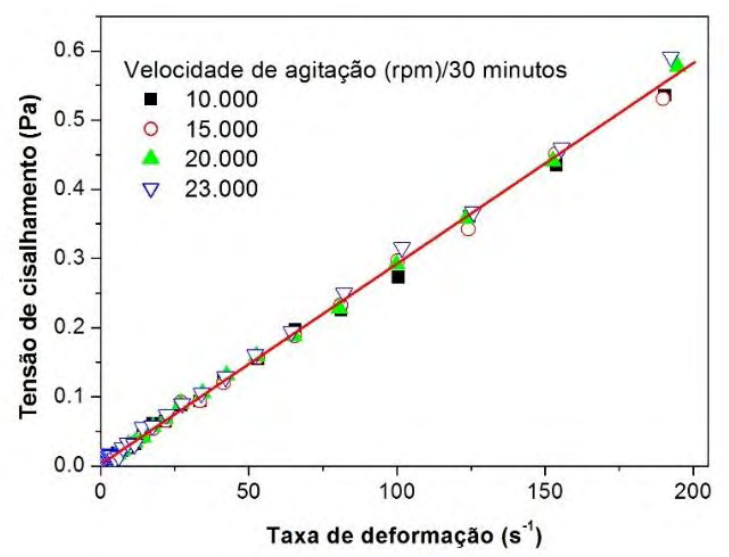

Fonte: própria autoria.

\subsection{Caracterização reológica das SFF à base de biopolímeros com laponita}

Nesta seção serão apresentados e discutidos os resultados referentes à caracterização reologica das SFF à base de gelatina e fécula de mandioca, contendo laponita.

\subsubsection{Ensaios estacionários}

Observou-se que os comportamentos das curvas de fluxo das SFF à base de gelatina e fécula de mandioca foram influenciados unicamente pela concentração do biopolímero na solução.

As curvas de fluxo das SFF à base de gelatina apresentaram um comportamento linear (Figura 10a), sendo bem descrito pelo modelo de Newton (Equação 7). Os valores de viscosidade das SFF à base de gelatina foram calculados por regressão linear, sendo de 4,6 $\pm 0.9 \mathrm{mPa} \cdot \mathrm{s}$ e 9,2 $\pm 1 \mathrm{mPa} \cdot \mathrm{s}$, nas soluções com 4 e $8 \mathrm{~g}$ de gelatina/100 $\mathrm{g}$ de $\mathrm{SFF}$, respectivamente, similares aos valores determinados por Makishi (2016) em soluções com 4 e $8 \mathrm{~g}$ de gelatina/100 g de SFF. 
Por outro lado, as curvas de fluxo das SFF à base de fécula de mandioca apresentaram um comportamento pseudoplástico (Figura 10b), sendo bem descrito pelo modelo da Lei da Potencia ("Power law"):

$\tau=k \dot{\gamma}^{n}$

sendo $k$, o índice de consistência $\left(\mathrm{Pa} \cdot \mathrm{s}^{\mathrm{n}}\right)$ e $n$, o índice de fluidez (adimensional).

Os parâmetros reológicos, calculados por regressão não-linear foram os seguintes: nas soluções com $2 \mathrm{~g}$ de fécula de mandioca/100 $\mathrm{g}$ de SFF: $k=8,7 \pm 0,0$ $\mathrm{Pa} \cdot \mathrm{s}^{\mathrm{n}}$, e $n=0,7 \pm 0,0$; e nas soluções com $4 \mathrm{~g}$ de fécula de mandioca/100 $\mathrm{g}$ de SFF: $k=$ $43,0 \pm 0,3 \times 10^{-2} \mathrm{~Pa} \cdot \mathrm{s}^{\mathrm{n}}$, e $n=0,7 \pm 0,0$; similares aos valores reportados por Valencia, Henao, Zapata (2012) em soluções com 3 g de fécula de mandioca/100 g SFF.

$\mathrm{O}$ aumento na concentração do biopolímero implicou em um aumento na viscosidade nas SFF à base de gelatina e no índice de consistência nas SFF à base de fécula de mandioca. Esses comportamentos foram devidos ao incremento nas interações biopolímero - biopolímero (MORAES et al., 2009), que não foram influenciadas pela presença da laponita, nas concentrações estudadas.

Figura 10 - Exemplos de curvas de fluxo das soluções com $8 \mathrm{~g}$ de gelatina/100 g SFF (a), e das soluções com 4 g de fécula de mandioca/100 g SFF (b), ambas com laponita $\left(C_{\text {lap }}\right)$.
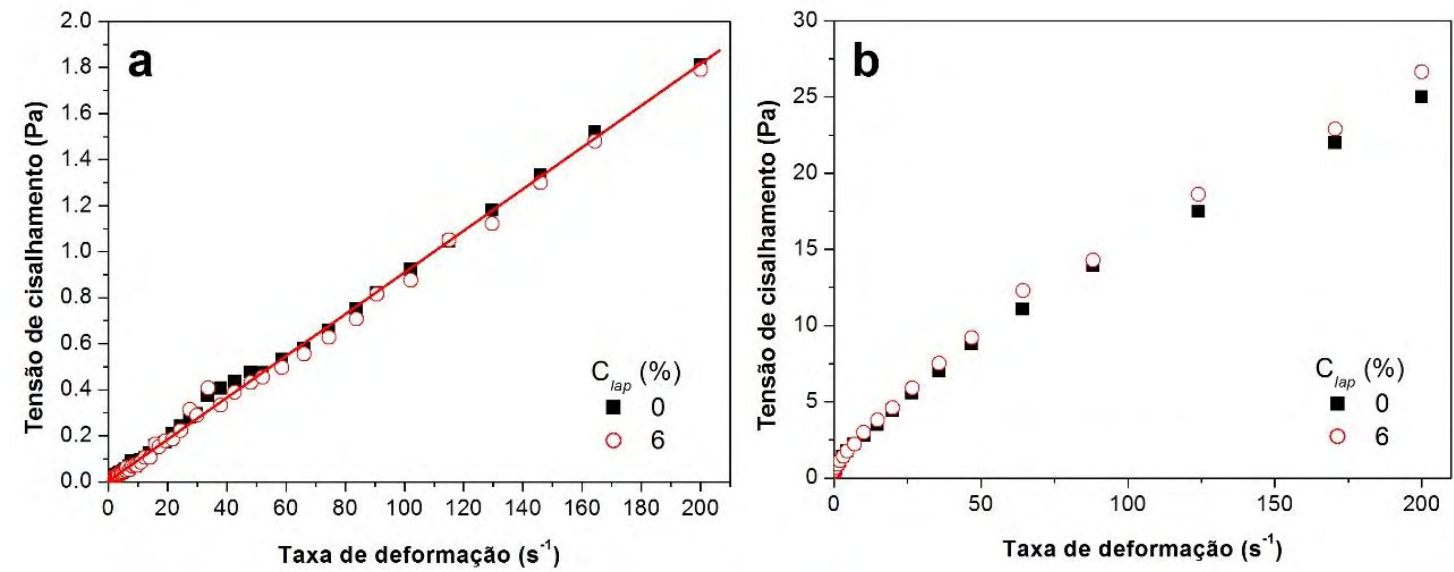

Fonte: própria autoria. 


\subsubsection{Ensaios oscilatórios}

Nas SFF à base de gelatina foram realizados testes de varredura de deformação e de varredura de temperatura. Nos testes de varredura de deformação, observou-se que as SFF à base de gelatina apresentaram um intervalo de região viscoelástica, entre $0,1 \mathrm{e}$ $15 \%$, região na qual, os módulos de armazenamento (G’) e de perda (G’'), permaneceram constantes (Figura 11). Dentro desta região de viscoelasticidade linear foi escolhido um valor de deformação de $10 \%$, utilizado para as análises de varredura de temperatura.

Figura 11 - Exemplos de curvas de varredura de deformação das soluções com $4 \mathrm{~g}$ de gelatina/100 g SFF, em função da concentração de laponita $\left(C_{l a p}\right)$, a $50{ }^{\circ} \mathrm{C}(\mathrm{a})$, e $10{ }^{\circ} \mathrm{C}$ (b).
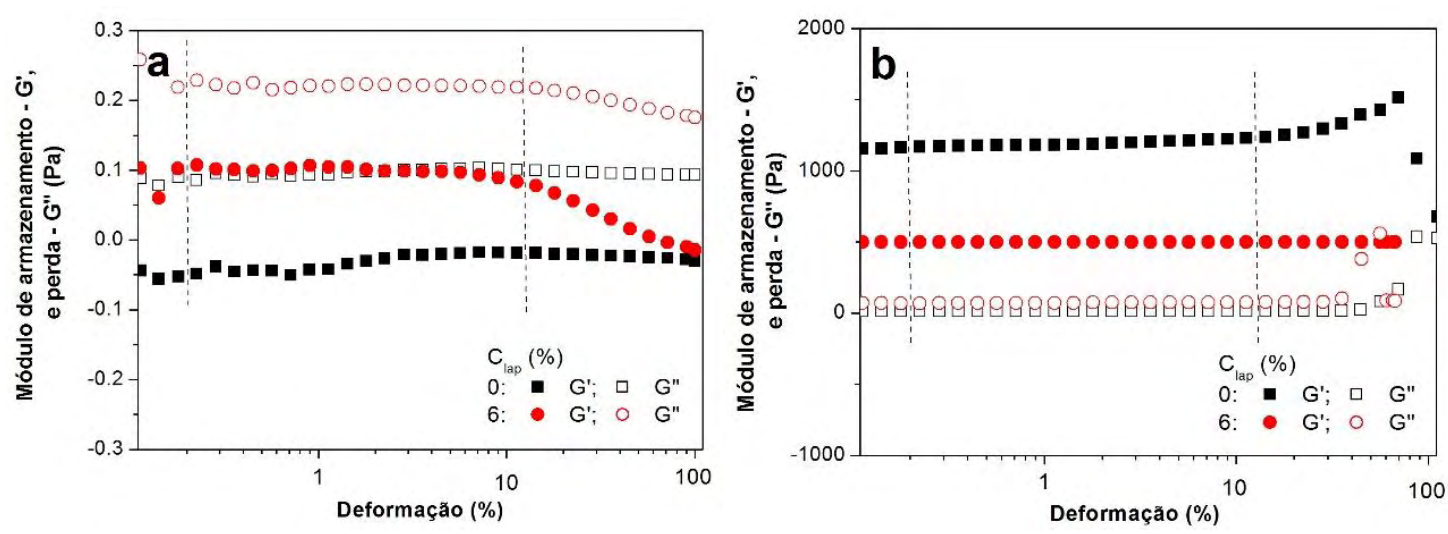

Fonte: própria autoria.

Nos testes de varredura de temperatura, observou-se que os valores de G' e G', incrementaram com a concentração de gelatina na SFF, contudo, os comportamentos viscoelásticos de G' e G', foram similares (Figura 12). Além disso, observou-se que os valores de $G^{\prime}$ aumentaram, como uma inflexão em determinada faixa de temperatura, durante o resfriamento, comportamento típico de géis físicos que apresentam transições sol - gel ( $\left.\mathrm{T}_{\text {sol-gel }}\right)$, e gel - sol ( $\left.\mathrm{T}_{\text {gel-sol }}\right)$ (GÓMEZ-ESTACA et al., 2009).

As soluções com $4 \mathrm{~g}$ de gelatina/100 $\mathrm{g}$ SFF apresentaram valores de $\mathrm{T}_{\text {sol-gel }} \mathrm{e} \mathrm{T}_{\text {gel- }}$ sol de $19,5 \pm 0,1{ }^{\circ} \mathrm{C}$ e $30,4 \pm 0,2{ }^{\circ} \mathrm{C}$, respectivamente (Figuras 12a e 12b). Com o aumento na concentração de gelatina na SFF, as $\mathrm{T}_{\text {sol-gel }}$ e $\mathrm{T}_{\text {gel-sol }}$ incrementaram, portanto, as soluções com $8 \mathrm{~g}$ de gelatina/100 g SFF apresentaram valores de $\mathrm{T}_{\text {sol-gel }} \mathrm{e}$ $\mathrm{T}_{\text {gel-sol }}$ de $24,3 \pm 0,3{ }^{\circ} \mathrm{C}$ e $33,4 \pm 0,2^{\circ} \mathrm{C}$, respectivamente (Figuras $12 \mathrm{c}$ e $12 \mathrm{~d}$ ). Segundo Djabourov, Nishinari, Ross-Murphy (2013), o aumento da $\mathrm{T}_{\text {sol-gel }}$ e $\mathrm{T}_{\text {gel-sol }}$ é 
consequência do aumento na concentração do biopolímero na SFF. Jorge et al. (2014) e Makishi (2016) encontraram valores similares de $T_{\text {sol-gel }}$ e $T_{\text {gel-sol }}$ em soluções com 4 e 8 g de gelatina/100 g SFF.

A laponita não influenciou as $\mathrm{T}_{\text {sol-gel }} \mathrm{e} \mathrm{T}_{\text {gel-sol }}$ nas $\mathrm{SFF}$ à base de gelatina. Entretanto, não se pode sugerir que não houve interações gelatina - laponita, pois os comportamentos observados podem ter sido consequência da fraca concentração da laponita nas SFF estudadas.

Figura 12 - Exemplos de curvas de varredura de temperatura das soluções com $4 \mathrm{~g}$ de gelatina/100 g SFF, em função da concentração de laponita $\left(C_{l a p}\right): 0 \%$ (a), e $6 \%$ (b); e das soluções com $8 \mathrm{~g}$ de gelatina/100 g SFF, em função da concentração de laponita $\left(C_{l a p}\right): 0 \%(\mathrm{c})$, e $6 \%(\mathrm{~d})$.
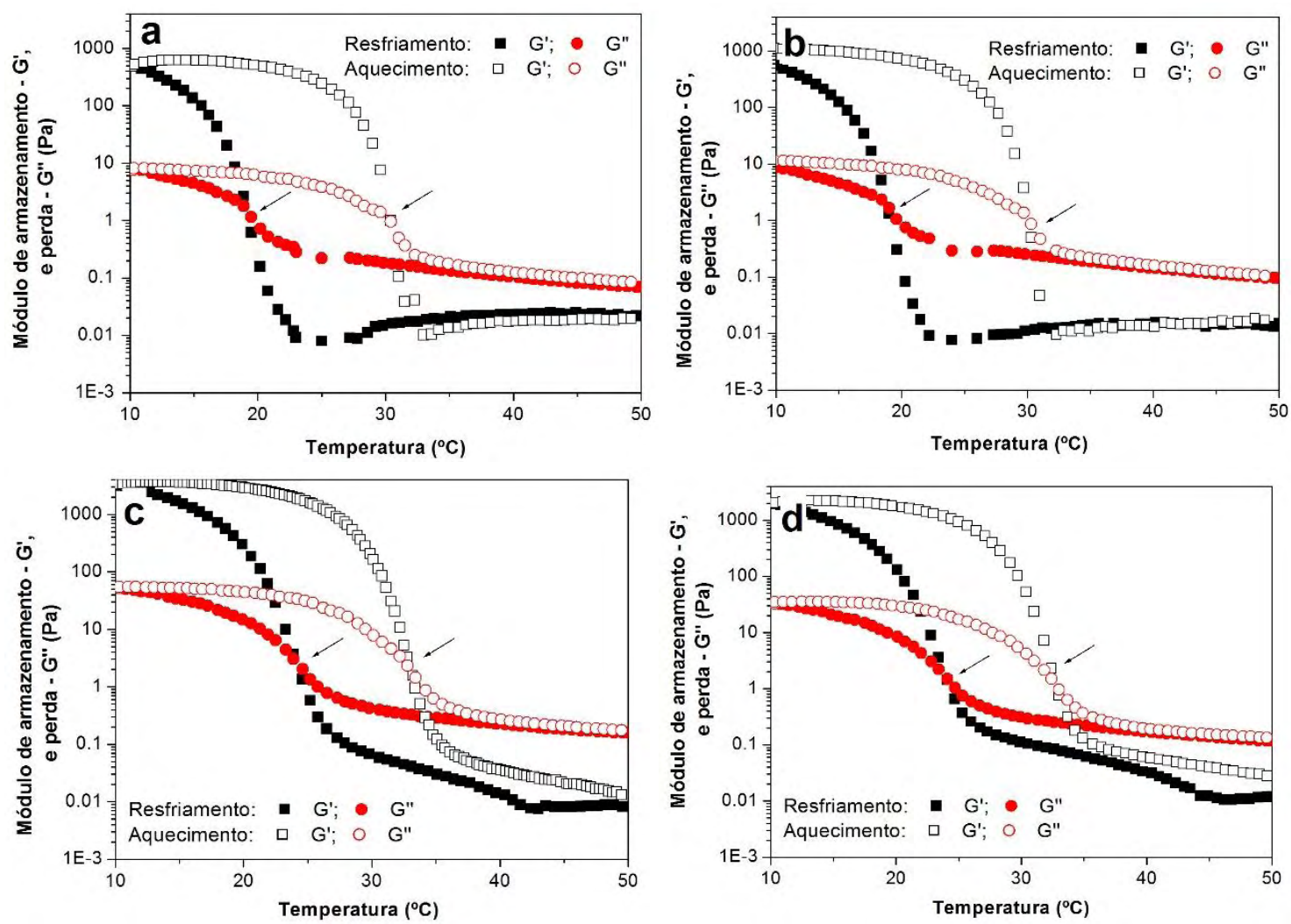

Fonte: própria autoria.

A partir dos testes de varredura de temperatura das SFF à base de gelatina com laponita, escolheu-se a temperatura de $27{ }^{\circ} \mathrm{C}$, como a temperatura ideal para verter as SFF à base de gelatina, nas placas de Petri ou de acrílico. Essa temperatura $\left(27^{\circ} \mathrm{C}\right)$ foi 
maior que $\mathrm{T}_{\text {sol-gel }}$ das soluções com $8 \mathrm{~g}$ de gelatina/100 $\mathrm{g}$ SFF, e foi padronizada para as outras SFF à base de colágeno e fécula de mandioca.

\subsection{Caracterização dos filmes nanocompósitos}

Nesta seção serão apresentados e discutidos os resultados da caracterização físico-química dos filmes de colágeno, gelatina e fécula de mandioca, contendo laponita.

\subsubsection{Aspecto visual, espessura e umidade}

Todos os filmes nanocompósitos apresentaram aspecto homogêneo, sendo facilmente retirados dos suportes (placas de Petri ou de acrílico). Observou-se que a adição da laponita não implicou em alterações visuais dos filmes (Figuras 13, 14 e 15).

Figura 13 - Imagens representativas dos filmes de colágeno $\left(C_{c o l}=4 \%\right)$, com laponita $\left(C_{\text {lap }}=6 \%\right)$, produzidos por: casting (a) e espalhamento mecânico (b).

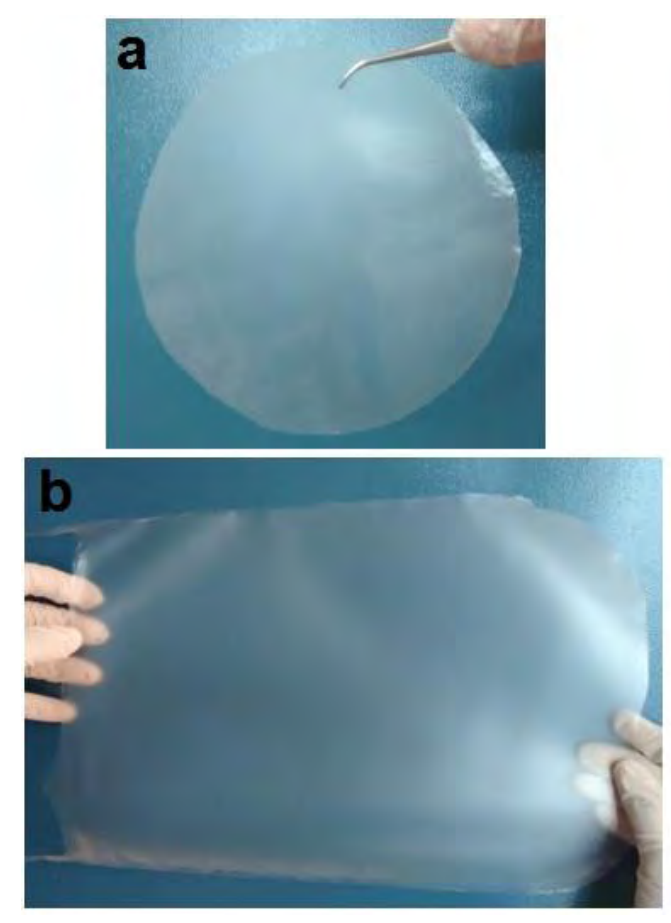

Fonte: própria autoria. 
Figura 14 - Imagens representativas dos filmes de gelatina $\left(C_{g e l}=4 \%\right)$, com laponita $\left(C_{\text {lap }}=6 \%\right)$, produzidos por: casting (a) e espalhamento mecânico (b).

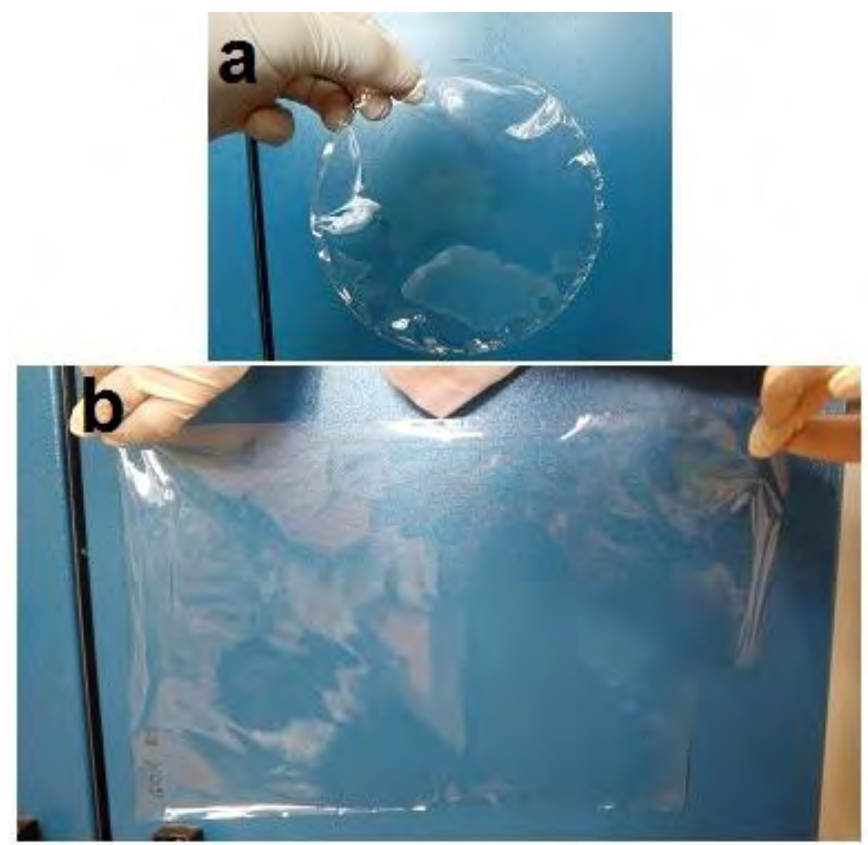

Fonte: própria autoria.

Figura 15 - Imagens representativas dos filmes de fécula de mandioca $\left(C_{f e ́ c}=4 \%\right)$, com laponita $\left(C_{l a p}=6 \%\right)$, produzidos por: casting (a) e espalhamento mecânico (b).
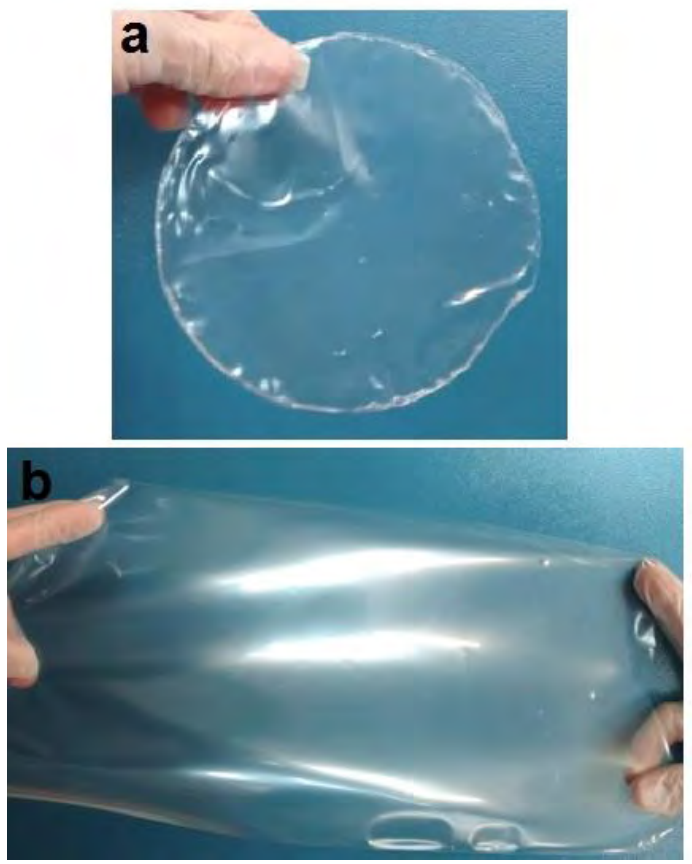

Fonte: própria autoria. 
O aumento da concentração do biopolímero nas SFF não influenciou a espessura dos filmes nanocompósitos de colágeno, gelatina ou fécula de mandioca $(p>0,05)$. Este resultado era esperado, pois durante a produção dos filmes nanocompósitos, a quantidade de matéria seca da SFF depositada por unidade de área foi mantida constante $\left(8 \mathrm{mg} / \mathrm{cm}^{2}\right)$. Portanto, a espessura dos filmes nanocompósitos se manteve constante, em $70 \pm 15 \mu \mathrm{m}$, independente da técnica de produção dos filmes nanocompósitos $(p>0,05)$.

A presença da laponita na matriz à base de colágeno, gelatina ou fécula de mandioca não alterou os valores de espessura nos filmes nanocompósitos $(p>0,05)$. Estes resultados indicam que as concentrações de laponita estudadas não alteraram a densidade dos filmes nanocompósitos. Em concordância com estes resultados, Li et al. (2015) não observaram alterações de espessura em filmes nanocompósitos de gelatina com $C_{\text {lap }}<6,7 \%$. Vannin et al. (2014) também não observaram variações de espessura em filmes nanocompósitos de gelatina com montmorilonita, para concentrações de montmorilonita $\left(C_{m o n}\right)<15 \%$. Dados de espessura em filmes nanocompósitos de colágeno e fécula de mandioca com laponita não foram encontrados na literatura.

A umidade dos filmes nanocompósitos foi controlada principalmente pelo biopolímero e pelo glicerol. Portanto, os filmes nanocompósitos usando colágeno, gelatina e fécula de mandioca tiveram valores de umidade de $17,7 \pm 0,8 \%, 15,5 \pm 1,5 \%$ e $12,5 \pm 0,9 \%$, respectivamente. Os valores de umidade nos filmes nanocompósitos de colágeno com laponita foram levemente superiores aos informados por Wolf, Sobral, Telis (2009) em filmes de colágeno $(14,1 \pm 1,4 \%)$ condicionados a $58 \%$ de UR, mas foram comparáveis aos encontrados por Makishi (2016) em filmes de colágeno (15,6 \pm 0,4\%) condicionados a 58\% de UR. Os valores de umidade nos filmes nanocompósitos de gelatina e fécula de mandioca foram comparáveis aos encontrados por Vanin et al. (2014) em filmes de gelatina condicionados em UR $=60 \pm 5 \%$, e por Aouada, Mattoso, Longo (2011) em filmes de amido de milho condicionados em UR $=53 \%$; todos plastificados com glicerol.

Com o intuito de conhecer a composição nos filmes nanocompósitos, e considerando que algumas das concentrações foram inicialmente expressas em termos de solução filmogênica, as concentrações de biopolímero, glicerol, laponita e água nos filmes foram calculadas por balanços de massa, considerando-se a perda de massa na secagem (Tabelas 2 e 3). Nos filmes de proteínas (colágeno e gelatina) foi considerado um valor de umidade de 16,6\%; este valor foi a média dos valores de umidade 
determinados nos filmes de colágeno e gelatina. Nos filmes de fécula de mandioca foi utilizado o valor de umidade previamente determinado (12,5\%).

Os filmes filmes de colágeno, gelatina e fécula de mandioca após secagem tiveram concentrações comparáveis de biopolímero, e na sequência, concentrações comparáveis de glicerol (Tabelas 2 e 3).

Tabela 2 - Composição das soluções formadoras de filmes (SFF) de proteínas e dos filmes de proteínas após secagem.

\begin{tabular}{|c|c|c|c|c|c|c|c|}
\hline \multicolumn{4}{|c|}{ Na SFF (g/1000 g) } & \multicolumn{4}{|c|}{ No filme $(\mathrm{g} / 1000 \mathrm{~g})$} \\
\hline Biopolímero & Glicerol & Laponita & Água & Biopolímero & Glicerol & Laponita & Água \\
\hline \multirow{5}{*}{20,0} & \multirow{5}{*}{6,0} & 0,0 & 974,0 & 641,5 & 192,5 & 0,0 & 166,0 \\
\hline & & 0,3 & 973,7 & 634,2 & 190,3 & 9,5 & 166,0 \\
\hline & & 0,6 & 973,4 & 627,1 & 188,1 & 18,8 & 166,0 \\
\hline & & 0,9 & 973,1 & 620,1 & 186,0 & 27,9 & 166,0 \\
\hline & & 1,2 & 972,8 & 613,2 & 184,0 & 36,8 & 166,0 \\
\hline \multirow{5}{*}{40,0} & \multirow{5}{*}{12,0} & 0,0 & 948,0 & 641,5 & 192,5 & 0,0 & 166,0 \\
\hline & & 0,6 & 947,4 & 634,2 & 190,3 & 9,5 & 166,0 \\
\hline & & 1,2 & 946,8 & 627,1 & 188,1 & 18,8 & 166,0 \\
\hline & & 1,8 & 946,2 & 620,1 & 186,0 & 27,9 & 166,0 \\
\hline & & 2,4 & 945,6 & 613,2 & 184,0 & 36,8 & 166,0 \\
\hline \multirow{5}{*}{80,0} & \multirow{5}{*}{24,0} & 0,0 & 896,0 & 641,5 & 192,5 & 0,0 & 166,0 \\
\hline & & 1,2 & 894,8 & 634,2 & 190,3 & 9,5 & 166,0 \\
\hline & & 2,4 & 893,6 & 627,1 & 188,1 & 18,8 & 166,0 \\
\hline & & 3,6 & 892,4 & 620,1 & 186,0 & 27,9 & 166,0 \\
\hline & & 4,8 & 891,2 & 613,3 & 184,0 & 36,8 & 166,0 \\
\hline
\end{tabular}

Fonte: própria autoria. 
Tabela 3 - Composição das soluções formadoras de filmes (SFF) de fécula de mandioca e dos filmes de fécula de mandioca após secagem.

\begin{tabular}{|c|c|c|c|c|c|c|c|}
\hline \multicolumn{4}{|c|}{ Na SFF (g/1000 g) } & \multicolumn{4}{|c|}{ No filme $(\mathrm{g} / 1000 \mathrm{~g})$} \\
\hline Biopolímero & Glicerol & Laponita & Água & Biopolímero & Glicerol & Laponita & Água \\
\hline \multirow{5}{*}{20,0} & \multirow{5}{*}{6,0} & 0,0 & 974,0 & 673,1 & 201,9 & 0,0 & 125,0 \\
\hline & & 0,3 & 973,7 & 665,4 & 199,6 & 10,0 & 125,0 \\
\hline & & 0,6 & 973,4 & 657,9 & 197,4 & 19,7 & 125,0 \\
\hline & & 0,9 & 973,1 & 650,5 & 195,2 & 29,3 & 125,0 \\
\hline & & 1,2 & 972,8 & 643,4 & 193,0 & 38,6 & 125,0 \\
\hline \multirow{5}{*}{40,0} & \multirow{5}{*}{12,0} & 0,0 & 948,0 & 673,1 & 201,9 & 0.0 & 125,0 \\
\hline & & 0,6 & 947,4 & 665,4 & 199.6 & 10,0 & 125,0 \\
\hline & & 1,2 & 946,8 & 657,9 & 197,4 & 19,7 & 125,0 \\
\hline & & 1,8 & 946,2 & 650,6 & 195,2 & 29,3 & 125,0 \\
\hline & & 2,4 & 945,6 & 643,4 & 193,0 & 38,6 & 125,0 \\
\hline
\end{tabular}

Fonte: própria autoria.

\subsubsection{Difração de raios $X$ e espectroscopia de infravermelho por transformada de Fourier}

Para um mesmo biopolímero, os filmes nanocompósitos apresenteram espectros de raios X similares (Figura 16), independente da concentração de biopolímero na SFF (Tabelas 2 e 3). Estes resultados podem ser consequência de ter produzido filmes nanocompósitos com uma mesma concentração de biopolímero por unidade de área (8 $\left.\mathrm{mg} / \mathrm{cm}^{2}\right)$, e portanto, com uma mesma espessura $(70 \pm 15 \mu \mathrm{m})$. Na presente tese, a não alteração do grau de restruturação dos filmes nanocompósitos, em função da concentração do biopolímero na SFF (Figura 16), levou a continuar os estudos com uma única concentração de biopolímero, conservando ainda as duas técnicas de preparo dos filmes. Escolheu-se a concentração de $4 \mathrm{~g}$ de biopolímero/100 g SFF, uma vez que, nesta concentração, todos os biopolímeros (colágeno, gelatina e fécula de mandioca) em estudo foram facilmente dispersos em água. 
Figura 16 - Exemplos de espectros obtidos por difração de raios $\mathrm{X}$ dos filmes nanocompósitos de colágeno (a), gelatina (b) e fécula de mandioca (c), em função da concentração de colágeno $\left(C_{c o l}\right)$, gelatina $\left(C_{g e l}\right)$, fécula de mandioca $\left(C_{f e ́ c}\right)$ e laponita $\left(C_{l a p}\right)$, produzidos por espalhamento mecânico.
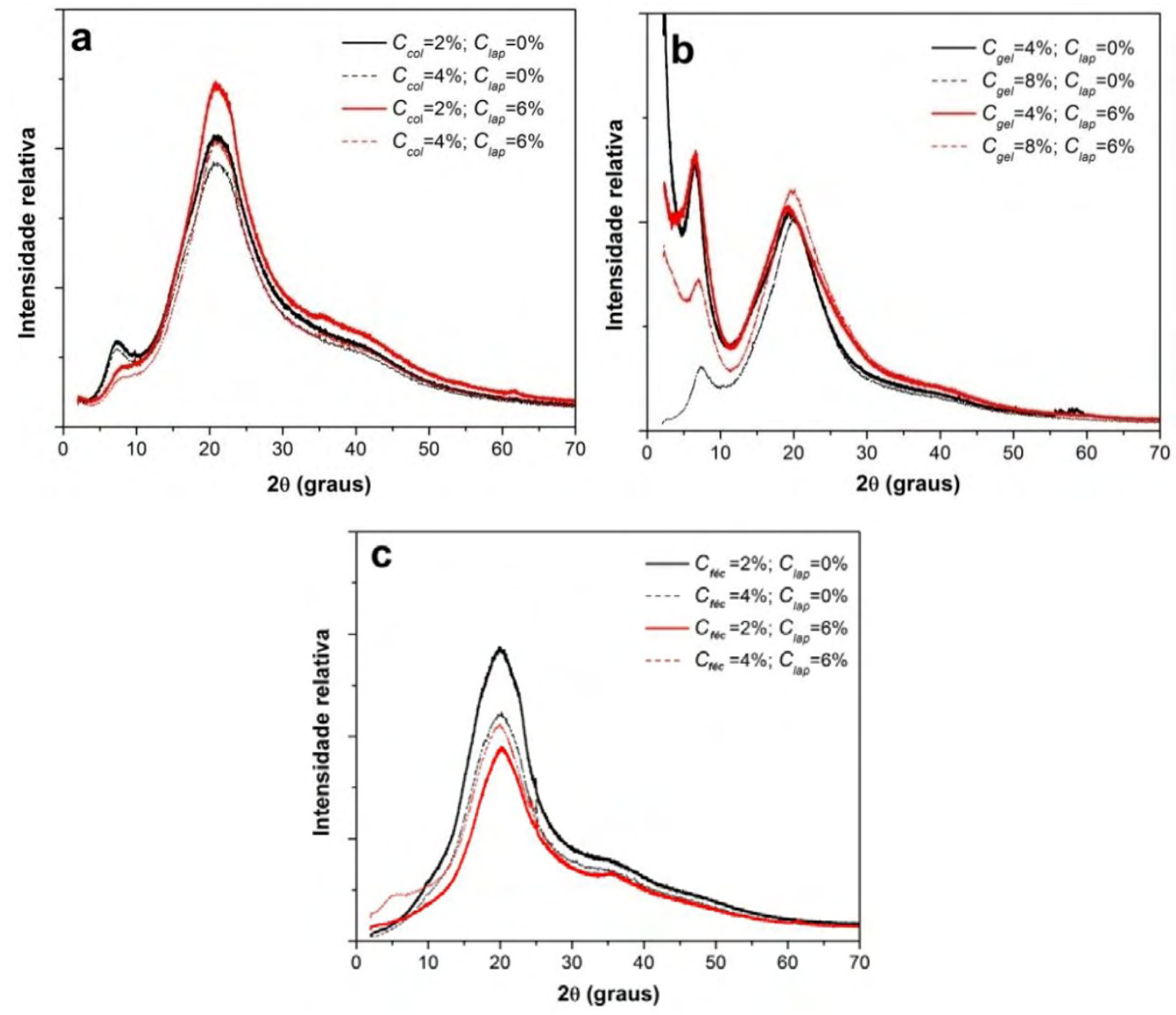

Fonte: própria autoria.

Os filmes à base de colágeno e gelatina sem laponita apresentaram espectros com um pico bem definido em $2 \theta=7,1^{\circ}$ (Figura 17a e 17b), atribuído à estrutura cristalina da triple hélice do colágeno e da gelatina (PEREDA et al., 2011; YAKIMETS et al., 2007), e uma banda em $2 \theta=20^{\circ}$, característica da fase amorfa do biopolímero (PEREDA et al., 2011). Os filmes à base de fécula de mandioca sem laponita também apresentaram uma banda em $2 \theta=20^{\circ}$ (Figura 17c), típica da região amorfa do biopolímero em estudo (PEROTTI et al., 2014). Esta banda indicou que não houve retrogradação do amido durante a secagem das SFF.

Os espectros dos filmes à base de colágeno e gelatina não foram alterados pela técnica de preparo. Em relação à concentração da laponita, obserbou-se que o pico e a banda observados nos espectros dos filmes à base de colágeno e gelatina não foram 
deslocados com a presença da laponita (Figura 17a e 17b). Resultado similar foi observado nos filmes nanocompósitos à base de fécula de mandioca com $C_{\text {lap }}=1,5 \mathrm{e}$ $3 \%$ (Figura 17c).

Nos filmes à base de colágeno foi observado que o aumento na concentração da laponita implicou em uma diminuição da intensidade do pico observado em $2 \theta=7,1^{\circ}$ (Figura 17a); sendo associado com uma diminuição na formação de estruturas cristálinas nestes filmes.

Figura 17 - Exemplos de espectros obtidos por difração de raios $\mathrm{X}$ dos filmes de colágeno (a), gelatina (b) e fécula de mandioca (c), em função da concentração de laponita $\left(C_{l a p}\right)$, produzidos por casting $\left(C_{c o l}, C_{g e l}, C_{f e ́ c}=4 \%\right)$.
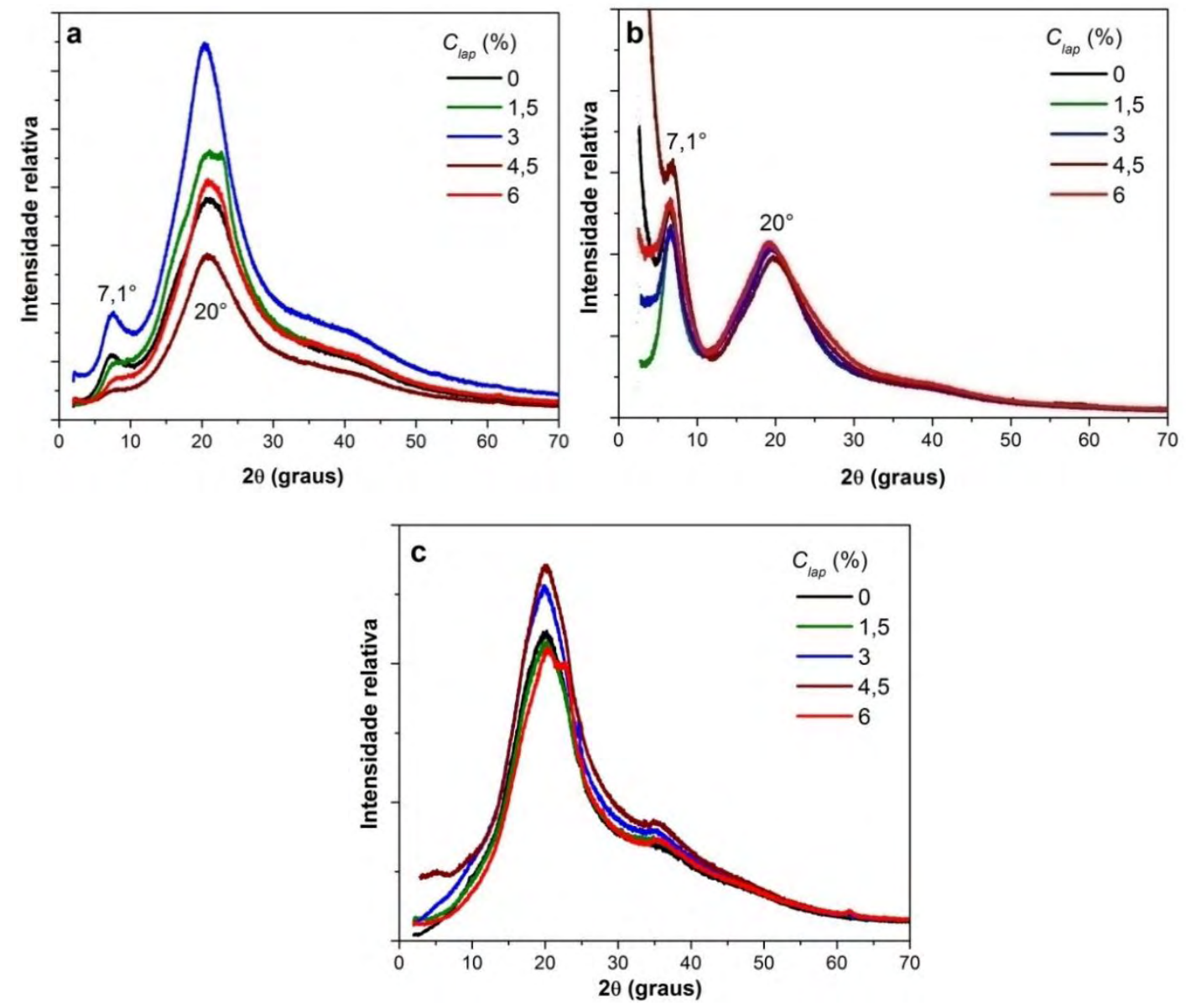

Fonte: própria autoria.

A ausência de um pico bem definido entre $2 \theta=2^{\circ}$ e $6,5^{\circ}$ nos filmes de proteínas com laponita, assim como nos filmes de fécula de mandioca com $C_{\text {lap }}=1,5$ e $3 \%$, indicou que as plaquetas de laponita foram completamente esfoliadas na matriz 
biopolimérica. $\mathrm{O}$ valor em $2 \theta=2^{\circ}$ foi utilizado para calcular o espaçamento interplanar ( $d$, em $\AA$ ), utilizando a Equação (1). O valor de espaçamento interplanar para $2 \theta=2^{\circ}$ foi $44 \AA$ A. Este valor indicou que as plaquetas de laponita nos filmes estão separadas ao menos $44 \AA$, entre si. Rao et al. (2007) observou que no estado exfoliado, o pico em $2 \theta$ $=6,5^{\circ}$ devido à reflexão basal das plaquetas de laponita (Figura 5a), desapareceu como consequência da exfoliação das plaquetas nas cadeias poliméricas.

$\mathrm{Na}$ Figura 18, se apresenta uma ampliação dos espectros obtidos nos filmes nanocompósitos de fécula de mandioca, na região de: $2 \theta=2^{\circ}$ e $13^{\circ}$. Nesta região, observou-se que os filmes nanocompósitos com $C_{\text {lap }}>3 \%$ tiveram um pico em $2 \theta=$ $5,2^{\circ}$, valor que esteve associado a uma separação das plaquetas de laponita de ao menos $17 \AA$ Å. Este pico foi associado com a presença de plaquetas de laponita intercaladas nos filmes. Estes resultados foram diferentes dos observados por Aouada, Mattoso, Longo (2011) e Perotti et al. (2014), os quais observaram a exfoliação das plaquetas de laponita em filmes nanocompósitos de amido de milho e de fécula de mandioca, com $C_{\text {lap }} \leq$ 15\%. Contudo, Cyras et al. (2008) e Almasi, Ghanbarzadeh, Entezami (2010) observaram a formação de estruturas intercaladas de montmorilonita em filmes à base de fécula de batata e amido de milho, com $C_{m o n}<7 \%$. 
Figura 18 - Exemplos de espectros obtidos por difração de raios $\mathrm{X}$ dos filmes de fécula de mandioca, na região de: $2 \theta=2^{\circ}$ e $13^{\circ}$, em função da concentração de laponita $\left(C_{l a p}\right)$, produzidos por casting $\left(C_{f e ́ c}=4 \%\right)$.
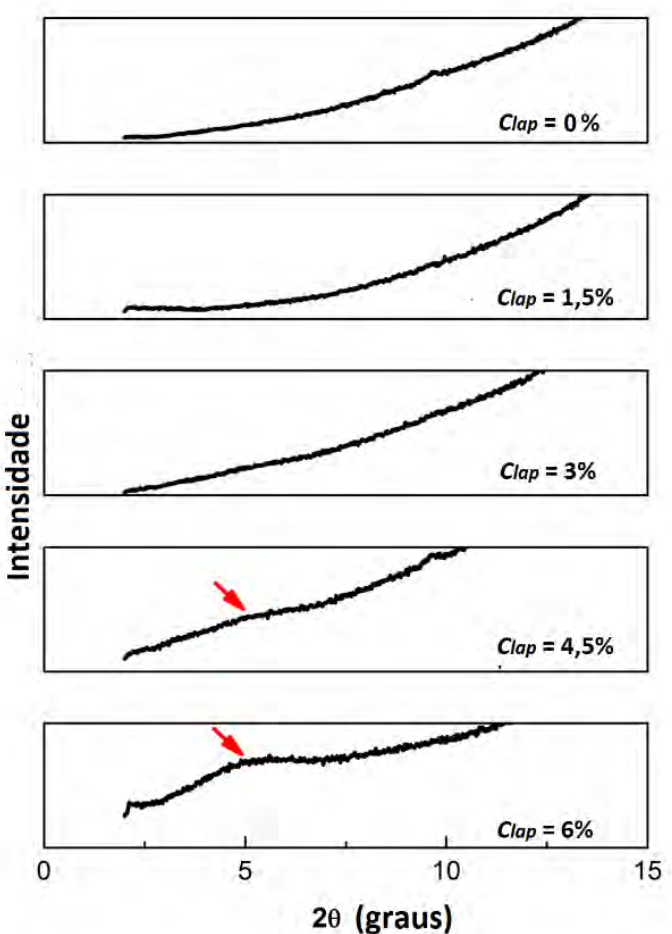

Fonte: própria autoria.

Os espectros obtidos por espectroscopia de infravermelho por transformada de Fourier (FTIR) nos filmes de colágeno e gelatina sem laponita (Figura 19a e 19b) apresentaram bandas em 3300 e $3090 \mathrm{~cm}^{-1}$, características do grupo amida I; em 1635 $\mathrm{cm}^{-1}$, característica da estrutura tripla-hélice que faz parte da estrutura novelo da gelatina; em 1540 e $1210 \mathrm{~cm}^{-1}$, que são típicas do grupo amida II (MORAES et al., 2008).

Os espectros FTIR dos filmes nanocompósitos à base de fécula de mandioca sem laponita (Figura 19c) apresentaram uma banda em $3322 \mathrm{~cm}^{-1}$, típica da elongação dos grupos - $\mathrm{OH}$; em $2932 \mathrm{~cm}^{-1}$, típica da elongação dos grupos $-\mathrm{CH}$; em $1640 \mathrm{~cm}^{-1}$, atribuída à vibração dos grupos $-\mathrm{OH}$, absorvidos pelo material; e em $1080 \mathrm{~cm}^{-1}$, típica da vibração dos grupos C-O-C, característicos do amido (VALENCIA; HENAO; ZAPATA, 2012). 
Figura 19 - Exemplos de espectros obtidos por espectroscopia de infravermelho por transformada de Fourier dos filmes de colágeno (a), gelatina (b) e fécula de mandioca (c), em função da concentração de laponita $\left(C_{l a p}\right)$, produzidos por espalhamento mecânico $\left(C_{c o l}, C_{g e l}, C_{f e ́ c}=4 \%\right)$.
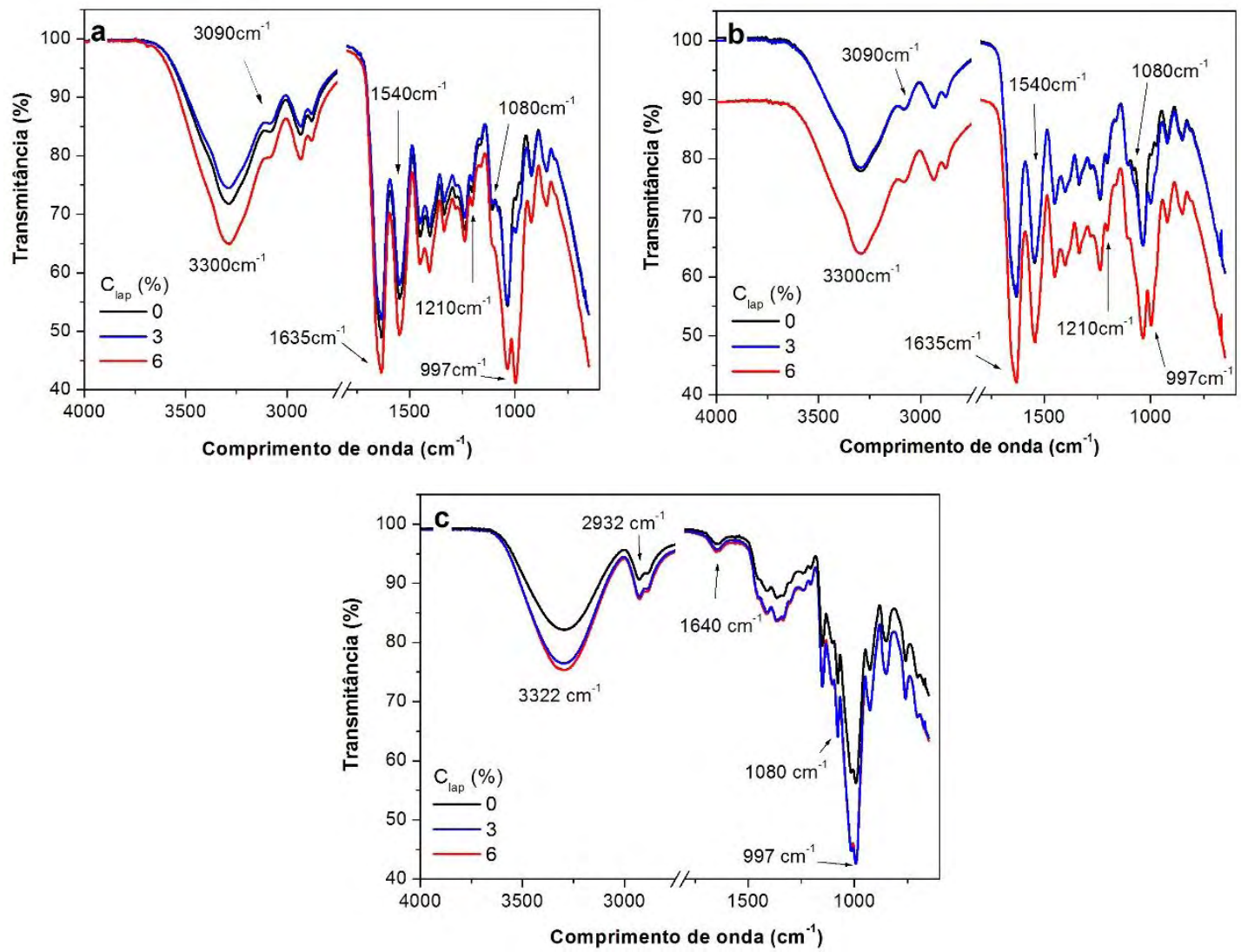

Fonte: própria autoria.

Os espectros FTIR dos filmes nanocompósitos não foram alterados pela técnica de produção.

Com a adição da laponita, observou-se que os espectros FTIR dos filmes de colágeno, gelatina e fécula de mandioca tiveram uma diminuição na intensidade da banda localizada em $1080 \mathrm{~cm}^{-1}$, devido, provavelmente à superposição de duas bandas: uma banda em $1088 \mathrm{~cm}^{-1}$, associada ao estiramento dos grupos C-O (do glicerol), e a banda em $1070 \mathrm{~cm}^{-1}$, atribuída à vibração dos grupos Si-O da laponita (MORAES et al., 2008; PÁLKOVÁ et al., 2010) (Figura 19). Também foi observado um aumento da intensidade da banda localizada em $997 \mathrm{~cm}^{-1}$, típica do estiramento dos grupos Si-O (PÁLKOVÁ et al., 2010). Estes resultados indicaram que não houve nenhuma formação de ligação química entre as plaquetas de laponita e os biopolímeros em estudo (colágeno, gelatina e fécula de mandioca). 


\subsubsection{Microscopia eletrônica de varredura}

Percebeu-se que a topografia superficial (superfície de secagem) e da seção transversal dos filmes nanocompósitos foram influenciadas pelo biopolímero utilizado. Os filmes controle de colágeno se caracterizaram por possuir topografia superficial (Figura 20) e de seção transversal (Figura 21) irregulares, devido à presença de fibras de colágeno que não foram solubilizadas durante o preparo da SFF (WOLF; SOBRAL; TELIS, 2009). Diferentemente, os filmes controle à base de gelatina apresentaram topografia superficial (Figura 22) e de seção transversal (Figura 23) regulares. Já os filmes controle de fécula de mandioca tiveram topografia superficial (Figura 24) e de seção transversal (Figura 25) irregulares, porém, menos irregulares que os filmes de colágeno. Segundo Cano et al. (2015), durante a secagem das SFF à base de amido, a amilose separa da amilopectina, produzindo filmes irregulares. 
Figura 20 - Imagens representativas das micrografias de superfície dos filmes de colágeno, com concentrações de laponita de: $0 \%$ (a), 1,5\% (b), 3\% (c), 4,5\% (d) e $6 \%$ (e), produzidos por casting $\left(C_{c o l}=4 \%\right)$.
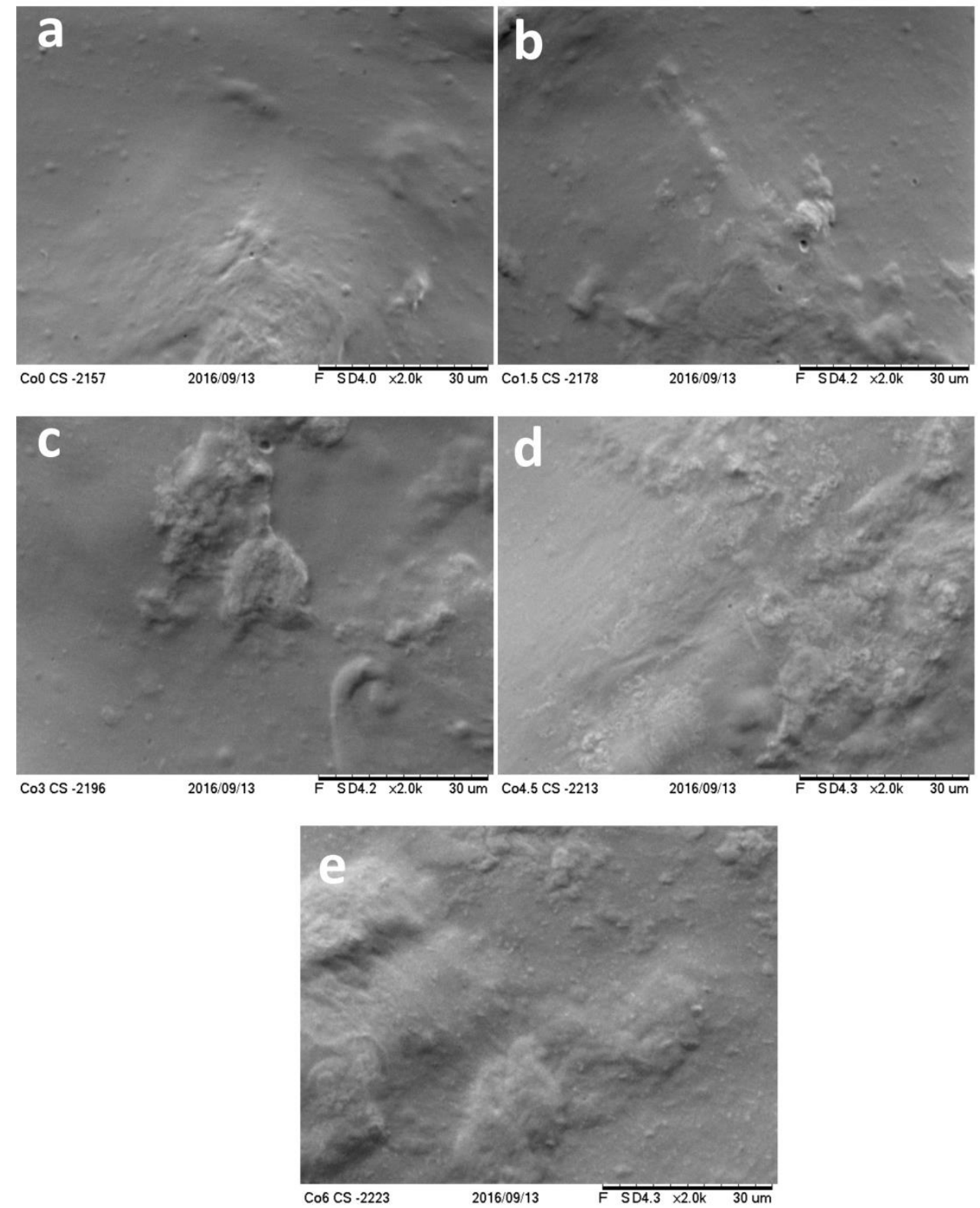

Fonte: própria autoria. 
Figura 21 - Imagens representativas das micrografias de seção transversal após criofratura dos filmes de colágeno, com concentrações de laponita de: 0\% (a), 1,5\% (b), $3 \%$ (c), $4,5 \%$ (d) e $6 \%$ (e), produzidos por casting $\left(C_{c o l}=4 \%\right)$.
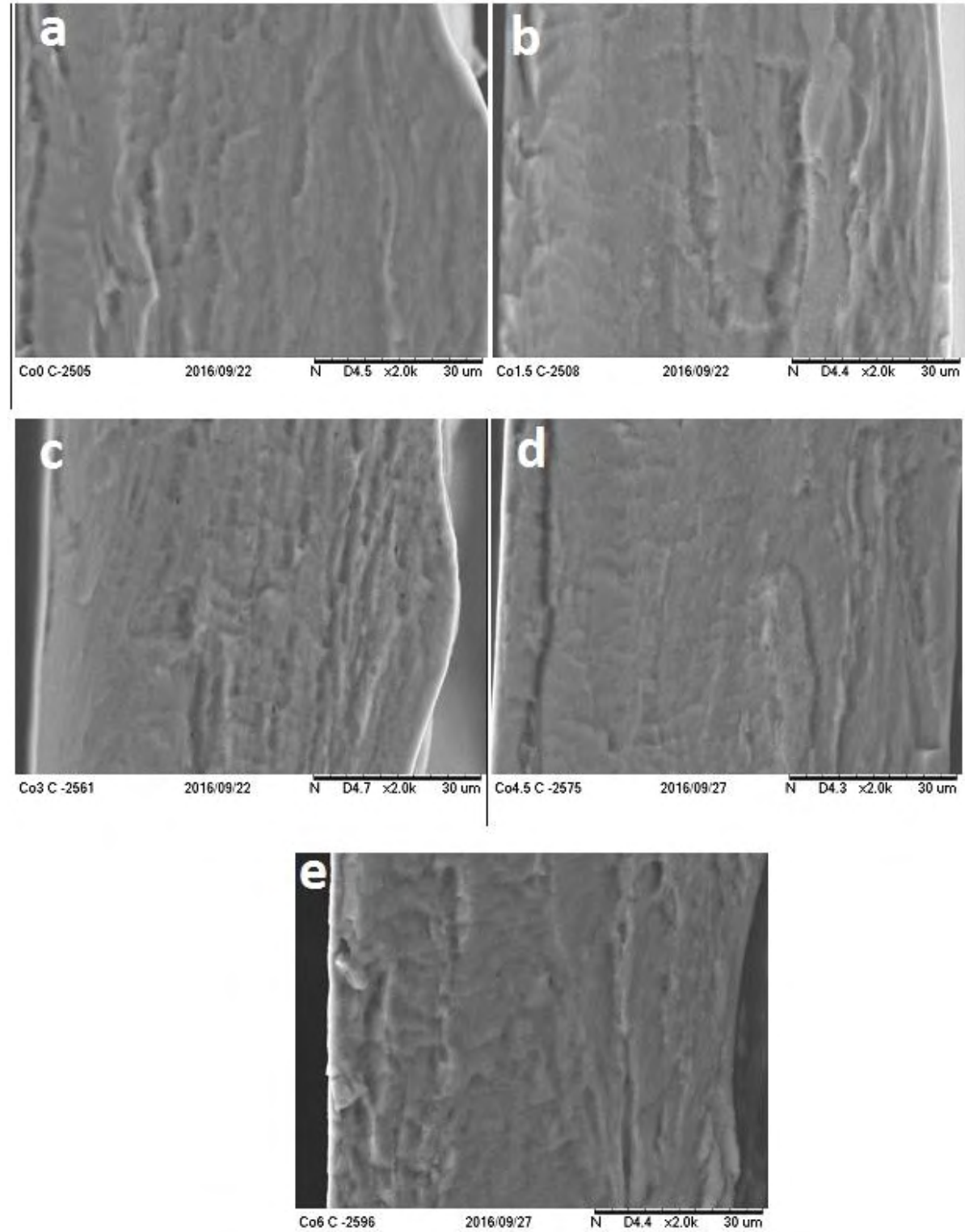

Fonte: própria autoria. 
Figura 22 - Imagens representativas das micrografias de superfície dos filmes de gelatina, com concentrações de laponita de: $0 \%$ (a), 1,5\% (b), 3\% (c), 4,5\% (d) e $6 \%$ (e), produzidos por espalhamento mecânico $\left(C_{g e l}=4 \%\right)$.

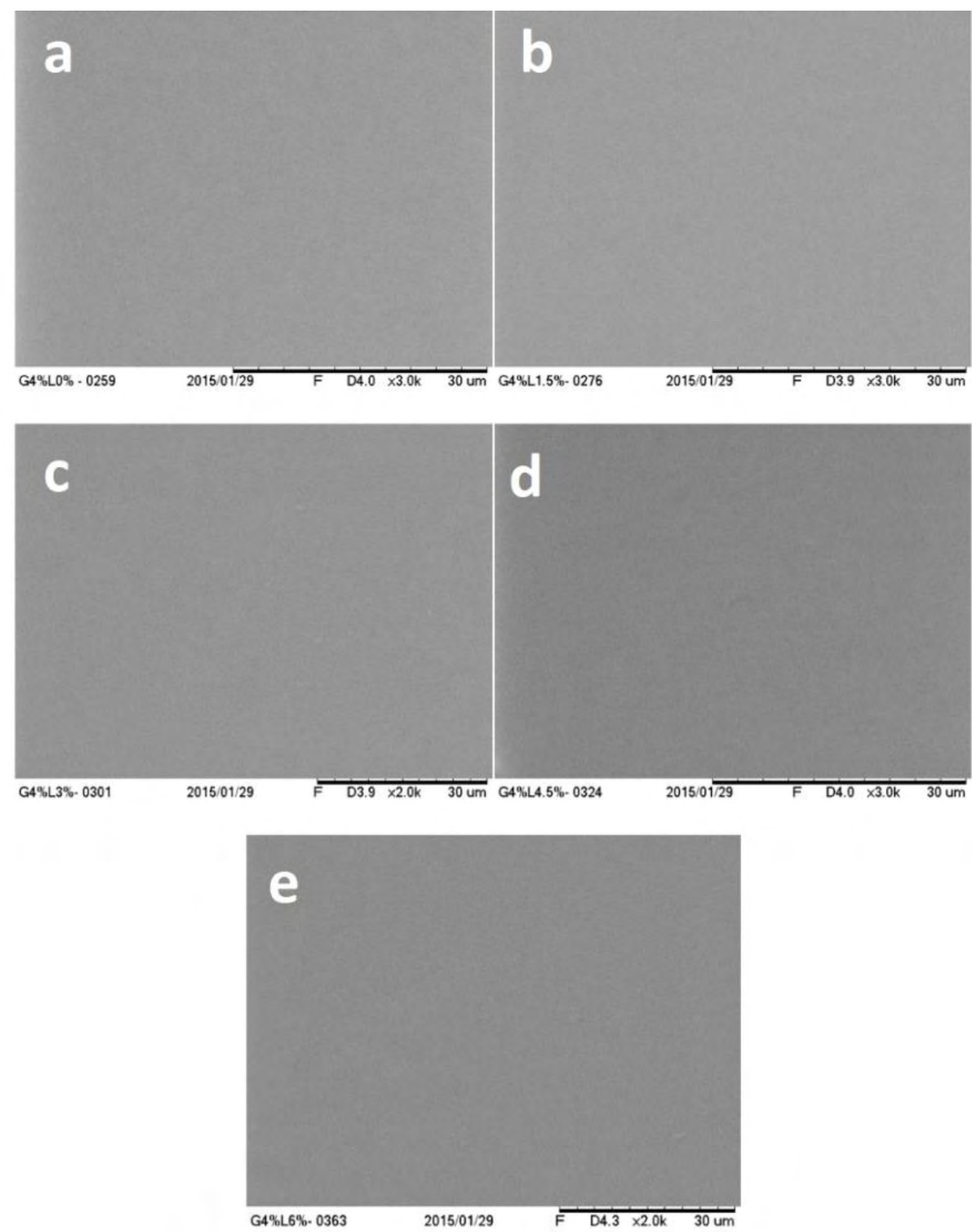

Fonte: própria autoria. 
Figura 23 - Imagens representativas das micrografias de seção transversal após criofratura dos filmes de gelatina, com concentrações de laponita de: 0\% (a), 1,5\% (b), $3 \%$ (c), $4,5 \%$ (d) e $6 \%$ (e), produzidos por espalhamento mecânico $\left(C_{g e l}=4 \%\right)$.
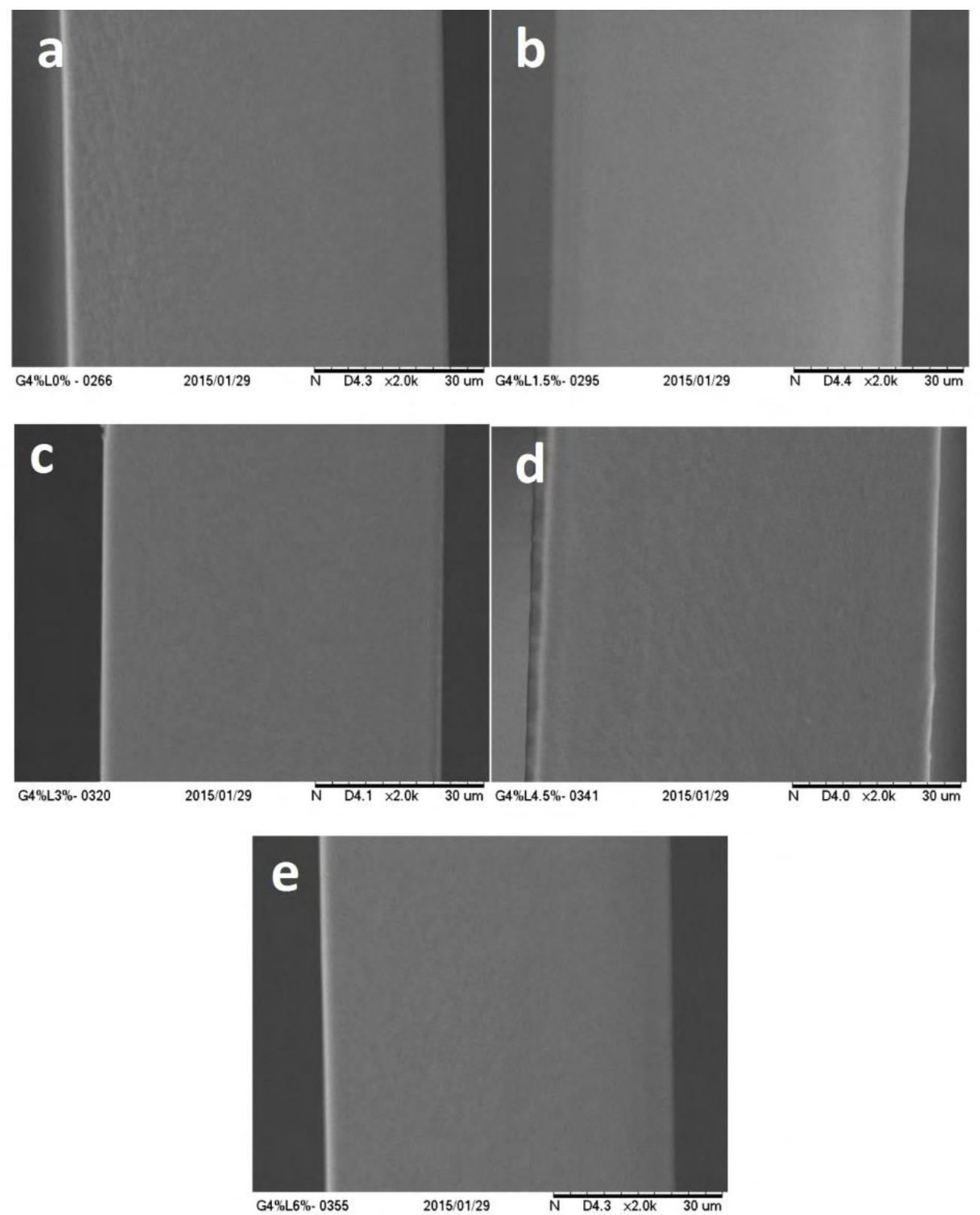

Fonte: própria autoria. 
Figura 24 - Imagens representativas das micrografias de superfície dos filmes de fécula de mandioca, com concentrações de laponita de: $0 \%$ (a), 1,5\% (b), 3\% (c), 4,5\% (d) e $6 \%$ (e), produzidos por espalhamento mecânico $\left(C_{f e ́ c}=4 \%\right)$.

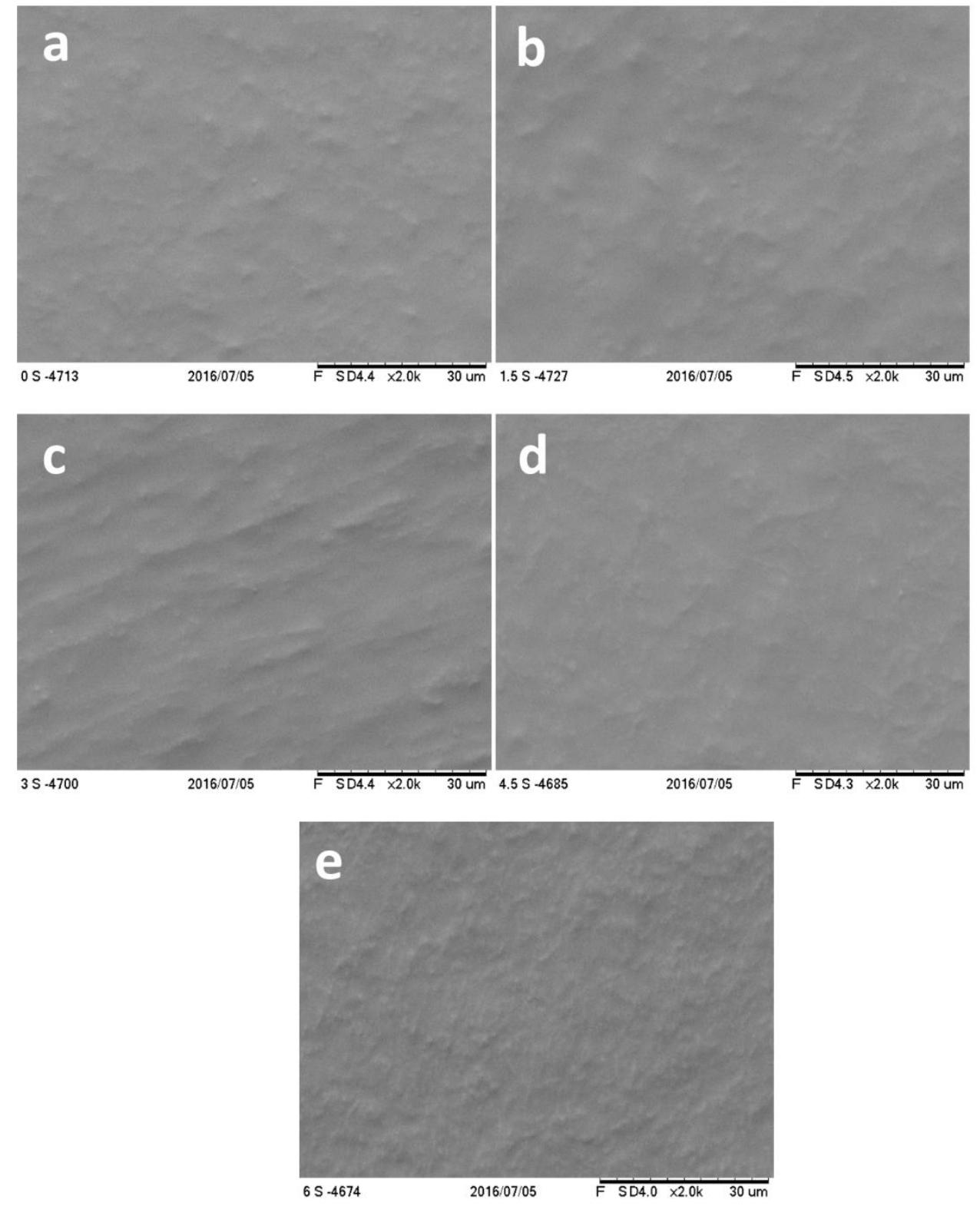

Fonte: própria autoria. 
Figura 25 - Imagens representativas das micrografias de seção transversal após criofratura dos filmes de fécula de mandioca, com concentrações de laponita de: 0\% (a), $1,5 \%$ (b), $3 \%$ (c), $4,5 \%$ (d) e $6 \%$ (e), produzidos por espalhamento mecânico $\left(C_{f e ́ c}=\right.$ $4 \%)$.
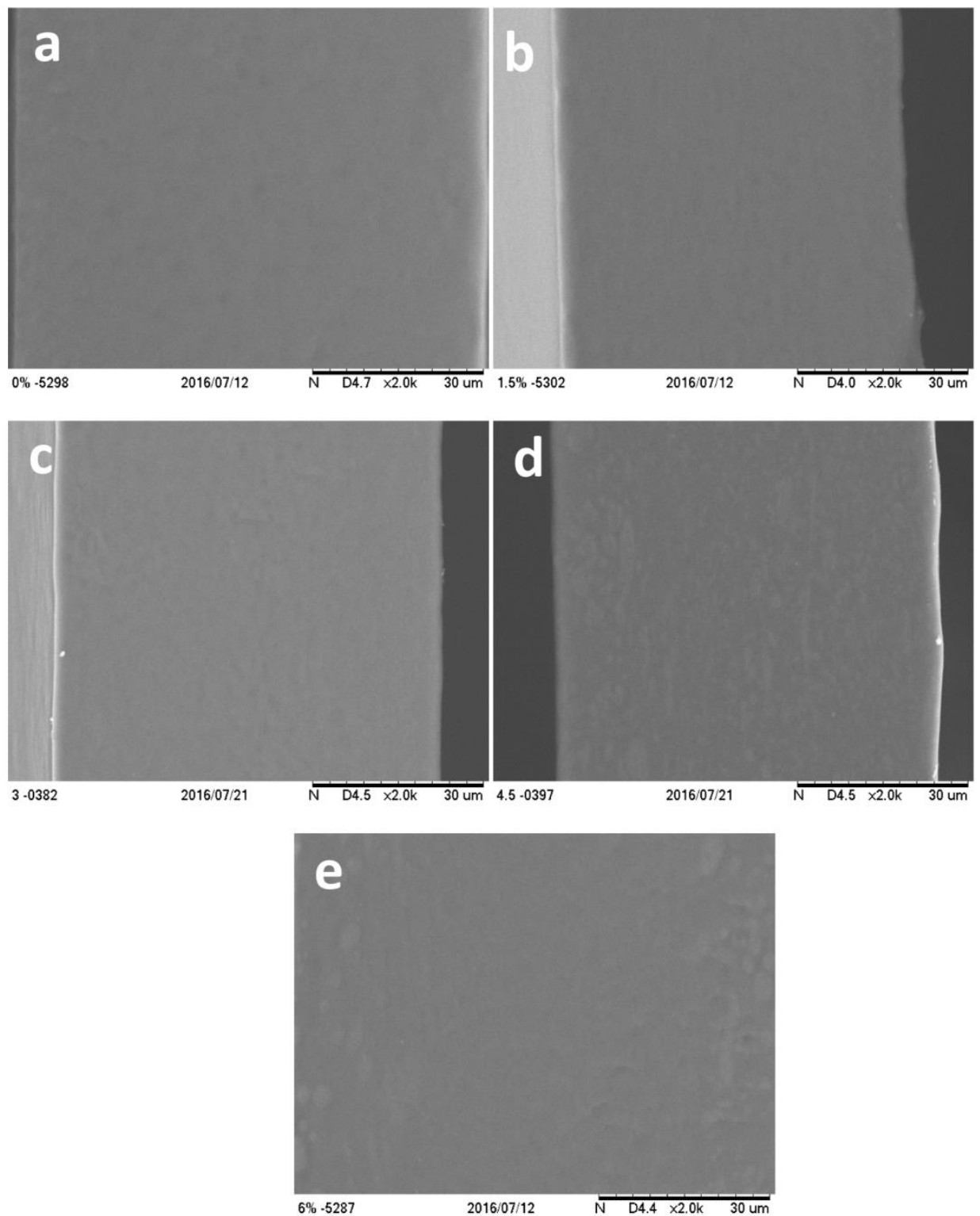

Fonte: própria autoria.

Em relação ao método de preparo, não foi observado nenhuma diferença morfológica entre os filmes nanocompósitos produzidos por casting ou espalhamento mecânico.

Em relação à adição da laponita, percebeu-se que a laponita implicou em um aumento da irregularidade superficial dos filmes de colágeno e fécula de mandioca 
(Figuras 20 e 24), devido, provavelmente à interação entre as plaquetas de laponita com as cadeias dos biopolímeros durante a secagem das soluções formadores de filmes. Cano et al. (2015) observaram que os nanocristais de celulose incrementaram a interação biopolímero - nanopartícula em filmes à base de amido de ervilha, consequentemente, estes filmes foram mais irregulares.

\subsubsection{Microscopia de força atômica}

As imagens de topografia superficial (superfície de secagem) dos filmes nanocompósitos de colágeno, gelatina e fécula de mandioca se apresentam nas Figuras 26, 27 e 28, respectivamente. As análises por microscopia de força atômica permitiram observar filmes de colágeno e de fécula de mandioca com topografia irregular (Figuras 26 e 28), e filmes de gelatina com topografia regular (Figura 27). Estes resultados foram similares aos descritos na seção 6.3.3.

A rugosidade média $\left(R_{a}\right)$ determinada diretamente das imagens obtidas por microscopia de força atômica nos filmes controle de colágeno, gelatina e fécula de mandioca tiveram valores de $127 \pm 4 \mathrm{~nm}, 1 \pm 0 \mathrm{~nm}$ e $117 \pm 6 \mathrm{~nm}$, respectivamente (Tabela 4). Os valores de rugosidade média nos filmes à base de colágeno, gelatina e fécula de mandioca foram similares aos encontrados em outros estudos (FLAKER et al., 2016; GROVER et al., 2012; MATHEW; BRAHMAKUMAR; ABRAHAM, 2006; STYLIANOU et al., 2011; STYLIANOU e YOVA, 2013; STYLIANOU; YOVA, ALEXANDRATOU, 2014).

A adição da laponita nos filmes nanocompósitos de colágeno e fécula de mandioca implicou em aumento dos valores de rugosidade média (Tabela 4). Cano et al. (2015) e Flaker et al. (2016) observaram aumento da rugosidade média em filmes de amido e gelatina com a adição de nanopartículas. 
Figura 26 - Imagens representativas das micrografias dos filmes de colágeno, com concentrações de laponita de: $0 \%$ (a), 1,5\% (b), 3\% (c), 4,5\% (d) e 6\% (e), produzidos por casting $\left(C_{c o l}=4 \%\right)$.

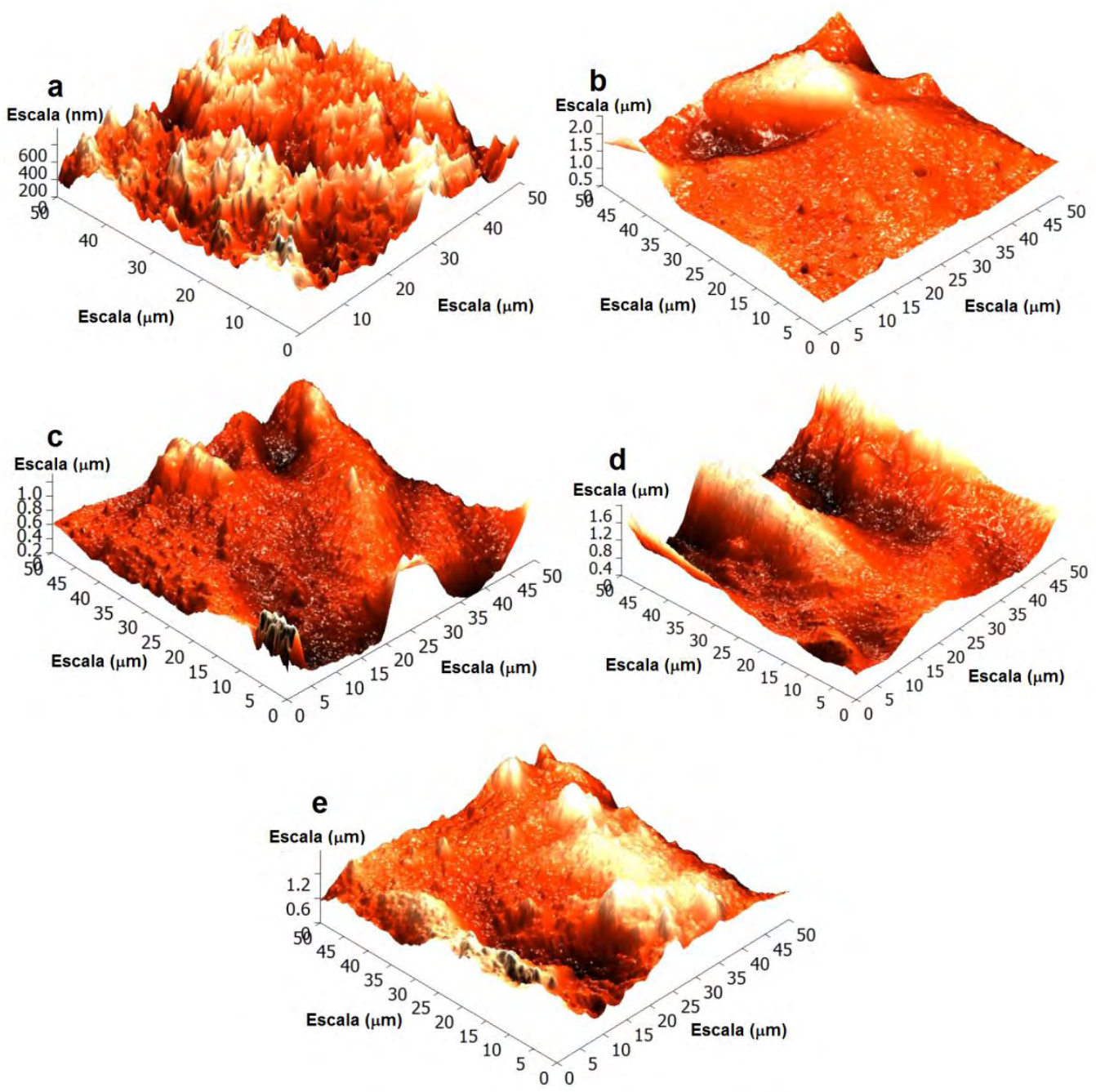

Fonte: própria autoria. 
Figura 27 - Imagens representativas das micrografias dos filmes de gelatina, com concentrações de laponita de: $0 \%$ (a), 1,5\% (b), 3\% (c), 4,5\% (d) e 6\% (e), produzidos por espalhamento mecânico $\left(C_{g e l}=4 \%\right)$.
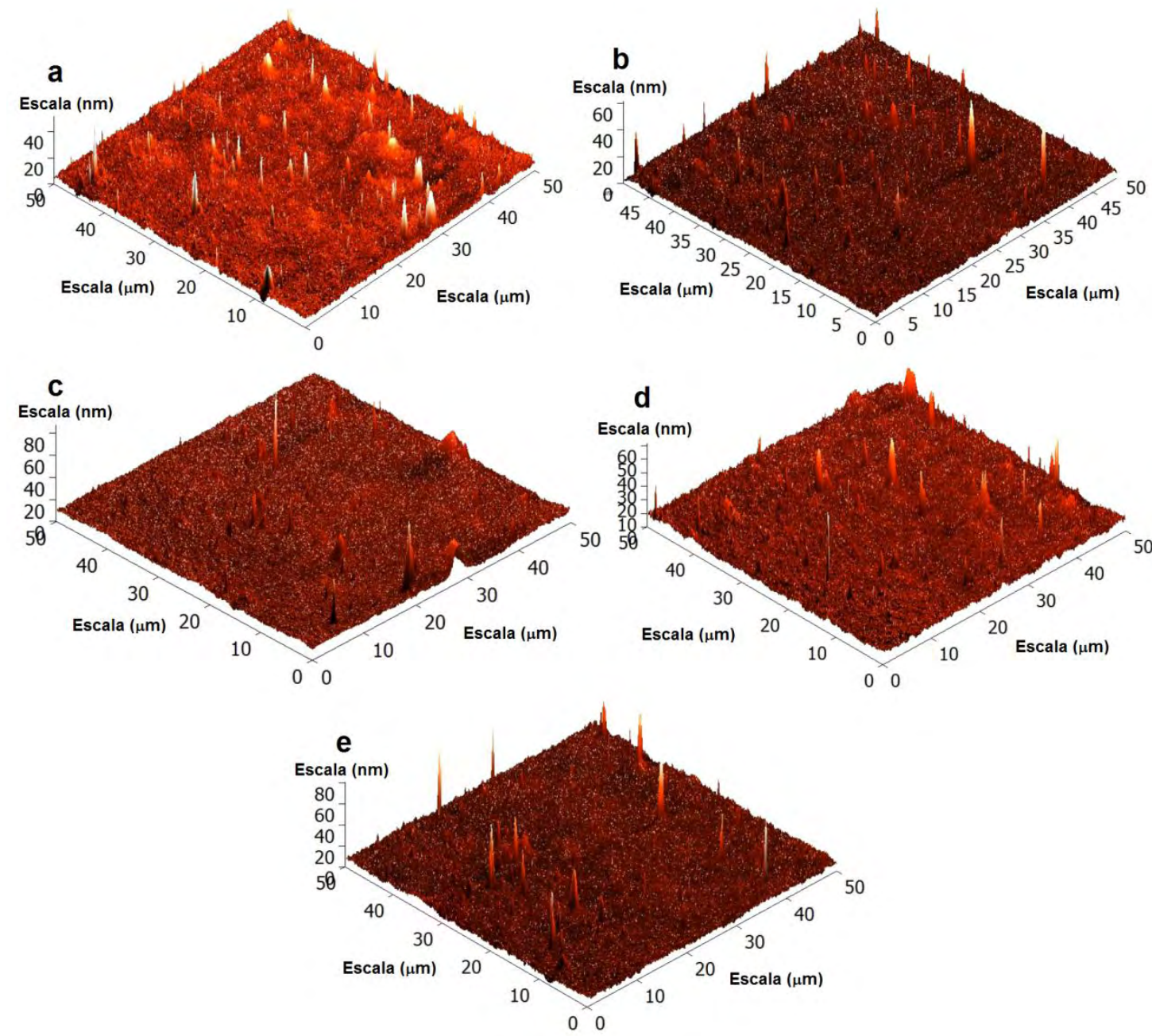

Fonte: própria autoria. 
Figura 28 - Imagens representativas das micrografias dos filmes de fécula de mandioca, com concentrações de laponita de: $0 \%$ (a), 1,5\% (b), 3\% (c), 4,5\% (d) e $6 \%$ (e), produzidos por casting $\left(C_{f e ́ c}=4 \%\right)$.
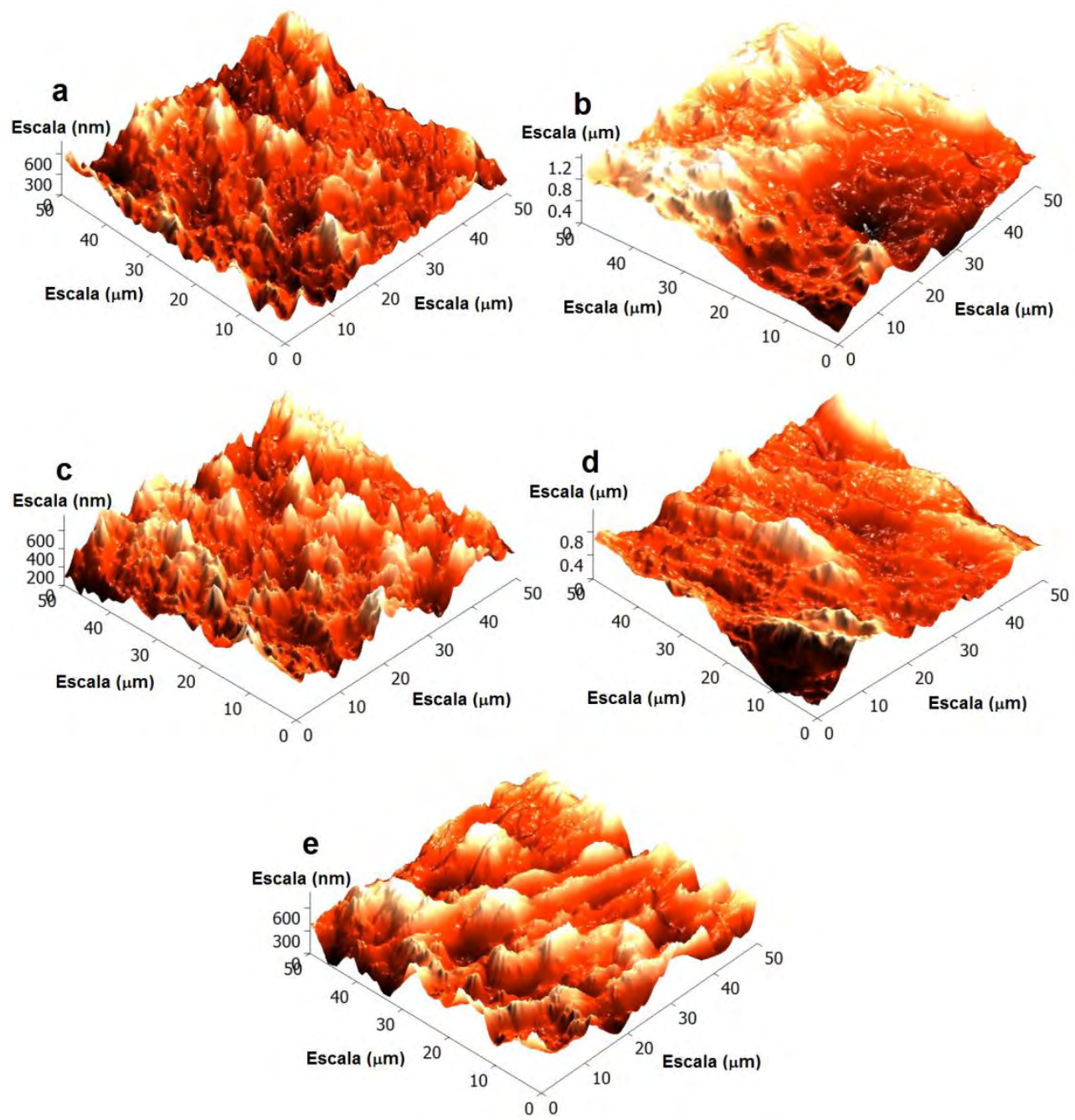

Fonte: própria autoria. 
Tabela 4 - Valores de rugosidade média $\left(R_{a}\right)$ e dimensão fractal $(D F)$ dos filmes de colágeno, gelatina e fécula de mandioca $\left(C_{c o l}, C_{g e l}, C_{f e ́ c}=4 \%\right)$, em função da concentração de laponita $\left(C_{\text {lap }}\right)^{*}$.

\begin{tabular}{|c|c|c|c|c|}
\hline \multirow{4}{*}{$\begin{array}{l}C_{\text {lap }} \\
(\%)\end{array}$} & \multicolumn{4}{|c|}{ Filmes à base de colágeno } \\
\hline & \multicolumn{2}{|c|}{$R_{a}(n m)$} & \multicolumn{2}{|c|}{$D F\left(\times 10^{1}\right)$} \\
\hline & & spalhamento & & Espalhamento \\
\hline & Casting & mecânico & Casting & mecânico \\
\hline 0 & $132 \pm 20^{\mathrm{C}}$ & $122 \pm 49^{\mathrm{C}}$ & $28,3 \pm 0,0^{\mathrm{C}}$ & $28,2 \pm 0,1^{\mathrm{D}}$ \\
\hline 1,5 & $209 \pm 66^{\mathrm{AB}}$ & $256 \pm 48^{\mathrm{AB}}$ & $29,3 \pm 0,1^{\mathrm{B}}$ & $29,0 \pm 0,2^{\mathrm{BC}}$ \\
\hline 3 & $309 \pm 81^{\mathrm{AB}}$ & $207 \pm 33^{\mathrm{AB}}$ & $29,2 \pm 0,1^{\mathrm{B}}$ & $28,9 \pm 0,2^{\mathrm{C}}$ \\
\hline 4,5 & $294 \pm 76^{\mathrm{AB}}$ & $263 \pm 48^{\mathrm{AB}}$ & $29,1 \pm 0,1^{\mathrm{B}}$ & $29,3 \pm 0,1^{\mathrm{B}}$ \\
\hline \multirow[t]{2}{*}{6} & $356 \pm 61^{\mathrm{A}}$ & $362 \pm 62^{\mathrm{A}}$ & $29,7 \pm 0,2^{\mathrm{A}}$ & $29,6 \pm 0,1^{\mathrm{A}}$ \\
\hline & \multicolumn{4}{|c|}{ Filmes à base de gelatina } \\
\hline 0 & $1 \pm 0$ & $1 \pm 0$ & $26,0 \pm 0,0$ & $26,0 \pm 0,1$ \\
\hline 1,5 & $1 \pm 0$ & $1 \pm 0$ & $26,0 \pm 0,1$ & $25,8 \pm 0,2$ \\
\hline 3 & $1 \pm 0$ & $1 \pm 0$ & $25,9 \pm 0,1$ & $25,9 \pm 0,2$ \\
\hline 4,5 & $1 \pm 0$ & $1 \pm 0$ & $26,0 \pm 0,1$ & $26,2 \pm 0,1$ \\
\hline \multirow[t]{2}{*}{6} & $1 \pm 0$ & $1 \pm 0$ & $26,1 \pm 0,1$ & $26,2 \pm 0,2$ \\
\hline & \multicolumn{4}{|c|}{ Filmes à base de fécula de mandioca } \\
\hline 0 & $111 \pm 6^{\mathrm{B}}$ & $124 \pm 8^{\mathrm{B}}$ & $25,8 \pm 0,1^{\mathrm{C}}$ & $25,8 \pm 0,1^{\mathrm{D}}$ \\
\hline 1,5 & $119 \pm 5^{\mathrm{B}}$ & $105 \pm 5^{\mathrm{C}}$ & $26,2 \pm 0,1^{\mathrm{B}}$ & $25,9 \pm 0,2^{\mathrm{D}}$ \\
\hline 3 & $138 \pm 10^{\mathrm{AB}}$ & $141 \pm 5^{\mathrm{A}}$ & $26,4 \pm 0,1^{\mathrm{B}}$ & $26,3 \pm 0,2^{\mathrm{CD}}$ \\
\hline 4,5 & $140 \pm 19^{\mathrm{AB}}$ & $136 \pm 12^{\mathrm{A}}$ & $26,7 \pm 0,1^{\mathrm{A}}$ & $26,6 \pm 0,1^{\mathrm{BC}}$ \\
\hline 6 & $161 \pm 26^{\mathrm{A}}$ & $163 \pm 34^{\mathrm{A}}$ & $26,8 \pm 0,2^{\mathrm{A}}$ & $26,9 \pm 0,1^{\mathrm{A}}$ \\
\hline
\end{tabular}

Fonte: própria autoria.

*Os valores são apresentados como média \pm desvio padrão $(\mathrm{n}=5)$.

Médias numa mesma coluna, seguidas por uma mesma letra maiúscula, não diferem entre si pelo teste de Tukey $(p<0,05)$.

Médias numa mesma linha, para um mesmo parâmetro e concentração de laponita, seguidas por uma mesma letra minúscula, não diferem entre si pelo teste de Tukey $(p<0,05)$.

Observou-se que os valores de $D F$ aumentaram com a adição de laponita nos filmes de colágeno e fécula de mandioca (Tabela 4). Os valores de $D F$ estiveram na faixa de 2,5 e 3, concordando com o observado por Quebedo et al. (2009) em filmes à base de biopolímeros. Segundo Arzate-Vázquez et al. (2012), valores de DF próximos a 3 são típicos de materiais com alta rugosidade superficial. Na presente tese, os valores de $D F$ em filmes à base de gelatina com laponita foram similares aos encontrados por Zarama et al. (2014), trabalhando com filmes de gelatina com nanotubos de carbono. De forma geral, os filmes à base de proteínas e fécula de mandioca tiveram valores de $D F$ 
superiores aos observados em filmes de alginato e quitosano (ARZATE-VÁZQUEZ et al., 2012).

\subsubsection{Cor e opacidade}

De forma geral, a técnica de preparo não alterou os parâmetros de cor, $\mathrm{L}^{*}, \mathrm{a}^{*} \mathrm{e}$ $b^{*}$, nas superfícies de secagem dos filmes nanocompósitos (Tabela 5). Comparando os filmes de colágeno, gelatina e fécula de mandioca sem laponita (filmes controle), percebeu-se que o parâmetro $\mathrm{L}^{*}$, associado com a luminosidade apresentou valores muito próximo entre si, independente do biopolímero (Tabela 5). Estes valores estiveram em torno de 91, ou seja, os filmes controle apresentaram tonalidade muito clara (MAKISHI, 2016).

Em relação ao parâmetro $\mathrm{a}^{*}$, que varia de verde $\left(-\mathrm{a}^{*}\right)$ ao vermelho $\left(\mathrm{a}^{*}\right)$, os filmes controle de proteínas mostraram-se mais esverdeados que os filmes controle de fécula de mandioca (Tabela 5). Especificamente, os filmes controle de colágeno apresentaram a maior tonalidade verde $\left(\mathrm{a}^{*}=-1,3\right)$, seguido pelos filmes controle de gelatina $\left(a^{*}=-1,1\right)$, e os filmes controle de fécula de mandioca $\left(a^{*}=-0,9\right)$.

Em relação ao parâmetro $b^{*}$, que varia de azul (-b*) ao amarelo $\left(b^{*}\right)$, os filmes controle de colágeno tiveram tonalidade mais amarela $\left(b^{*}=3,7\right)$, quando comparados com os filmes controle de gelatina $\left(b^{*}=2,0\right)$ (Tabela 5). Já os filmes controle de fécula de mandioca tiveram um valor médio de $b^{*}=2,2$ (Tabela 5).

Os valores de $\Delta E^{*}$ dos filmes controle de colágeno, gelatina e fécula de mandioca foram de 2,6 $0,1,3,3 \pm 0,0$ e 2,1 $\pm 0,1$, respectivamente.

A presença da laponita não implicou em alterações significativas dos parâmetros $\mathrm{L}^{*}, \mathrm{a}^{*} \mathrm{e} \mathrm{b}^{*}$, dos filmes de colágeno, gelatina e fécula de mandioca (Tabela 5), portanto, os valores $\Delta E^{*}$ nesses filmes nanocompósitos foram similares aos determinados nos filmes controle.

Em relação à opacidade, os filmes de colágeno, gelatina e fécula de mandioca tiveram valores de opacidade de $5 \pm 1 \%, 0,3 \pm 0,1 \%$ e $0,6 \pm 0,1 \%$, respectivamente. A opacidade não foi alterada pela concentração de laponita, nem pelo método de produção dos filmes nanocompósitos. Os filmes de colágeno, gelatina e fécula de mandioca, com ou sem laponita podem ser classificados como materiais com pouca opacidade (MAKISHI, 2016).

Os valores de cor e opacidade dos filmes nanocompósitos de colágeno, gelatina e fécula de mandioca foram comparáveis aos encontrados por Makishi (2016), Sobral et 
al. (2001) e Moraes et al. (2013), trabalhando com filmes de colágeno, gelatina e fécula de mandioca, respectivamente.

Tabela 5 - Valores dos parâmetros de cor dos filmes de colágeno, gelatina e fécula de mandioca $\left(C_{c o l}, C_{g e l}, C_{f e ́ c}=4 \%\right)$, em função da concentração de laponita $\left(C_{l a p}\right)^{*}$.

\begin{tabular}{|c|c|c|c|c|c|}
\hline \multirow{3}{*}{$\begin{array}{l}C_{\text {lap }} \\
(\%)\end{array}$} & \multicolumn{5}{|c|}{ Filmes à base de colágeno } \\
\hline & \multicolumn{2}{|c|}{$\mathbf{L}^{*}$} & $\mathbf{a}^{*}$ & \multicolumn{2}{|c|}{$\mathbf{b}^{*}$} \\
\hline & Casting & $\begin{array}{l}\text { Espalhamento } \\
\text { mecânico }\end{array}$ & Casting & Casting & $\begin{array}{c}\text { Espalhamento } \\
\text { mecânico }\end{array}$ \\
\hline 0 & $92,1 \pm 0,2$ & $92,2 \pm 0,1$ & $-1,3 \pm 0,0^{\mathrm{B}, \mathrm{a}}$ & $3,7 \pm 0,1^{\mathrm{B}}$ & $3,7 \pm 0,0^{\mathrm{B}}$ \\
\hline 1,5 & $92,3 \pm 0,0$ & $91,9 \pm 0,3$ & $-1,3 \pm 0,0^{\mathrm{B}, \mathrm{b}}$ & $3,9 \pm 0,1^{\mathrm{A}}$ & $4,0 \pm 0,1^{\mathrm{A}}$ \\
\hline 3 & $92,2 \pm 0,0$ & $92,0 \pm 0,2$ & $-1,3 \pm 0,0^{\mathrm{B}, \mathrm{b}}$ & $3,9 \pm 0,1^{\mathrm{A}}$ & $3,8 \pm 0,1^{\mathrm{A}}$ \\
\hline 4,5 & $92,3 \pm 0,1$ & $92,3 \pm 0,1$ & $-1,4 \pm 0,0^{\mathrm{A}, \mathrm{a}}$ & $3,9 \pm 0,3^{\mathrm{A}}$ & $3,8 \pm 0,1^{\mathrm{A}}$ \\
\hline \multirow[t]{2}{*}{6} & $92,5 \pm 0,1$ & $92,3 \pm 0,1$ & $-1,4 \pm 0,0^{\mathrm{A}, \mathrm{a}}$ & $3,9 \pm 0,1^{\mathrm{A}}$ & $3,9 \pm 0,1^{\mathrm{A}}$ \\
\hline & \multicolumn{5}{|c|}{ Filmes à base de gelatina } \\
\hline 0 & $90,4 \pm 0,0$ & $90,3 \pm 0,2$ & $-1,1 \pm 0,0$ & $2,0 \pm 0,1$ & $2,0 \pm 0,2$ \\
\hline 1,5 & $90,4 \pm 0,0$ & $90,6 \pm 0,3$ & $-1,1 \pm 0,0$ & $2,0 \pm 0,0$ & $1,9 \pm 0,0$ \\
\hline 3 & $90,4 \pm 0,0$ & $90,5 \pm 0,1$ & $-1,1 \pm 0,0$ & $1,9 \pm 0,1$ & $1,9 \pm 0,1$ \\
\hline 4,5 & $90,4 \pm 0,0$ & $90,6 \pm 0,1$ & $-1,1 \pm 0,0$ & $2,0 \pm 0,1$ & $1,9 \pm 0,1$ \\
\hline \multirow[t]{2}{*}{6} & $90,3 \pm 0,0$ & $90,5 \pm 0,1$ & $-1,1 \pm 0,0$ & $2,0 \pm 0,0$ & $1,9 \pm 0,1$ \\
\hline & \multicolumn{5}{|c|}{ Filmes à base de fécula de mandioca } \\
\hline 0 & $90,6 \pm 0,0^{\mathrm{A}}$ & $90,7 \pm 0,1^{\mathrm{A}}$ & $-0,9 \pm 0,0^{\mathrm{A}}$ & $2,2 \pm 0,0^{\mathrm{B}}$ & $2,2 \pm 0,0^{\mathrm{C}}$ \\
\hline 1,5 & $90,7 \pm 0,1^{\mathrm{A}}$ & $90,7 \pm 0,1^{\mathrm{A}}$ & $-0,8 \pm 0,0^{\mathrm{B}}$ & $2,2 \pm 0,1^{\mathrm{B}}$ & $2,2 \pm 0,0^{\mathrm{C}}$ \\
\hline 3 & $90,6 \pm 0,1^{\mathrm{A}}$ & $90,6 \pm 0,2^{\mathrm{AB}}$ & $-0,8 \pm 0,1^{\mathrm{AB}}$ & $2,3 \pm 0,1^{\mathrm{BC}}$ & $2,3 \pm 0,0^{\mathrm{B}}$ \\
\hline 4,5 & $90,6 \pm 0,0^{\mathrm{A}}$ & $90,5 \pm 0,1^{\mathrm{AB}}$ & $-0,8 \pm 0,0^{\mathrm{B}}$ & $2,4 \pm 0,2^{\mathrm{AB}}$ & $2,3 \pm 0,0^{\mathrm{B}}$ \\
\hline 6 & $90,4 \pm 0,1^{\mathrm{B}}$ & $90,4 \pm 0,1^{\mathrm{B}}$ & $-0,8 \pm 0,0^{\mathrm{B}}$ & $2,5 \pm 0,0^{\mathrm{A}}$ & $2,5 \pm 0,1^{\mathrm{A}}$ \\
\hline
\end{tabular}

Fonte: própria autoria.

*Os valores são apresentados como média \pm desvio padrão $(\mathrm{n}=3)$.

Médias numa mesma coluna, seguidas por uma mesma letra maiúscula, não diferem entre si pelo teste de Tukey $(p<0,05)$.

Médias numa mesma linha, para um mesmo parâmetro e concentração de laponita, seguidas por uma mesma letra minúscula, não diferem entre si pelo teste de Tukey $(p<0,05)$. 


\subsubsection{Brilho}

Os resultados de brilho, determinados com ângulo de $20^{\circ}$ apresentaram uma grande dispersão, com valores de desvio padrão na ordem de 60 unidades. Assim, estes valores não foram utilizados na caracterização dos filmes nanocompósitos. Segundo Villalobos et al. (2005), o ângulo de $20^{\circ}$ na medição do brilho é comumente empregado em filmes com superfícies bem polidas e que na sequência terão altos valores de brilho.

Para um ângulo de $60^{\circ}$, os valores de brilho nas superfícies de secagem dos filmes nanocompósitos foram reprodutíveis (Tabela 6).

Em relação à adição de laponita nos filmes, observou-se que nos filmes de colágeno e fécula de mandioca, a adição da laponita implicou na diminuição dos valores de brilho a $60^{\circ}$, da superfície de secagem (Tabela 6). Segundo Villalobos et al. (2005), a diminuição dos valores de brilho pode estar relacionada com um aumento da rugosidade superficial nos filmes. Na presente tese, a diminuição dos valores de brilho a $60^{\circ}$, na superfície de secagem dos filmes de colágeno e fécula de mandioca também estiveram relacionadas com um aumento na rugosidade superficial, como observado na seção 6.3.4.

Em relação ao método de produção do filmes nanocompósitos, observou-se que os valores de brilho a $60^{\circ}$ nos filmes produzidos por casting ou espalhamento mecânico não tiveram diferenças significativas $(p>0,05)$ (Tabela 6).

Segundo Trezza \& Krochta (2000), considerando os valores de brilho para um ângulo de $60^{\circ}$, filmes com valores de brilho maior que 70 unidades podem ser considerados como filmes brilhantes. Portanto, na presente tese, as superfícies dos filmes nanocompósitos de colágeno e fécula de mandioca podem ser classificadas como de pouco brilho, e as superfícies dos filmes de gelatina podem ser calssificadas como brilhantes. Os valores de brilho a $60^{\circ}$ nos filmes nanocompósitos de colágeno foram comparáveis aos observados por Makishi (2016), trabalhando com filmes de colágeno. E, os valores de brilho a $60^{\circ}$ nos filmes nanocompósitos de gelatina foram maiores que os observados em filmes nanocompósitos de gelatina com montmorilonita (JORGE, 2012, FLAKER et al., 2015), mas foram comparáveis que os observados em filmes de gelatina com poli(vinil álcool) (SILVA et al., 2008). Finalmente, os valores de brilho a $60^{\circ}$ nos filmes nanocompósitos de fécula de mandioca foram comparáveis que os encontrados por Bangyekan, Aht-Ong, Srikulkit (2006), trabalhando com filmes de fécula de mandioca e por Villalobos et al. (2005), trabalhando com filmes de hidroximetil celulose. 
Tabela 6 - Valores de brilho a $60^{\circ}$ dos filmes de colágeno, gelatina e fécula de mandioca $\left(C_{c o l}, C_{g e l}, C_{f e ́ c}=4 \%\right)$, em função da concentração de laponita $\left(C_{l a p}\right)^{*}$.

\begin{tabular}{|c|c|c|}
\hline \multirow{2}{*}{$\begin{array}{l}C_{\text {lap }} \\
(\%)\end{array}$} & \multicolumn{2}{|c|}{ Filmes à base de colágeno } \\
\hline & Casting & Espalhamento mecânico \\
\hline 0 & $16,7 \pm 0,6^{\mathrm{A}}$ & $16,2 \pm 0,2^{\mathrm{A}}$ \\
\hline 1,5 & $15,4 \pm 0,5^{\text {B }}$ & $16,1 \pm 0,5^{\mathrm{AB}}$ \\
\hline 3 & $14,9 \pm 0,6^{\mathrm{B}}$ & $14,6 \pm 0,1^{\mathrm{C}}$ \\
\hline 4,5 & $14,0 \pm 0,7^{\mathrm{BC}}$ & $13,7 \pm 0,1^{\mathrm{D}}$ \\
\hline \multirow[t]{2}{*}{6} & $13,9 \pm 0,4^{\mathrm{C}}$ & $13,9 \pm 0,1^{\mathrm{D}}$ \\
\hline & \multicolumn{2}{|c|}{ Filmes à base de gelatina } \\
\hline 0 & $160,0 \pm 4,2$ & $148,3 \pm 6,2$ \\
\hline 1,5 & $160,9 \pm 2,7$ & $152,5 \pm 1,8$ \\
\hline 3 & $161,3 \pm 0,8$ & $148,4 \pm 5,6$ \\
\hline 4,5 & $161,7 \pm 0,9$ & $148,9 \pm 6,5$ \\
\hline \multirow[t]{2}{*}{6} & $161,2 \pm 1,4$ & $149,1 \pm 5,3$ \\
\hline & \multicolumn{2}{|c|}{ Filmes à base de fécula de mandioca } \\
\hline 0 & $54,1 \pm 4,0^{\mathrm{A}}$ & $53,2 \pm 2,0^{\mathrm{A}}$ \\
\hline 1,5 & $45,7 \pm 5,6^{\mathrm{B}}$ & $52,9 \pm 4,3^{\mathrm{A}}$ \\
\hline 3 & $48,6 \pm 4,2^{\mathrm{B}}$ & $42,2 \pm 2,2^{\mathrm{B}}$ \\
\hline 4,5 & $38,5 \pm 5,1^{\mathrm{C}}$ & $31,4 \pm 2,3^{\mathrm{C}}$ \\
\hline 6 & $33,5 \pm 3,8^{\mathrm{C}}$ & $33,1 \pm 2,4^{\mathrm{C}}$ \\
\hline
\end{tabular}

Fonte: própria autoria.

*Os valores são apresentados como média \pm desvio padrão $(\mathrm{n}=3)$.

Médias numa mesma coluna, seguidas por uma mesma letra maiúscula, não diferem entre si pelo teste de Tukey $(p<0,05)$.

Médias numa mesma linha, para uma mesma concentração de laponita, seguidas por uma mesma letra minúscula, não diferem entre si pelo teste de Tukey $(p<0,05)$.

\subsubsection{Calorimetria diferencial de varredura}

Alguns termogramas representativos dos filmes de colágeno, gelatina e fécula de mandioca são apresentados na Figura 29. As curvas DSC da primeira varredura nos filmes de proteínas proporcionaram termogramas típicos de materiais parcialmente cristalinos (SOBRAL et al., 2011). Com o aumento da temperatura foi observado uma $\mathrm{T}_{\mathrm{g}}$, que oscilou entre $-77 \mathrm{e}-70{ }^{\circ} \mathrm{C}$ (Tabela 7$)$, sendo associada à fase rica em glicerol (SOBRAL et al., 2001). Posteriormente, foi observado outra $T_{g}$ que oscilou entre $42 \mathrm{e}$ 
$47{ }^{\circ} \mathrm{C}$ (Tabela 7), sendo associada à fração rica em biopolímero. Este comportamento tem sido extensamente observado na literatura, sendo atribuído à separação do biopolímero e o glicerol (JORGE, 2012; MAKISHI, 2016; SOBRAL et al., 2001; VANNIN et al., 2005). Na sequência, foi observado um pico endotérmico típico em materiais parcialmente cristalinos (SOBRAL et al., 2011), em temperaturas entre 57 e $76{ }^{\circ} \mathrm{C}$ (Tabela 8), sendo associado à fusão dos cristais presentes no colágeno e na gelatina (MAKISHI, 2016; PRESTES, 2012; SOBRAL et al., 2001; VANNIN et al., 2005).

Figura 29 - Exemplos de termogramas dos filmes de colágeno (a), gelatina (b) e fécula de mandioca $(c)$, em função da concentração de laponita $\left(C_{\text {lap }}\right)$, produzidos por casting $\left(C_{c o l}, C_{g e l}, C_{f e ́ c}=4 \%\right)$.
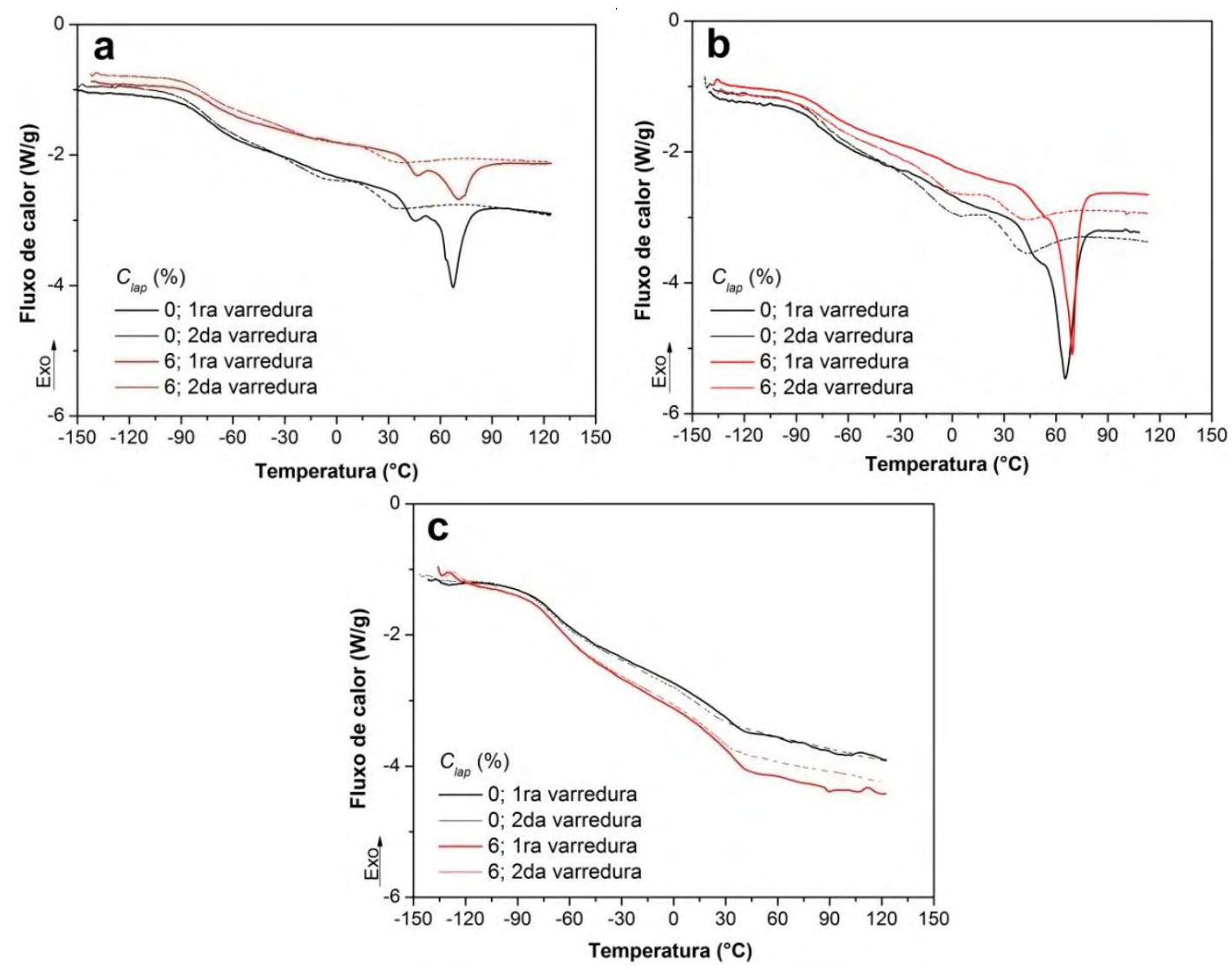

Fonte: própria autoria.

Na segunda varredura de temperaturas nos filmes de proteínas foram observados termogramas típicos de materiais amorfos, com duas $\mathrm{T}_{\mathrm{g}}$ : a primeira $\mathrm{T}_{\mathrm{g}}$ aconteceu na mesma faixa de temperaturas descrita previamente, sendo associada à fração rica em glicerol (Tabela 7) e, a segunda $T_{g}$ foi observada para uma faixa de temperaturas entre 
21 e $34{ }^{\circ} \mathrm{C}$, sendo associada à fração rica em biopolímero (Tabela 7). A segunda $\mathrm{T}_{\mathrm{g}}$ foi menor que a da primeira varredura de temperaturas, devido à fusão dos cristais de gelatina durante a primeira varredura de temperatura (SOBRAL e HABITANTE, 2001).

Com a adição da laponita, nenhuma propriedade térmica foi alterada nos filmes de proteínas, excepto a entalpia de fusão nos filmes de colágeno, que decresceu com $C_{\text {lap }}$ (Tabela 8). Estes resultados indicaram que a presença de laponita diminuiu a formação de estruturas cristalinas nos filmes de colágeno como observado na seção 6.3.2.

Os termogramas dos filmes de fécula de mandioca foram típicos de materiais completamente amorfos. Com o aumento da temperatura foi evidenciada uma $T_{g}$ que oscilou entre -70 e $-65^{\circ} \mathrm{C}$ (Tabela 7), e que foi associada com a fase rica em glicerol (SOBRAL et al., 2001). Posteriormente, foi observada uma $T_{g}$ que oscilou entre 29 e 32 ${ }^{\circ} \mathrm{C}$ (Tabela 7), associada à fração rica em biopolímero. A ausência de picos endotérmicos durante a primeira varredura de temperatura indicou que não houve retrogradação do biopolímero durante a secagem das SFF. Na segunda varredura de temperatura, os filmes de fécula de mandioca apresentaram as mesmas duas $\mathrm{T}_{\mathrm{g}}$ observadas previamente na primeira varredura de temperatura. Nenhuma das duas $\mathrm{T}_{\mathrm{g}}$ observadas nos filmes de fécula de mandioca foram alteradas com a presença de laponita. Cano et al. (2015) reforçaram filmes de amido com nanocristais de celulose e não observaram mudanças significativas das propriedades térmicas dos filmes com a adição da nanopartícula de celulose de até 5\%. Em contraste, Tang e Alavi (2012) observaram modificações nas transições térmicas dos filmes à base de blendas de amido de milho e poli(vinil álcool), $\operatorname{com} C_{l a p}<20 \%$.

Em relação ao método de produção dos filmes nanocompósitos, observou-se que as propriedades térmicas destes filmes mudaram levemente com o método de produção, contudo, estas mudanças não tiveram importância do ponto de vista tecnológico. 
Tabela 7 - Temperatura de transição vítrea $\left(\mathrm{T}_{\mathrm{g}}\right)$ dos filmes de colágeno, gelatina e fécula de mandioca $\left(C_{c o l}, C_{g e l}, C_{f e ́ c}=4 \%\right)$, em função da concentração de laponita $\left(C_{l a p}\right)$, para as duas varreduras de temperaturas*.

\begin{tabular}{|c|c|c|c|c|c|c|c|c|}
\hline \multirow{3}{*}{$\begin{array}{c}C_{\text {lap }} \\
(\%)\end{array}$} & \multicolumn{8}{|c|}{ Filmes à base de colágeno } \\
\hline & \multicolumn{2}{|c|}{$\mathbf{1}^{\mathrm{ra}} \mathrm{T}_{\mathrm{g}}\left({ }^{\circ} \mathrm{C}\right), \mathbf{1}^{\mathrm{ra}}$ varredura } & \multicolumn{2}{|c|}{$\mathbf{1}^{\mathrm{ra}} \mathbf{T}_{\mathrm{g}}\left({ }^{\circ} \mathbf{C}\right), 2^{\mathrm{da}}$ varredura } & \multicolumn{2}{|c|}{$2^{\text {da }} \mathbf{T}_{\mathrm{g}}\left({ }^{\circ} \mathbf{C}\right), \mathbf{1}^{\text {ra }}$ varredura } & \multicolumn{2}{|c|}{$2^{\text {da }} \mathbf{T}_{\mathrm{g}}\left({ }^{\circ} \mathbf{C}\right), 2^{\text {da }}$ varredura } \\
\hline & Casting & $\begin{array}{l}\text { Espalhamento } \\
\text { mecânico }\end{array}$ & Casting & $\begin{array}{c}\text { Espalhamento } \\
\text { mecânico }\end{array}$ & Casting & $\begin{array}{c}\text { Espalhamento } \\
\text { mecânico }\end{array}$ & Casting & $\begin{array}{c}\text { Espalhamento } \\
\text { mecânico }\end{array}$ \\
\hline 0 & $-74,1 \pm 1,7$ & $-70,8 \pm 5,5$ & $-72,7 \pm 3,3$ & $-71,1 \pm 3,41$ & $42,2 \pm 2,0^{b}$ & $47,2 \pm 0,6^{\mathrm{a}}$ & $26,9 \pm 4,0$ & $28,2 \pm 2,3$ \\
\hline 1,5 & $-76,2 \pm 2,6$ & $-74,5 \pm 1,5$ & $-75,2 \pm 2,0$ & $-76,3 \pm 1,5$ & $42,0 \pm 1,2^{\mathrm{b}}$ & $47,2 \pm 2,0 \mathrm{a}$ & $25,2 \pm 3,8$ & $27,2 \pm 2,5$ \\
\hline 3 & $-72,5 \pm 3,9$ & $-73,2 \pm 4,7$ & $-72,6 \pm 4,3$ & $-70,7 \pm 3,2$ & $43,1 \pm 0,2^{b}$ & $47,5 \pm 0,7^{\mathrm{a}}$ & $26,7 \pm 3,5$ & $29,6 \pm 1,7$ \\
\hline 4,5 & $-77,1 \pm 1,4$ & $-71,0 \pm 3,0$ & $-76,3 \pm 4,4$ & $-70,2 \pm 2,6$ & $42,1 \pm 4,4^{\mathrm{b}}$ & $47,1 \pm 0,4^{\mathrm{a}}$ & $23,4 \pm 2,7^{\mathrm{b}}$ & $30,2 \pm 0,7^{\mathrm{a}}$ \\
\hline \multirow[t]{2}{*}{6} & $-74,1 \pm 0,7$ & $-71,7 \pm 0,5$ & $-75,1 \pm 2,5$ & $-73,1 \pm 2,8$ & $43,1 \pm 1,0^{\mathrm{b}}$ & $46,5 \pm 1,0^{\mathrm{a}}$ & $21,7 \pm 2,1$ & $25,2 \pm 1,9$ \\
\hline & \multicolumn{8}{|c|}{ Filmes à base de gelatina } \\
\hline 0 & $-74,1 \pm 4,3$ & $-74,4 \pm 1,0$ & $-74,7 \pm 2,6$ & $-76,4 \pm 1,4$ & $44,2 \pm 1,2$ & $46,2 \pm 2,6$ & $34,6 \pm 2,2$ & $31,5 \pm 3,4$ \\
\hline 1,5 & $-75,9 \pm 1,8$ & $-76,3 \pm 0,6$ & $-72,4 \pm 3,3$ & $-76,5 \pm 3,7$ & $46,3 \pm 6,5$ & $45,0 \pm 0,2$ & $31,2 \pm 0,7$ & $27,0 \pm 4,0$ \\
\hline 3 & $-74,9 \pm 2,6$ & $-76,8 \pm 1,9$ & $-76,0 \pm 1,4$ & $-76,0 \pm 0,8$ & $42,8 \pm 2,1$ & $45,4 \pm 0,6$ & $29,8 \pm 2,1$ & $29,9 \pm 2,5$ \\
\hline 4,5 & $-76,3 \pm 2,6$ & $-77,4 \pm 3,7$ & $-74,7 \pm 2,9$ & $-74,4 \pm 1,4$ & $44,8 \pm 0,2$ & $45,9 \pm 3,3$ & $30,7 \pm 3,2$ & $30,3 \pm 1,4$ \\
\hline \multirow[t]{2}{*}{6} & $-73,3 \pm 0,3$ & $-74,8 \pm 2,3$ & $-76,6 \pm 3,6$ & $-78,7 \pm 1,1$ & $44,9 \pm 1,3$ & $47,8 \pm 2,3$ & $29,8 \pm 3,7$ & $31,5 \pm 1,6$ \\
\hline & \multicolumn{8}{|c|}{ Filmes à base de fécula de mandioca } \\
\hline 0 & $-67,8 \pm 3,6$ & $-68,0 \pm 1,6$ & $-70,4 \pm 2,9$ & $-71,2 \pm 1,0$ & $32,4 \pm 1,5$ & $32,7 \pm 1,7$ & $20,4 \pm 1,1$ & $18,1 \pm 2,1$ \\
\hline 1,5 & $-68,2 \pm 2,5$ & $-69,6 \pm 1,8$ & $-67,5 \pm 3,8$ & $-69,1 \pm 3,6$ & $29,6 \pm 6,4$ & $28,1 \pm 5,2$ & $21,6 \pm 2,0$ & $24,4 \pm 1,9$ \\
\hline 3 & $-70,8 \pm 4,1$ & $-67,9 \pm 3,9$ & $-68,2 \pm 0,2$ & $-67,8 \pm 7,0$ & $27,7 \pm 3,5$ & $33,1 \pm 2,2$ & $18,9 \pm 2,7$ & $20,0 \pm 3,2$ \\
\hline 4,5 & $-68,7 \pm 2,3$ & $-65,1 \pm 8,4$ & $-68,6 \pm 2,7$ & $-66,5 \pm 0,7$ & $29,5 \pm 6,4$ & $29,2 \pm 3,3$ & $19,9 \pm 7,3$ & $20,9 \pm 0,7$ \\
\hline 6 & $-70,8 \pm 6,2$ & $-67,4 \pm 1,7$ & $-68,1 \pm 0,1$ & $-68,5 \pm 4,4$ & $31,6 \pm 4,8$ & $29,3 \pm 4,9$ & $21,6 \pm 6,8$ & $19,5 \pm 1,7$ \\
\hline
\end{tabular}

Fonte: própria autoria. 
*Os valores são apresentados como média \pm desvio padrão $(\mathrm{n}=3)$.

Médias numa mesma coluna, seguidas por uma mesma letra maiúscula não diferem entre si pelo teste de Tukey $(p<0,05)$.

Médias numa mesma linha, para uma mesma Tg e concentração de laponita, seguidas por uma mesma letra minúscula, não diferem entre si pelo teste de Tukey $(p<0,05)$. 
Tabela 8 - Valores de temperatura $\left(\mathrm{T}_{\mathrm{m}}\right)$ e entalpia $(\Delta \mathrm{H})$ de fusão dos filmes de colágeno e gelatina $\left(C_{c o l}, C_{g e l}=4 \%\right)$., em função da concentração de laponita $\left(C_{l a p}\right)^{*}$.

\begin{tabular}{|c|c|c|c|c|}
\hline \multirow{3}{*}{$\begin{array}{l}C_{\text {lap }} \\
(\%)\end{array}$} & \multicolumn{4}{|c|}{ Filmes à base de colágeno } \\
\hline & Casting & $\begin{array}{l}\text { Espalhamento } \\
\text { mecânico }\end{array}$ & Casting & $\begin{array}{l}\text { Espalhamento } \\
\text { mecânico }\end{array}$ \\
\hline & \multicolumn{2}{|c|}{$\mathbf{T}_{\mathbf{m}}\left({ }^{\circ} \mathbf{C}\right)$} & \multicolumn{2}{|c|}{$\Delta \mathbf{H}(\mathbf{J} / \mathbf{g})$} \\
\hline 0 & $69,2 \pm 2,2^{b}$ & $74,2 \pm 1,0^{\mathrm{a}}$ & $9,5 \pm 0,3^{\mathrm{A}, \mathrm{b}}$ & $10,1 \pm 0,3^{\mathrm{A}, \mathrm{a}}$ \\
\hline 1,5 & $69,5 \pm 0,8^{b}$ & $73,9 \pm 1,3^{\mathrm{a}}$ & $9,3 \pm 0,3^{\mathrm{A}, \mathrm{a}}$ & $8,8 \pm 0,4^{\mathrm{B}, \mathrm{a}}$ \\
\hline 3 & $70,0 \pm 1,5^{b}$ & $75,3 \pm 0,2^{\mathrm{a}}$ & $9,3 \pm 0,2^{\mathrm{A}, \mathrm{a}}$ & $8,9 \pm 0,0^{\mathrm{B}, \mathrm{b}}$ \\
\hline 4,5 & $70,0 \pm 1,5^{\mathrm{b}}$ & $76,0 \pm 0,7^{\mathrm{a}}$ & $8,0 \pm 0,4^{\mathrm{B}, \mathrm{a}}$ & $8,1 \pm 0,2^{\mathrm{C}, \mathrm{a}}$ \\
\hline \multirow[t]{2}{*}{6} & $72,3 \pm 1,7^{\mathrm{b}}$ & $72,6 \pm 1,5^{\mathrm{a}}$ & $8,0 \pm 0,5^{\mathrm{B}, \mathrm{a}}$ & $7,5 \pm 1,5^{\mathrm{D}, \mathrm{a}}$ \\
\hline & \multicolumn{4}{|c|}{ Filmes à base de gelatina } \\
\hline 0 & $67,5 \pm 2,1^{\mathrm{a}}$ & $66,3 \pm 0,3^{\mathrm{a}}$ & $14,9 \pm 1,4^{\mathrm{b}}$ & $19,3 \pm 0,4^{\mathrm{a}}$ \\
\hline 1,5 & $68,1 \pm 1,0^{\mathrm{a}}$ & $67,3 \pm 1,5^{\mathrm{a}}$ & $14,6 \pm 0,8^{\mathrm{b}}$ & $18,1 \pm 1,7^{\mathrm{a}}$ \\
\hline 3 & $66,4 \pm 1,1^{\mathrm{a}}$ & $66,9 \pm 0,4^{\mathrm{a}}$ & $14,0 \pm 0,7^{\mathrm{b}}$ & $17,7 \pm 0,6^{\mathrm{a}}$ \\
\hline 4,5 & $67,6 \pm 0,3^{\mathrm{a}}$ & $67,7 \pm 0,7^{\mathrm{a}}$ & $16,0 \pm 1,7^{\mathrm{a}}$ & $17,2 \pm 1,0^{\mathrm{a}}$ \\
\hline 6 & $69,0 \pm 1,9^{\mathrm{a}}$ & $65,0 \pm 1,0^{\mathrm{b}}$ & $14,5 \pm 0,4^{\mathrm{b}}$ & $17,2 \pm 1,1^{\mathrm{a}}$ \\
\hline
\end{tabular}

Fonte: própria autoria.

*Os valores são apresentados como média \pm desvio padrão $(\mathrm{n}=3)$.

Médias numa mesma coluna, seguidas por uma mesma letra maiúscula, não diferem entre si pelo teste de Tukey $(p<0,05)$.

Médias numa mesma linha, para um mesmo parâmetro e concentração de laponita, seguidas por uma mesma letra minúscula, não diferem entre si pelo teste de Tukey $(p<0,05)$.

\subsubsection{Propriedades mecânicas: ensaios de tração uniaxial e de perfuração}

Em relação ao teste de tração uniaxial, observou-se que o método de produção dos filmes não alterou as propriedades mecânicas dos mesmos (Tabela 9). Nos filmes de colágeno (Tabela 9), os valores do módulo elástico (ME) diminuíram com $C_{\text {lap }}$, e os valores de tensão (TR) e deformação na ruptura (DR) permaneceram constantes com $C_{\text {lap }}$. Os valores de ME e TR nos filmes de colágeno sem laponita foram similares aos observados por Makishi (2016), trabalhando com filmes de colágeno, para uma mesma concentração de biopolímero na SFF (4 g de colágeno/100 g de SFF). Borges et al. (2016) encontraram valores de $\mathrm{TR}=25,3 \mathrm{MPa}$ e $\mathrm{DR}=52,1 \%$, em filmes de colágeno hidrolizado (2 g de colágeno/100 g de SFF). 
Por outro lado, a laponita aumentou a rigidez e resistência dos filmes de gelatina, aumentado os valores de ME e TR nos filmes nanocompósitos (Tabela 9). Contudo, os valores de DR permaneceram constantes. Os valores de ME, TR e DR nos filmes de gelatina sem laponita foram comparáveis aos observados por Jorge (2012), Flaker (2014) e Makishi (2016), trabalhando em filmes de gelatina, para uma mesma concentração de biopolímero (4 g de gelatina/100 g de SFF). Bae et al. (2009) encontraram valores de TR e DR em filmes de gelatina com montmorilonita comparáveis aos encontrados na presente tese nos filmes nanocompósitos de gelatina.

Com relação aos filmes de fécula de mandioca, observou-se que a laponita aumentou o ME nestes filmes, contudo, os valores de TR e DR permaneceram constantes (Tabela 9). Perotti et al. (2014) encontraram valores similares de ME e TR em filmes de fécula de mandioca, com $C_{\text {lap }} \leq 10 \%$.

Os valores de ME, TR e DR dos filmes nanocompósitos de gelatina e fécula de mandioca produzidos nesta tese estão de acordo com resultados encontrados na literatura, onde foi observado que a laponita melhorou as propriedades mecânicas de filmes de amido de milho e de fécula de mandioca, assim como de gelatina (AOUADA; MATTOSO; LONGO, 2011; Li et al., 2015; PEROTTI et al., 2014; TANG e ALAVI, 2012).

Com relação ao teste de perfuração, foi observado que o método de produção não alterou as propriedades mecânicas dos filmes nanocompósitos (Tabela 10).

Nos filmes de colágeno e fécula de mandioca, a adição da laponita não alterou os valores de deformação (DP), nem de força (FP) na perfuração (Tabela 10). A adição de laponita modificou significativamente os valores de DP $(p<0,05)$ nos filmes de gelatina, porém, estas mudanças não tiveram importância do ponto de vista tecnológico. Os valores de DP e FP nos filmes de gelatina sem laponita foram similares aos encontrados por Flaker (2014) e Makishi (2016), trabalhando em filmes de gelatina. 
Tabela 9 - Valores das propriedades mecânicas determinados por testes de tração dos filmes de colágeno, gelatina e fécula de mandioca $\left(C_{c o l}\right.$, $\left.C_{g e l}, C_{f e ́ c}=4 \%\right)$, em função da concentração de laponita $\left(C_{l a p}\right)^{*}$.

\begin{tabular}{|c|c|c|c|c|c|c|}
\hline \multirow{3}{*}{$\begin{array}{l}C_{\text {lap }} \\
(\%)\end{array}$} & \multicolumn{6}{|c|}{ Filmes à base de colágeno } \\
\hline & \multicolumn{2}{|c|}{ TR (MPa) } & \multicolumn{2}{|c|}{ DR $(\%)$} & \multicolumn{2}{|c|}{ ME (x10-2 MPa $)$} \\
\hline & Casting & $\begin{array}{l}\text { Espalhamento } \\
\text { mecânico }\end{array}$ & Casting & $\begin{array}{l}\text { Espalhamento } \\
\text { mecânico }\end{array}$ & Casting & $\begin{array}{c}\text { Espalhamento } \\
\text { mecânico }\end{array}$ \\
\hline 0 & $10,2 \pm 1,1$ & $12,7 \pm 1,8$ & $47,1 \pm 9,9$ & $48,1 \pm 2,9$ & $0,8 \pm 0,4$ & $0,9 \pm 0,3$ \\
\hline 1,5 & $9,2 \pm 0,3$ & $10,3 \pm 1,9$ & $42,3 \pm 7,9$ & $39,4 \pm 2,1$ & $0,7 \pm 0,3$ & $0,8 \pm 0,2$ \\
\hline 3 & $11,0 \pm 1,7$ & $9,4 \pm 1,0$ & $43,8 \pm 8,8$ & $34,6 \pm 2,8$ & $0,4 \pm 0,2$ & $0,5 \pm 0,1$ \\
\hline 4,5 & $9,2 \pm 1,2$ & $10,4 \pm 1,4$ & $42,2 \pm 8,8$ & $42,5 \pm 1,8$ & $0,4 \pm 0,1$ & $0,5 \pm 0,1$ \\
\hline \multirow[t]{2}{*}{6} & $11,0 \pm 1,7$ & $10,3 \pm 1,2$ & $44,8 \pm 6,1$ & $42,2 \pm 3,8$ & $0,4 \pm 0,1$ & $0,4 \pm 0,2$ \\
\hline & \multicolumn{6}{|c|}{ Filmes à base de gelatina } \\
\hline 0 & $23,0 \pm 1,3^{\mathrm{B}}$ & $22,7 \pm 1,8^{\mathrm{B}}$ & $48,1 \pm 5,5$ & $48,1 \pm 2,9$ & $3,7 \pm 0,7^{\mathrm{C}}$ & $3,7 \pm 0,6^{\mathrm{C}}$ \\
\hline 1,5 & $24,2 \pm 2,1^{\mathrm{B}}$ & $23,3 \pm 1,9^{\mathrm{B}}$ & $49,6 \pm 5,2$ & $49,4 \pm 2,1$ & $4,6 \pm 0,4^{\mathrm{B}}$ & $4,4 \pm 0,2^{\mathrm{B}}$ \\
\hline 3 & $24,4 \pm 1,2^{\mathrm{B}}$ & $23,4 \pm 1,0^{\mathrm{B}}$ & $45,4 \pm 3,1$ & $46,6 \pm 2,8$ & $5,2 \pm 0,6^{\mathrm{AB}}$ & $5,2 \pm 0,3^{\mathrm{AB}}$ \\
\hline 4,5 & $26,9 \pm 1,6^{\mathrm{A}}$ & $27,4 \pm 1,4^{\mathrm{A}}$ & $46,8 \pm 4,1$ & $47,5 \pm 1,8$ & $5,3 \pm 0,3^{\mathrm{AB}}$ & $5,9 \pm 0,4^{\mathrm{AB}}$ \\
\hline \multirow[t]{2}{*}{6} & $28,9 \pm 2,6^{\mathrm{A}}$ & $29,3 \pm 1,2^{\mathrm{A}}$ & $47,7 \pm 4,5$ & $47,2 \pm 3,8$ & $5,8 \pm 0,7^{\mathrm{A}}$ & $6,0 \pm 0,2^{\mathrm{A}}$ \\
\hline & \multicolumn{6}{|c|}{ Filmes à base de fécula de mandioca } \\
\hline 0 & $15,9 \pm 1,1$ & $15,7 \pm 1,4$ & $15,1 \pm 2,5$ & $18,1 \pm 3,0$ & $3,3 \pm 0,5$ & $3,4 \pm 0,3$ \\
\hline 1,5 & $16,2 \pm 1,4$ & $15,1 \pm 1,6$ & $17,6 \pm 1,2$ & $16,3 \pm 2,1$ & $3,5 \pm 0,4$ & $3,5 \pm 0,3$ \\
\hline 3 & $14,5 \pm 3,9$ & $13,5 \pm 1,0$ & $18,4 \pm 1,1$ & $17,7 \pm 1,8$ & $3,8 \pm 0,3$ & $3,6 \pm 0,3$ \\
\hline 4,5 & $14,9 \pm 1,5$ & $14,4 \pm 2,4$ & $16,7 \pm 2,1$ & $17,5 \pm 2,5$ & $3,9 \pm 0,6$ & $3,7 \pm 0,3$ \\
\hline 6 & $17,1 \pm 1,5$ & $16,3 \pm 1,2$ & $17,7 \pm 1,5$ & $17,2 \pm 1,4$ & $4,1 \pm 0,4$ & $3,9 \pm 0,3$ \\
\hline
\end{tabular}

Fonte: própria autoria.

*Os valores são apresentados como média \pm desvio padrão $(\mathrm{n}=15)$. 
Médias numa mesma coluna, seguidas por uma mesma letra maiúscula, não diferem entre si pelo teste de Tukey $(p<0,05)$.

Médias numa mesma linha, para um mesmo parâmetro e concentração de laponita, seguidas por uma mesma letra minúscula, não diferem entre si pelo teste de Tukey $(p<0,05)$.

$\mathrm{TR}$ = tensão na ruptura; $\mathrm{DR}$ = deformação na ruptura; $\mathrm{ME}=$ módulo elástico. 
Tabela 10 - Valores das propriedades mecânicas determinadas por testes de perfuração dos filmes de colágeno, gelatina e fécula de mandioca $\left(C_{c o l}, C_{g e l}, C_{f e ́ c}=4 \%\right)$, em função da concentração de laponita $\left(C_{l a p}\right)^{*}$.

\begin{tabular}{|c|c|c|c|c|}
\hline \multirow{3}{*}{$\begin{array}{l}C_{\text {lap }} \\
(\%)\end{array}$} & \multicolumn{4}{|c|}{ Filmes à base de colágeno } \\
\hline & \multicolumn{2}{|c|}{ DP (\%) } & \multicolumn{2}{|c|}{$\mathbf{F P}(\mathbf{N})$} \\
\hline & Casting & $\begin{array}{l}\text { Espalhamento } \\
\text { mecânico }\end{array}$ & Casting & $\begin{array}{l}\text { Espalhamento } \\
\text { mecânico }\end{array}$ \\
\hline 0 & $7,8 \pm 0,1$ & $7,5 \pm 0,2$ & $12,6 \pm 1,2$ & $11,7 \pm 1,3$ \\
\hline 1,5 & $7,6 \pm 0,7$ & $7,5 \pm 0,2$ & $10,6 \pm 0,7$ & $11,1 \pm 1,2$ \\
\hline 3 & $7,6 \pm 0,1$ & $7,3 \pm 0,3$ & $8,2 \pm 1,2$ & $9,5 \pm 1,4$ \\
\hline 4,5 & $7,2 \pm 0,6$ & $7,2 \pm 0,3$ & $10,0 \pm 0,4$ & $9,4 \pm 1,2$ \\
\hline \multirow{2}{*}{6} & $7,3 \pm 0,4$ & $7,4 \pm 0,2$ & $9,7 \pm 0,6$ & $9,5 \pm 1,1$ \\
\hline & \multicolumn{4}{|c|}{ Filmes à base de gelatina } \\
\hline 0 & $4,8 \pm 0,2^{\mathrm{A}}$ & $4,5 \pm 0,2^{\mathrm{A}}$ & $17,1 \pm 2,2^{\mathrm{AB}}$ & $17,2 \pm 1,6$ \\
\hline 1,5 & $4,5 \pm 0,3^{\mathrm{AB}}$ & $4,5 \pm 0,2^{\mathrm{A}}$ & $15,4 \pm 1,0^{\mathrm{C}}$ & $15,7 \pm 1,9$ \\
\hline 3 & $4,2 \pm 0,2^{\mathrm{B}}$ & $4,4 \pm 0,2^{\mathrm{A}}$ & $15,7 \pm 0,8^{\mathrm{BC}}$ & $14,5 \pm 1,9$ \\
\hline 4,5 & $4,0 \pm 0,2^{\mathrm{B}}$ & $4,0 \pm 0,1^{\mathrm{BC}}$ & $18,4 \pm 0,9^{\mathrm{A}}$ & $15,4 \pm 2,3$ \\
\hline \multirow[t]{2}{*}{6} & $4,1 \pm 0,3^{\mathrm{C}}$ & $3,9 \pm 0,2^{\mathrm{C}}$ & $18,2 \pm 0,9^{\mathrm{A}}$ & $16,3 \pm 1,2$ \\
\hline & \multicolumn{4}{|c|}{ Filmes à base de fécula de mandioca } \\
\hline 0 & $2,3 \pm 0,2$ & $2,2 \pm 0,2$ & $5,5 \pm 0,7$ & $5,6 \pm 0,7$ \\
\hline 1,5 & $2,4 \pm 0,2$ & $2,5 \pm 0,3$ & $5,4 \pm 0,9$ & $5,2 \pm 0,9$ \\
\hline 3 & $2,1 \pm 0,3$ & $2,2 \pm 0,2$ & $5,7 \pm 0,6$ & $5,5 \pm 0,9$ \\
\hline 4,5 & $2,3 \pm 0,3$ & $2,2 \pm 0,3$ & $5,9 \pm 1,4$ & $5,8 \pm 0,7$ \\
\hline 6 & $2,1 \pm 0,2$ & $2,0 \pm 0,3$ & $5,8 \pm 1,3$ & $5,8 \pm 1,0$ \\
\hline
\end{tabular}

Fonte: própria autoria.

*Os valores são apresentados como média \pm desvio padrão $(\mathrm{n}=10)$.

Médias numa mesma coluna, seguidas por uma mesma letra maiúscula, não diferem entre si pelo teste de Tukey $(p<0,05)$.

Médias numa mesma linha, para um mesmo parâmetro e concentração de laponita, seguidas por uma mesma letra minúscula, não diferem entre si pelo teste de Tukey $(p<0,05)$.

$\mathrm{DP}=$ deformação na perfuração; FR= força na perfuração.

\subsubsection{Solubilidade em água}

A solubilidade em água dos filmes nanocompósitos foi controlada principalmente pelo biopolímero e pelo plastificante, não havendo alterações drásticas com a adição da laponita e/ou o método de produção (Tabela 11). As pequenas alterações na solubilidade dos filmes com o incremento da laponita não tiveram 
importância do ponto de vista tecnológico. A não alteração nos valores de solubilidade em água nos filmes nanocompósitos com a presença da laponita pode ser creditada à não formação de ligações químicas entre a nanopartícula e os biopolímeros em estudo.

Comparando os resultados obtidos na presente tese com outras pesquisas, observou-se que os valores de solubilidade dos filmes nanocompósitos de colágeno foram comparáveis aos resultados encontrados por Makishi (2016), trabalhando com filmes de colágeno plastificados com glicerol. Os valores de solubilidade dos filmes nanocompósitos de gelatina nesta tese foram comparáveis aos resultados encontrados por Farahnaky, Dadfar, Shahbazi (2014), Flaker (2014) e Li et al. (2015), trabalhando com filmes de gelatina com montmorilonita ou laponita, com $C_{m o n}$ ou $C_{\text {lap }} \leq 7 \%$, plastificados com glicerol. Finalmente, os valores de solubilidade dos filmes nanocompósitos de fécula de mandioca desta tese foram comparáveis aos encontrados por Ghanbarzadeh, Almasi, Entezami (2010) e (2011), trabalhando com filmes de amido plastificados com glicerol.

Tabela 11 - Valores de solubilidade dos filmes de colágeno, gelatina e fécula de mandioca $\left(C_{c o l}, C_{g e l}, C_{f e ́ c}=4 \%\right)$, em função da concentração de laponita $\left(C_{l a p}\right)^{*}$.

\begin{tabular}{ccc}
\hline & \multicolumn{2}{c}{ Filmes à base de colágeno } \\
\cline { 2 - 3 } $\boldsymbol{C}_{\text {lap }}$ & Casting & Espalhamento mecânico \\
\hline 0 & $40,5 \pm 0,6$ & $40,0 \pm 0,6$ \\
1,5 & $40,4 \pm 1,1$ & $38,4 \pm 1,2$ \\
3 & $39,8 \pm 0,4$ & $39,5 \pm 1,3$ \\
4,5 & $39,9 \pm 0,7$ & $41,9 \pm 1,4$ \\
6 & $40,4 \pm 1,4$ & $39,5 \pm 1,2$ \\
\cline { 2 - 3 } 0 & \multicolumn{2}{c}{ Filmes à base de gelatina } \\
\cline { 2 - 3 } 1,5 & $33,6 \pm 0,7^{\mathrm{AB}}$ & $32,7 \pm 0,8^{\mathrm{A}}$ \\
3 & $32,6 \pm 0,3^{\mathrm{AB}}$ & $32,3 \pm 0,9^{\mathrm{A}}$ \\
4,5 & $32,6 \pm 1,2^{\mathrm{AB}}$ & $32,4 \pm 0,8^{\mathrm{AB}}$ \\
6 & $30,8 \pm 0,9^{\mathrm{BC}}$ & $31,4 \pm 0,4^{\mathrm{B}}$ \\
& Filmes à base de fécula de mandioca \\
\cline { 2 - 3 } 0 & $32,8 \pm 0,4$ & $33,0 \pm 1,9$ \\
1,5 & $32,5 \pm 0,5$ & $33,4 \pm 1,0$ \\
3 & $31,7 \pm 0,4$ & $32,6 \pm 0,8$ \\
4,5 & $31,4 \pm 1,5$ & $32,0 \pm 0,8$ \\
6 & $31,4 \pm 1,7$ & $32,2 \pm 0,8$ \\
\hline
\end{tabular}

Fonte: própria autoria.

*Os valores são apresentados como média \pm desvio padrão $(\mathrm{n}=3)$. 
Médias numa mesma coluna, seguidas por uma mesma letra maiúscula, não diferem entre si pelo teste de Tukey $(p<0,05)$.

Médias numa mesma linha, para uma mesma concentração de laponita, seguidas por uma mesma letra minúscula, não diferem entre si pelo teste de Tukey $(p<0,05)$.

\subsubsection{0. Ângulo de contato}

Segundo Rhim et al. (2006), a hidrofobicidade superficial dos materiais, medida como o ângulo $(\theta)$, formado pela interseção de um liquido com uma superfície sólida é uma das propriedades de superfície mais importantes em materiais à base de biopolímeros. Na presente tese, foi observado que o ângulo de contato nos filmes nanocompósitos apresentaram valores constantes durante os primeiros 20 segundos de analise (resultados não apresentados). Portanto, as análises comparativas foram realizadas para um tempo de 15 segundos, após a gota de água ter tocado a superfície dos filmes nanocompósitos (Tabela 12).

Os valores de ângulo de contato a 15 segundos dos filmes nanocompósitos de proteínas foram controlados principalmente pelo biopolímero e pelo plastificante, não havendo alterações drásticas com a adição da laponita e/ou o método de produção (Tabela 12). Os valores de ângulo de contato nos filmes de colágeno e gelatina foram típicos de materiais à base de proteínas plastificados com glicerol, oscilando entre $70^{\circ} \mathrm{e}$ 95 (FLAKER, 2014; MAKISHI, 2016).

Com relação aos filmes de fécula de mandioca, observou-se que os valores de ângulo de contato não foram alterados pelo método de produção, porém, a adição de laponita, implicou em alterações significativas dos valores de ângulo de contato nos filmes de fécula de mandioca (Tabela 12). Este comportamento poderia ser consequência da maior hidrofilicidade dos filmes de fécula de mandioca, quando comparados com os filmes de porteínas (Tabela 12). Os valores de ângulo de contato nos filmes controle de fécula de mandioca foram similares aos observados por Bangyekan, Aht-Ong, Srikulkit (2006), trabalhando com filmes de fécula de mandioca plastificados com glicerol.

Segundo Vloger (1998), os valores de ângulo de contato, maiores que $65^{\circ}$ são típicos de superfícies hidrofóbicas. Portanto, na presente tese, os filmes de proteínas podem ser classificados como superfícies hidrofóbicas, e os filmes de fécula de mandioca como superfícies hidrofilícas. 
Tabela 12 - Valores de ângulo de contato $\left(^{\circ}\right)$ dos filmes de colágeno, gelatina e fécula de mandioca $\left(C_{c o l}, C_{g e l}, C_{f e ́ c}=4 \%\right)$, em função da concentração de laponita $\left(C_{l a p}\right)^{*}$.

\begin{tabular}{ccc}
\hline $\boldsymbol{C}_{\text {lap }}$ & \multicolumn{2}{c}{ Filmes à base de colágeno } \\
\cline { 2 - 3 }$(\boldsymbol{\%})$ & Casting & Espalhamento mecânico \\
\hline 0 & $88,9 \pm 4,2$ & $80,3 \pm 10,9$ \\
1,5 & $92,8 \pm 10,0$ & $91,2 \pm 8,4$ \\
3 & $89,2 \pm 4,2$ & $87,7 \pm 4,6$ \\
4,5 & $87,9 \pm 0,9$ & $86,1 \pm 6,1$ \\
6 & $86,2 \pm 6,4$ & $87,2 \pm 9,2$ \\
\hline & \multicolumn{2}{c}{ Filmes à base de gelatina } \\
\cline { 2 - 3 } 0 & $95,2 \pm 2,3$ & $94,7 \pm 0,6$ \\
1,5 & $94,6 \pm 4,3$ & $93,3 \pm 2,9$ \\
3 & $94,6 \pm 1,2$ & $92,4 \pm 3,8$ \\
4,5 & $96,8 \pm 3,9$ & $93,4 \pm 2,4$ \\
6 & $94,0 \pm 2,5$ & $94,3 \pm 2,2$ \\
\hline & Filmes à base d fécula de mancioca \\
\cline { 2 - 3 } 0 & $55,3 \pm 0,0^{\mathrm{A}}$ & $53,1 \pm 1,9^{\mathrm{A}}$ \\
1,5 & $42,7 \pm 5,0^{\mathrm{B}}$ & $43,4 \pm 0,9^{\mathrm{B}}$ \\
3 & $29,8 \pm 0,7^{\mathrm{C}}$ & $30,6 \pm 0,7^{\mathrm{C}}$ \\
4,5 & $32,4 \pm 2,0^{\mathrm{C}}$ & $32,0 \pm 0,6^{\mathrm{C}}$ \\
6 & $29,9 \pm 3,9^{\mathrm{C}}$ & $30,2 \pm 0,6^{\mathrm{C}}$ \\
\hline
\end{tabular}

Fonte: própria autoria.

*Os valores são apresentados como média \pm desvio padrão $(\mathrm{n}=3)$.

Médias numa mesma coluna, seguidas por uma mesma letra maiúscula, não diferem entre si pelo teste de Tukey $(p<0,05)$.

Médias numa mesma linha, para uma mesma concentração de laponita, seguidas por uma mesma letra minúscula, não diferem entre si pelo teste de Tukey $(p<0,05)$.

\subsubsection{Isotermas de sorção}

As isotermas de sorção dos filmes nanocompósitos foram controladas principalmente pelo biopolímero e pelo plastificante, não havendo alterações drásticas com a adição da laponita e/ou o método de produção (Figura 30). Estes resultados indicaram que a concentração de laponita e o método de produção não alteraram a adsorção de molêculas de água na superfície dos filmes nanocompósitos. Todas as isotermas de sorção dos filmes nanocompósitos apresentaram forma sigmodial, sendo classificadas como uma curva tipo II, típica de materiais biológicos (BRUNAUER; EMMETT; TELLER, 1938). 
Os filmes de colágeno e gelatina apresentaram valores similares de adsorção de água em função da UR, sendo estes, similares aos obtidos por Wolf, Sobral, Telis (2009), trabalhando com filmes de colágeno plastificados com glicerol, e a $25^{\circ} \mathrm{C}$. Com relação aos filmes de fécula de mandioca, os valores de adsorção de água em função da UR foram similares aos observados por Souza, Souza, Pena (2013), trabalhando com filmes de fécula de mandioca plastificados com glicerol, e a $25^{\circ} \mathrm{C}$.

O modelo de GAB (Equação 9) foi ajustado aos valores experimentais de isotermas sorção dos filmes nanocompósitos.

$x=x_{m} \frac{C_{G A B} * K_{G A B} * A_{w}}{\left(1-K_{G A B} * A_{w}\right)\left(1+\left(C_{G A B}-1\right) * K_{G A B} * A_{w}\right)}$

sendo $x$ e $x_{m}$, os valores de umidade em equilíbrio, e umidade da monocamada de água (g de água/g de matéria seca), $A_{w}$, a atividade de água (entre 0 e 1), $C_{G A B}$ e $K_{G A B}$, constantes do modelo (SOBRAL e HABITANTE, 2001).

Os filmes nanocompósitos de proteínas tiveram valores de: $C_{G A B}=28,1 \pm 0,1$, $K_{G A B}=1,0 \pm 0,0$, e $x_{m}=0,1 \pm 0,0 \mathrm{~g}$ de água/g de matéria seca, com $\mathrm{R}^{2}$ de 0,9 . Por outro lado, os filmes nanocompósitos de fécula de mandioca tiveram valores de: $C_{G A B}=253,0$ $\pm 3,0, K_{G A B}=0,9 \pm 0,0, x_{m}=0,1 \pm 0,0 \mathrm{~g}$ de água/g de matéria seca, com $\mathrm{R}^{2}$ de 0,9 .

Comparando os resultados obtidos na presente tese com outras pesquisas, observou-se que os valores de $x_{m}$ obtidos pelo modelo de GAB foram similares aos encontrados por Sobral e Habitante (2001), trabalhando em filmes de gelatina $\left(x_{m}=0,1\right.$ g de água/g de matéria seca); e por Perdomo et al. (2009), trabalhando em filmes de fécula de mandioca $\left(x_{m}=0,1 \mathrm{~g}\right.$ de água/g de matéria seca). 
Figura 30 - Exemplos de isotermas de sorção dos filmes nanocompósitos de colágeno (a), gelatina (b) e fécula de mandioca (c), em função da concentração de laponita $\left(C_{l a p}\right)$, produzidos por casting $\left(C_{c o l}, C_{g e l}, C_{f e ́ c}=4 \%\right)$.

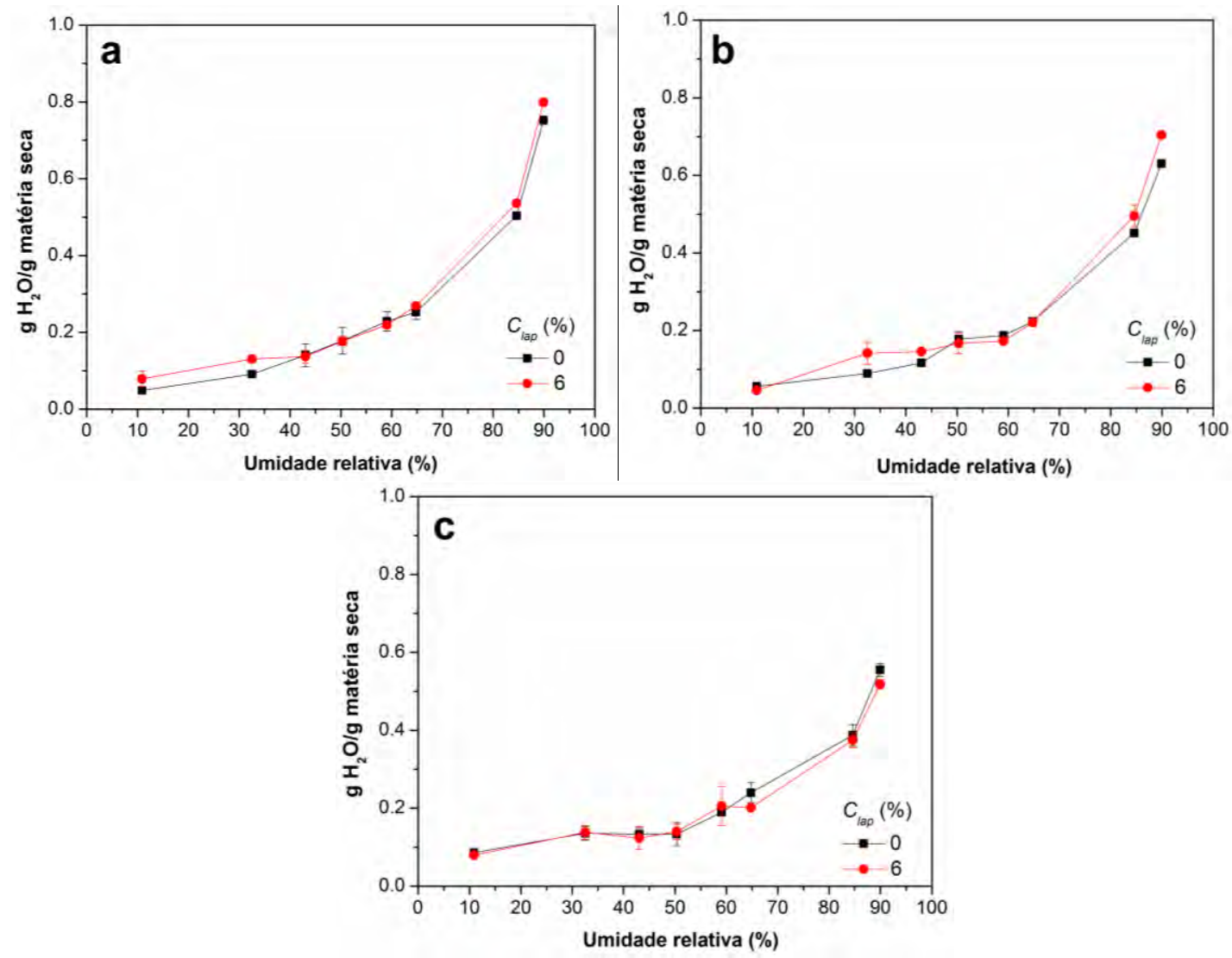

Fonte: própria autoria.

\subsubsection{Permeabilidade ao vapor de água}

De forma geral, a permeabilidade ao vapor de água dos filmes de colágeno, gelatina e fécula de mandioca foi influenciada pelo biopolímero, assim como pelo plastificante (Tabela 13). Com relação aos filmes de colágeno e gelatina, os valores de permeabilidade ao vapor de água foram típicos de materiais à base de proteínas (JORGE, 2012; FLAKER et al., 2015; MAKISHI, 2016). Com a presença de laponita, os filmes de colágeno tiveram leves alterações dos valores de permeabilidade ao vapor de água, contudo, estas variações não tiveram importância do ponto de vista tecnológico.

Nesta tese, os valores de permeabilidade ao vapor de água nos filmes de colágeno foram similares aos encontrados por Makishi (2016), trabalhando com filmes de colágeno plastificados com glicerol. Os valores de permeabilidade ao vapor de água dos filmes de gelatina determinados nesta tese foram comparáveis aos encontrados por 
Flaker et al. (2015), trabalhando com filmes de gelatina com montmorilonita $\left(C_{m o n} \leq\right.$ $5 \%$ ), plastificados com glicerol. Finalmente, os valores de permeabilidade ao vapor de água dos filmes de fécula de mandioca encontrados nesta tese foram comparáveis aos determinados por Ghanbarzadeh, Almasi, Entezami (2010), trabalhando com filmes de amido de milho, plastificados com glicerol, e por Tang e Alavi (2012), trabalhando com filmes à base de blendas de amido de milho e poli(vinil álcool), com laponita $\left(C_{\text {lap }} \leq\right.$ $15 \%)$, plastificados com glicerol.

Tabela 13 - Valores de permeabilidade ao vapor de água $\left(\mathrm{g} \cdot \mathrm{mm} / \mathrm{m}^{2} \cdot \mathrm{h} \cdot \mathrm{kPa}\right)$ dos filmes de colágeno, gelatina e fécula de mandioca $\left(C_{c o l}, C_{g e l}, C_{f e ́ c}=4 \%\right)$, em função da concentração de laponita $\left(C_{\text {lap }}\right)^{*}$.

\begin{tabular}{ccc}
\hline$C_{\text {lap }}$ & \multicolumn{2}{c}{ Filmes à base de colágeno } \\
\cline { 2 - 3 }$(\%)$ & Casting & Espalhamento mecânico \\
\hline 0 & $0,4 \pm 0,0^{\mathrm{A}}$ & $0,4 \pm 0,0^{\mathrm{A}}$ \\
1,5 & $0,3 \pm 0,1^{\mathrm{A}}$ & $0,3 \pm 0,0^{\mathrm{B}}$ \\
3 & $0,3 \pm 0,1^{\mathrm{A}}$ & $0,3 \pm 0,0^{\mathrm{B}}$ \\
4,5 & $0,3 \pm 0,0^{\mathrm{B}}$ & $0,3 \pm 0,0^{\mathrm{B}}$ \\
6 & $0,3 \pm 0,1^{\mathrm{A}}$ & $0,3 \pm 0,0^{\mathrm{B}}$ \\
\cline { 2 - 3 } 0 & \multicolumn{1}{c}{ Filmes à base de gelatina } \\
\cline { 2 - 3 } 1,5 & $0,4 \pm 0,0$ & $0,4 \pm 0,0$ \\
3 & $0,4 \pm 0,0$ & $0,4 \pm 0,0$ \\
4,5 & $0,4 \pm 0,0$ & $0,4 \pm 0,0$ \\
6 & $0,4 \pm 0,0$ & $0,4 \pm 0,0$ \\
& $0,4 \pm 0,0$ & $0,4 \pm 0,0$ \\
\cline { 2 - 3 } 0 & Filmes à base de fécula de mandioca \\
\cline { 2 - 3 } 1,5 & $0,2 \pm 0,0^{\mathrm{AB}}$ & $0,2 \pm 0,0$ \\
3 & $0,2 \pm 0,0^{\mathrm{A}}$ & $0,2 \pm 0,0$ \\
4,5 & $0,2 \pm 0,0^{\mathrm{AB}}$ & $0,2 \pm 0,0$ \\
6 & $0,2 \pm 0,0^{\mathrm{BC}}$ & $0,2 \pm 0,0$ \\
\hline
\end{tabular}

Fonte: própria autoria.

*Os valores são apresentados como média \pm desvio padrão $(n=3)$.

Médias numa mesma coluna, seguidas por uma mesma letra maiúscula, não diferem entre si pelo teste de Tukey $(p<0,05)$.

Médias numa mesma linha, para uma mesma concentração de laponita, seguidas por uma mesma letra minúscula, não diferem entre si pelo teste de Tukey $(p<0,05)$. 


\section{CONCLUSÕES}

Os resultados obtidos nessa tese permitem concluir que:

O tamanho das partículas de laponita em água foi alterado com os tratamentos utilizados no ultraturrax (velocidades e tempos de agitação). O aumento na velocidade e/ou tempo de agitação utilizados no ultraturrax implicaram na diminuição do tamanho das partículas de laponita em água. As melhores condições de dispersão no ultraturrax foram as que utilizaram velocidades de agitação de $20.000 \mathrm{rpm}$, por 30 minutos, obtendo partículas de laponita com tamanhos menores que $50 \mathrm{~nm}$, estáveis, com valores de potencial $\zeta$ de $-40 \mathrm{mV}$ e $\mathrm{pH}>10$.

O método de produção dos filmes nanocompósitos (casting ou espalhamento mecânico) não influenciou as propriedades físico-químicas, nem de topografia superficial estudadas nos filmes nanocompósitos. Assim, o método de espalhamento mecânico, sob as condições utilizadas nesta tese, não implicou na orientação das cadeias biopoliméricas nem das nanopartículas em estudo, durante o espalhamento das soluções formadoras de filmes sobre as placas de acrílico.

A laponita não alterou a densidade nos filmes nanocompósitos para a faixa de concentrações estudadas $\left(0 \% \leq C_{\text {lap }} \leq 6 \%\right)$. Dessa forma, a espessura nos filmes nanocompósitos se manteve contante em $70 \mu \mathrm{m}$.

Através das análises de difração de raios $\mathrm{X}$, observou-se que a laponita foi esfoliada nos filmes à base de colágeno, gelatina e fécula de mandioca. Para algumas concentrações de laponita nos filmes à base de fécula de mandioca $\left(C_{l a p}>3 \%\right)$, percebeu-se que a laponita esteve intercalada nas cadeias biopoliméricas. A separação mínima das plaquetas de laponita foi calculada pela lei de Bragg, obtendo-se separações mínimas de $44 \AA$, nas plaquetas esfoliadas, e de $17 \AA$, nas plaquetas intercaladas. Nos filmes à base de colágeno foi observado que a presença da laponita diminuiu a formação de estruturas cristálinas (triple hélice), associadas ao biopolímero.

Através dos espectros de infravermelho por transformada de Fourier percebeu-se que não houve nenhuma formação de ligação química entre as plaquetas de laponita e os biopolímeros estudados (colágeno, gelatina e fécula de mandioca).

A laponita incrementou a rugosidade superficial dos filmes nanocompósitos, sendo mais evidente nos filmes à base de colágeno e fécula de mandioca. Este comportamento foi atribuído à formação de aglomerados produto da interação biopolímero - nanopartícula durante a secagem das soluções formadoras de filmes. O 
incremento na rugosidade superficial diminuiu o brilho nos filmes nanocompósitos determinado no ângulo de $60^{\circ}$.

A exfoliação e/ou intercalação da laponita nas matrizes biopoliméricas permitiu obter filmes nanocompósitos com propriedades óticas similáres dos filmes controle (filmes à base de biopolímero sem laponita).

A laponita não alterou as transições vítreas observadas nos filmes à base de biopolímeros, contudo, nos filmes à base de colágeno e gelatina, a laponita diminuiu a formação de estruturas cristálinas, sendo observado uma diminuição dos valores de entalpia de fusão com o aumento na concentração da laponita.

A laponita não alterou as propriedades mecânicas dos filmes nanocompósitos à base de colágeno e fécula de mandioca possivelmente porque estas matrizes são compostas. Já nos filmes à base de gelatina, a laponita teve um efeito reforçador, aumentando os valores de tensão na ruptura e módulo elástico.

A laponita não alterou a solubilidade em água dos filmes nanocompósitos possivelmente pela ausência de ligações químicas entre as nanopartículas e os biopolímeros estudados (colágeno, gelatina e fécula de mandioca).

A laponita não alterou o ângulo de contato à água nos filmes à base de colágeno e gelatina, sendo devido a hidrofobicidade dos biopolímeros. Os filmes controle à base de fécula de mandioca tiveram superfícies hidrofílicas as quais se tornaram mais hidrofílicas com a presença da laponita.

A laponita não alterou a adsorção de água nem a tortuosidade nos filmes nanocompósitos, dessa forma as isotermas de sorção, assim como a permeabilidade ao vapor de água permaneceram constantes nos filmes à base de biopolímeros contendo laponita. 


\section{SUGESTÕES PARA TRABALHOS FUTUROS}

Para trabalhos futuros sugere-se o seguinte:

$\checkmark$ Estudar a birrefringência, a permeabilidade ao oxigênio e a barreira a luz UV-Vis nos filmes nanocompósitos.

$\checkmark$ Estudar maiores concentrações da laponita $\left(C_{l a p}>6 \%\right)$ nos filmes à base de proteínas, visando a identificação da concentração mínima da nanopartícula necessária para produzir filmes nanocompósitos contendo plaquetas de laponita intercaladas.

$\checkmark$ Estudar o efeito da espessura e da concentração da laponita nos filmes à base de proteínas sob a formação da triple hélice, e o seu efeito sob as propriedades mecânicas, térmicas e de cristalinidade nos filmes nanocompósitos. 


\section{REFER̂̂ENCIAS}

ALMASI, H.; GHANBARZADEH, B.; ENTEZAMI, A.A. Physicochemical properties of starch-CMC-nanoclay biodegradable films. International Journal of Biological Macromolecules, Amsterdã, Países Baixos, v. 46, n. 1, p. 1-5, 2010.

ANDERSON, R.L. et al. Clay swelling - A challenge in the oilfield. Earth-Science Reviews, Amsterdã, Países Baixos, v. 98, n. 3-4, p. 201-216, 2010.

ANDREUCCETTI, C.; CARVALHO, R.A.; GROSSO, C.R.F. Gelatin-based films containing hydrophobic plasticizers and saponin from Yucca schidigera as the surfactant. Food Research International, Ottawa, Ontaro, Canadá, v. 43, n. 6, p. 1710-1718, 2010.

AOUADA, F.A.; MATTOSO, L.H.C.; LONGO, E. A simple procedure for the preparation of laponite and thermoplastic starch nanocomposites: structural, mechanical, and thermal characterizations. Journal of Thermoplastic Composite Material, Deleware, EUA, v. 26, n. 1, p. 109-124, 2011.

ARZATE-VÁZQUEZ, I. et al. Microstructural characterization of chitosan and alginate films by microscopy techniques and texture image analysis. Carbohydrate Polymers, Londres, Inglaterra, v. 87, n. 1, p. 289-299, 2012.

ASTM. Standard test methods for tensile properties of thin plastic sheeting. Standard designation: D882. Annual books of American standards testing methods. Filadélfia, EUA, p. 182-188, 1985.

AVERY, R.G.; RAMSAY. Colloidal properties of synthetic hectorite clay dispersions II. Light and small angle neutron scattering. Journal of Colloid and Interface Science, Orlando, EUA, v. 109, n. 2, p.448-454, 1986.

AYRANCI, E.; TUNC, S. A method for the measurement of the oxygen permeability and the development of edible films to reduce the rate of oxidative reactions in fresh foods. Food Chemistry, Barking, Inglaterra, v. 80, n 3, p. 423-431, 2003.

AYRANCI, E.; TUNC, S. The effect of edible coatings on water and vitamin C loss of apricots (Armeniaca vulgaris Lam.) and green peppers (Capsicum annuum L.). Food Chemistry, Barking, Inglaterra, v. 87, n. 3, p. 339-342, 2004.

BAE, H.J. et al. Effect of clay content, homogenization RPM, pH, and ultrasonication on mechanical and barrier properties of fish gelatin/montmorillonite nanoparticles. LWT-Food Science and Technology, Londres, Inglaterra, v. 42, n. 6, p. 1179-1186, 2009.

BALDWIN, E.A.; WOOD, B. Use of edible coating to preserve pecans at room temperature. Hort Science, Virginia, EUA, v. 41, n. 1, p. 188-192, 2006.

BALNOIS, E.; VIDAL, S.D.; LEVITZ, P. Probing the morphology of laponite Clay colloids by atomic force microscopy. Langmuir, Washington, DC, EUA, v. 19, n. 17, p. 6633-6637, 2003. 
BANGYEKAN, C.; AHT-ONG, D.; SRIKULKIT, K. Preparation and properties evaluation of chitosan-coated cassava starch films. Carbohydrate Polymers, Londres, Inglaterra, v. 63, n. 1, p. 61-71, 2006.

BARROSO, M.D.B. Desenvolvimento de compósitos com matriz de geopolímeros reforçados com partículas de quasicristais AlCuFe. 2009. 64f. Dissertação de Mestrado, Universidade Federal da Paraiba, João Pessoa, 2009.

BERGO, P.; MORAES, I.C.F.; SOBRAL, P.J.A. Effects of moisture content on structural and dielectric properties of cassava starch films. Starch, Weinheim, Alemanha, v. 64, n. 10, p. 835-839, 2012.

BERTUZZI, M.A.; ARMADA, M.; GOTTIFREDI, J.C. Physicochemical characterization of starch based films. Journal of Food Engineering, Londres, Inglaterra, v. 82, n. 1, p. 17-25, 2007.

BESOMBES, J.L. et al. Improvement of the analytical characteristics of enzyme electrode for free and total cholesterol via laponita clay additives. Analytica Chimica Acta, Amsterdã, Países Baixos, v. 317, n. 1-3, p. 275-280, 1995.

BIPPUS, L.; JABER, M.; LEBEAU, B. Laponite and hybrid surfactant/laponite particles processed as spheres by spray-drying. New Journal of Chemistry, Cambridge, Inglaterra, v. 33, n. 5, p. 1116-1126, 2009.

BODINI, R.B. et al. Properties of gelatin-based films with added ethanol-propolis extract. LWT - Food Science and Technology, Londres, Inglaterra, v. 51, n. 1, p. 104$110,2013$.

BONILLA, J. et al. Physical, structural and antimicrobial properties of poly vinyl alcohol-chitosan biodegradable films. Food Hydrocolloids, Washington, DC, EUA, v. 35, n. 1, p. 463-470, 2014.

BORGES, J.G. et al. Lecithin, gelatin and hydrolyzed collagen orally disintegrating films: functional properties. International Journal of Biological Macromolecules, Amsterdã, Países Baixos, v. 86, p. 907-916, 2016.

BOUWMEESTER, H. et al. Review of health safety aspect of nanotechnologies in food production. Regulatory Toxicology and Pharmacolofy, Amsterdã, Países Baixos, v. 53, n. 1, p. 52-62, 2009.

BREUNINGER, W.F.; PIYACHOMKMAN, K.; SRIROTH, K. Tapioca/cassava starch: production and use. In: Starch, Chemistry and Technology. Capítulo 12; 3ra Ed., 2009. Academic Press.

BRUNAUER, S.; EMMETT, P.H., TELLER, E. Adsorption of gases in multimolecular layers. Journal of the Americam Chemical Society, Washington, DC, EUA, v. 60, n. 2, p. 309-319, 1938. 
CANO, A. et al. Effect of cellulose nanocrystals on the properties of pea starch - poly (vinyl alcohol) blend films, Journal of Material Science, Norwell, MA, EUA, v. 50, n. 21, p. 6979-6992, 2015.

CAO, G.; WANG, Y. Nanostructure and Materials: Synthesis, properties, and applications. Imperial College Pres, 2da Ed, 2011.

CHEN, C.H.; KUO, W.S.; LAI, L.S. Rheological and physical characterization of filmforming solutions and edible films from tapioca starch/decolorized hsian-tsao leaf gum. Food Hydrocolloids, Washington, DC, EUA, v. 23, n. 8, p. 2132-2140, 2009.

CHIOU, B.-S. et al. Rheology of starch-clay nanocompostes. Carbohydrate Polymers, Londres, Inglaterra, v. 59, n. 5, p. 467-475, 2005.

CHIOU, B.-S. et al. Extruded starch-nanoclay nanocomposites: effects of glycerol and nanoclay concentration. Polymer Engineering Science, Malden MA, EUA, v. 47, n.11, p. 1898-1904, 2007.

CHIDANANDAIAH, R.C.K.; SANYAL, M.K. Effect of sodium alginate coating with preservatives on the quality of meat patties during refrigerated $\left(4 \pm 1{ }^{\circ} \mathrm{C}\right)$ storage. Journal of Muscle Foods, Malden MA, EUA, v. 20, n. 3, p. 275-292, 2009.

CHUNG, Y.L. et al. Preparation and properties of biodegradable starch-clay nanocomposites. Carbohydrate Polymers, Londres, Inglaterra, v. 79, n. 2, p. 391-396, 2010 .

COELHO, A.C.V.; SANTOS, P.S. Argilas especiais: o que são, caracterização e propriedades. Quimica Nova, São Paulo, Brasil, v. 30, p. 146-152, 2007.

CUMMINS, H.Z. Liquid, glass, gel: The phases of colloidal laponite. Journal of NonCristalline Solids, Amsterdã, Países Baixos, v. 353, n. 41-43, p. 3891-3905, 2007.

CYRAS, V.P. et al. Physical and mechanical properties of thermoplastic starch/montmorillonite nanocomposite films. Carbohydrate Polymers, Londres, Inglaterra, v. 73, n. 1, p. 55-63, 2008.

DANIEL, L.M; FROST, R.L.; ZHU, H.Y. Synthesis and characterization of claysupported titania photocatalysts. Journal of Colloid and Interface Science, Nova Iorque, EUA, v. 316, n. 1, p. 72-79, 2007.

DIAS, T.P. et al. Effect of the addition of soy lecithin and Yucca schidigera extract on the properties of gelatin and glycerol based biodegradable films. Polímeros, São Carlos, Brasil, v. 23, n. 3, p. 339-345, 2013.

DJABOUROV, M.; NISHINARI, K.; ROSS-MURPHY, S.B. Physical gels from biological and synthetic polymers. Cambrige University Press, 1ra Ed, 2013.

FARAHNAKY, A.; DADFAR, S.M.M; SHAHBAZI, M. Physical and mechanical properties of gelatin-clay nanocomposites. Journal of Food Engineering, Londres, Inglaterra, v. 122, n. 1, p. 78-83, 2014. 
FILIPPO, E. et al. Green synthesis of silver nanoparticles with sucrose and maltose: Morphological and structural characterization. Journal of Non-Crystalline Solids, Amsterdã, Países Baixos, v. 356, n. 6-8, p.344-350, 2010.

FlAKER, C.H.C. Estudo da dispersão da nanopartícula em água e seu efeito nas propriedades de filmes nanocompósitos de gelatina. 2014. 74f. Dissertação de Mestrado. Universidade de São Paulo, Faculdade de Zootecnia e Engenharia de Alimentos. Pirassununga. 2014.

FLAKER, C.H.C. et al. Gelatin-based nanocomposite films: a study on montmorillonite dispersion and concentration. Journal of Food Engineering, Londres, Inglaterra, v. 167, p. 65-70, 2015.

FLAKER, C.H.C. et al. Montmorillonite dispersion in water affects some physical properties of gelatin-based nanocomposites films. Biointerface Research in Applied Chemistry, Bucareste, Romênia, v. 6, n. 2, p. 1093-1098, 2016.

FRAILE, J.M. et al. Clay-supported non-chiral and chiral Mn(salen) complexes as catalysts for olefin epoxidation. Journal of Molecular Catalysis A: Chemical, Amsterdã, Países Baixos, v. 136, n. 1, p. 47-57, 1998.

GALDEANO, M.C. et al. Effects of production process and plasticizers on stability of films and sheets of oat starch. Materials Science and Engineering C, Amsterdã, Países Baixos, v. 29, n. 2, p. 492-498, 2009.

GARCIA, M.A; MARTINO, M.N; ZARITZKI, N.E. Barrier properties of edible starchbased films and coatings. Journal of Food Science, Malden, EUA, v. 65, n. 6, p. 941947, 2000.

GENNADIOS, A. et al. Edible coatings and films based on proteins. In J.M. Krochta, E.A. Baldwin, \& M. Nisperos-Carriedo (Eds.), Edible coatings and films to improve food quality. Lancaster, Technomic, p. 210-278, 1994.

GENNADIOS, A. et al. Mechanical and barrier properties of egg albumen films. Journal of Food Science, Malden, EUA, v. 61, n. 3, p.585-589, 1996.

GHANBARZADEH, B.; ALMASI, H.; ENTEZAMI, A.A. Physical properties of edible modified starch/carboxymethyl cellulose films. Innovative Food Science and Emerging Technologies, Washington, DC, EUA, v. 11, n. 4, p. 697-702, 2010.

GHANBARZADEH, B.; ALMASI, H.; ENTEZAMI, A.A. Improving the barrier and mechanical properties of corn starch-based edible films: effect of citric acid and carboxymetil cellulose. Industrial Crops and Products, Amsterdã, Países Baixos, v. 33, n. 1, p. 229-235, 2011.

GOMEZ-ESTACA, J. et al. Effect of functional edible films and high pressure processing on microbial and oxidatives poilage in cold-smoked sardine (Sardina pilchardus). Food Chemistry, Barking, Inglaterra, v. 105, n. 2, p. 511-520, 2007. 
GÓMEZ-ESTACA, J. et al. Physico-chemical and film-forming properties of bovinehide and tuna-skin gelatin: a comparative study. Journal of Food Engineering, Londres, Inglaterra, v. 90, n. 4,p. 480-486, 2009.

GONTARD, N.; GUILBERT, S.; CUQ, J.L. Edible wheat gluten films: influence of the main process variables on film properties using response surface methodology. Journal of Food Science, Malden, EUA, v. 57, n. 1, p. 190-195, 1992.

GONTARD, N.; RING, S. Edible wheat gluten film: influence of water content on glass transition temperature. Journal of Agricultural and Food Chemistry, Washington, DC, EUA, v. 44, n. 11, p. 3474-3478, 1996.

GROVER, C.N. et al. Crosslinkig and composition influence the surface properties, mechnical stiffness and cell reactivity of collagen-based films. Acta Biomaterialia, Oxford, Inglaterra, v. 8, n. 8, p. 3080-3090, 2012.

HERRERA, N.N. et al. Aqueous dispersions of silane-functionalized laponite clay platelets. A first step toward the elaboration of water-based polymer/clay nanocomposites. Langmuir, Washington, DC, EUA, v. 20, n. 5, p. 1564-1571, 2004.

JORGE, M.F.C. Caracterização de filmes nanocompósitos biodegradáveis à base de gelatina produzidos com um aplicador automático de filmes. 2012. 137f. Tese de Doutorado. Universidade de São Paulo, Faculdade de Zootecnia e Engenharia de Alimentos. Pirassununga. 2012.

JORGE, M.F.C. et al. Viscoelastic and rheological properties of nanocompositeforming solutions based on gelatin and montmorillonite. Journal of Food Engineering, Londres, Inglaterra, v. 120, p. 81-87, 2014.

KAMPEERAPAPPUN, P. et al. Preparation of cassava starch/montmorillonite composite film. Carbohydrate Polymers, Londres, Inglaterra, v. 67, n. 2, p. 155-163, 2007.

KOJIMA, Y. et al. Synthesis of nylon 6-clay hybrid by montmorillonite intercalated with $\epsilon$-caprolactam. Journal of Polymer Science Part A: Polymer Chemistry, Washington, DC, EUA, v. 31, n. 4, p. 983-986, 1993.

KOJIMA, Y. et al. Fine structure of nylon-6-clay hybrid. Journal of Polymer Science Part B: Polymer Physics, Washington, DC, EUA, v. 32, n. 4, p. 625-630, 1994.

KUMAR, N.V.N.; MURALIDHAR, K.; JOSHI, Y.M. On the refractive index of ageing dispersions of laponite. Applied Clay Science, Amsterdã, Países Baixos, v. 42, n. 1-2, p. 326-330, 2008.

KUNTE, L.A.; GENNADIOS, A.; CUPPETT, S.L. Cast films from soy protein isolates and fractions. Cereal Chemistry, Malden, EUA, v. 74, n. 2, p. 115-118, 1997.

LEE, S.Y. et al. Whey-protein-coated peanuts assessed by sensory evaluation and static headspace gas chromatography. Journal Food Science, Malden, EUA, v. 67, n. 3, p. 1212-1218, 2002. 
LEVITZ, P. et al. Liquid-solid transition of laponite suspensions at very low ionic strength: Long-range electrostatic stabilization of anisotropic colloids. Europhysics Letters, França, v. 49, n. 5, p. 672-677, 2000.

LI, X. et al. Fabrication of gelatin-laponite composite films: Effect of the concentration of laponite on physical properties and the freshness of meat during storage, Food Hydrocolloids, Washington, DC, EUA, v. 44, p. 390-398, 2015.

LIANOS, P.; THOMAS, J.K. Cadmium sulfite of small dimensions produced inverted micelles. Chemical Physical Letters, Amsterdã, Países Baixos, v.125, n. 3, p. 299-302, 1986.

LISIEKI, I.; PILENI, M.P. Synthesis of copper metallic clusters using reverse micelles as microreactors. Journal of the American Chemical Society, Easton, EUA, v. 115, n. 10, p. 3887-3892, 1993.

LIU, P. Polymer modified clay minerals: A review. Applied Clay Science, Amsterdã, Países Baixos, v. 38, n. 1-2, p. 64-76, 2007.

LIU, H. et al. Thermal processing of starch-based polymers. Progress in Polymer Science, Oxford, Inglaterra, v. 34, n. 12, p. 1348-1368, 2009.

LOPEZ-CABALLERO, M.E. et al. A chitosan-gelatin blend as a coating for fish patties. Food Hydrocolloids, Washington, DC, EUA, v. 19, n. 2, p. 303-311, 2005.

MAKISHI, G.L.A. Propriedades de soluções filmogênicas de gelatina ou colágeno com extratos de boldo-do-chile. 2016. 157f. Tese de doutorado. Universidade de São Paulo, Faculdade de Zootecnia e Engenharia de Alimentos. Pirassununga. 2016.

MALI, S.; GROSSMANN, M.V.E. Effects of yam films on storability and quality of fresh strawberries (Fragaria ananassa). Journal of Food Agricultural and Chemistry, Washington, DC, EUA, v. 51, n. 24, p. 7005-7011, 2003.

MARIA, T.M.C. et al. The effect of the degree of hydrolysis of the PVA and the plasticizer concentration on the color, opacity, and thermal and mechanical properties of films based on PVA and gelatin blends. Journal of Food Engineering, Londres, Inglaterra, v. 87, n. 2, p. 191-199, 2008.

MATHEW, S.; BRAHMAKUMAR, M.; ABRAHAM, T.E. Microstructural imaging and characterization of the mechanical, chemical, thermal, and swelling properties of starch-chitosan blend films. Biopolymers, Nova Iorque, NY, EUA, v. 82, n. 2, p. 176187, 2006.

MAZUR, L.P. Preparação e caracterização de nanocompósitos de poli(l-ácido láctico) e diferentes argilas organofílicas. 2012. 133f. Dissertação de Mestrado. Universidade da Região de Joinville. Joinville, 2012.

MORAES, I.C. et al. Influência do grau de hidrólise do poli(vinil álcool) nas propriedades físicas à base de blendas de gelatina e poli(vinil álcool) plastificados com 
glicerol. Ciência e Tecnologia de Alimentos, Campinas, São Paulo, v. 28, n. 3, p. 738745, 2008.

MORAES, I.C.F. et al. Film forming solution based on gelatin and poly(vinil alcohol) blends: Thermal and rheological characterizations. Journal of Food Engineering, Londres, Inglaterra, v. 95, p. 588-596, 2009.

MORAES, J.O. et al. Scale-up of the production of cassava starch based films using tape-casting. Journal of Food Engineering, Londres, Inglaterra, v. 119, n. 4, p. 800808, 2013.

NAVARRO-TARAZAGA, M.L; SOTHORNVIT, R; PEREZ-GAGO, M.B. Effect of plasticizer type and amount on hydroxypropyl methylcellulose_beeswax edible film properties and postharvest quality of coated plums (cv. Angeleno). Journal of Agricultural and Food Chemistry, Washington, DC, EUA, v. 50, n. 20, p. 9502-9509, 2008.

NELSON, A.; COSGROVE, T. A small-angle neutron scattering study of adsorbed poly(ethylene oxide) on laponite. Langmuir, Washington, DC, EUA, v. 20, n. 6, p. 2298-2304, 2004.

NICOLAI, T.; COCARD, S. Light scattering study of the dispersion of laponite. Langmuir, Washington, DC, EUA, v. 16, n. 21, p. 8189-8193, 2000.

OU, S. et al. Role of ferulic acid in preparing edible films from soy protein isolate. Journal of Food Engineering, Washington, DC, EUA, v. 70, n. 2, p. 205-210, 2005.

OUSSALAH, M. et al. Antimicrobial an dantioxidant effects of milk protein-based film containing essential oils for the preservation of whole beef muscle. Journal of Agriculture and Food Chemistry, Washington, DC, EUA, v. 52, n. 18, p. 5598-5605, 2004.

PAIVA, L.; MORALES, A.R.; GUIMARÃES, T.R. Propriedades Mecânicas de Nanocompósitos de Polipropileno e Montmorilonita Organofílica. Polímeros, São Carlos, Brasil, v. 16, n. 2, p. 136-140, 2006.

PÁLKOVÁ, H. et al. Laponite-derived porous clay heterostructures: II. FTIR study of the structure evolution. Microporus and Mesoporous Materials, Amsterdã, Países Baixos, v. 127, n. 3, p. 237-244, 2010.

PAOLI, M.A. Degradação e estabilização de Polímeros. 2da versão, São Paulo: Artliber Editora, 2008.

PEREDA, M. et al. Chitosan-gelatin composites and bi-layer films with potential antimicrobial activity. Food Hydrocolloids, Washington, DC, EUA, v. 25, n. 5, p. 1372-1381, 2011.

PEREZ-GAGO, M.B.; SERRA, M.; RIO, D.M.A. Color change of fresh-cut apples coated with whey protein concentrate-based edible coatings. Postharvest Biology and Technology, Amsterdã, Países Baixos, v. 39, n. 1, p. 84-92, 2006. 
PERDOMO, J. et al. Glass transition temperatures and water sorption isotherms of cassava starch. Carbohydrate Polymers, Londres, Inglaterra, v. 76, n. 2, p. 305-313, 2009.

PEROTTI, G.F. et al. Bacterial cellulose-laponite clay nanocomposites. Polymer, Oxford, Inglaterra, v. 52, n. 1, p. 157-163, 2011.

PEROTTI, G.F. et al. Biopolymer-Clay nanocomposites: cassava starch synthetic cast films. Journal of the Brazilian Chemical Society, São Paulo, Brasil, v. 25, n. 2, p. 320-330, 2014.

PIGNON, F. et al. A yield stress thixotropic clay suspension: investigations of structure by light, neutron and x-ray scatterin. Physical Review E, Nova Iorque, EUA, v. 56, p. 3281-3289, 1997.

POMMET, M. et al. Study of wheat gluten plasticization with fatty acids. Polymer, Oxford, Inglaterra, v. 44, n. 1, p. 115-122, 2003.

PONCE, A. et al. Antimicrobial and antioxidant activities of edible coatings enriched with natural plant extracts: in vitro and in vivo studies. Postharvest Biology and Technology, Amsterdã, Países Baixos, v. 49, n. 2, p. 294-300, 2008.

PRESTES, R.C. Colágeno e seus derivados: características e aplicações em productos cárneos. UNOPAR Científica Ciências Biológicas e da Saúde, Londrina, Paraná, v. 15 , n. 1, p. 65-74, 2013.

QUEBEDO, R. et al. Quantification of enzymatic browning in apple slices applying the fractal texture Fourier image. Journal of Food Engineering, Londres, Inglaterra, v. 95, n. 2, p. 285-290, 2009.

RAO, Y.Q. Gelatin-clay nanocomposites of improved properties. Polymer, Oxford, Inglaterra, v. 48, n. 18, p. 5369-5375, 2007.

RAY, S. et al. The potential use of polymer-clay nanocomposites in food packaging. International Journal of Food Engineering, Malden, EUA, v. 2, n. 4, p. 1-13, 2006.

RHIM, J.W. et al. Preparation and characterization of chitosan-based nanocomposite films with antimicrobial activity. Journal of Agricultural and Food Chemistry, Washington, DC, EUA, v. 54, n. 16, p. 5814-5822, 2006.

RUZICKA, B.; ZACCARELLI, E. A fresh look at the laponite phase diagram. Soft Mater, Cambridge, Inglaterra, v. 7, n. 4, p. 1268-1286, 2011.

SHAN, D. et al. Reagent less biosensor for hydrogen peroxide based on self-assebled films of horseradish peroxidase/laponite/chitosan and the primary investigation on the inhibitory effect by sulfide. Biosensors and Bioelectronics, Oxford, Inglaterra, v. 26, n. 2, p. 536-541, 2010. 
SHAIKH, H.M. et al. Utilization of sugarcane bagasse cellulose for producing cellulose acetates: novel use of residual hemicellulose as plasticizer. Carbohydrate Polymers, Londres, Inglaterra, v. 76, n. 1-2, p. 23-29, 2009.

SILVA, G.G.D. et al. Biodegradable films based on blends of gelatin and poly(vinyl alcohol): effect of PVA type or concentration on some physical properties of films. Journal of Polymers and the Environment, Nova Iorque, EUA, v. 16, n. 4, p. 276$285,2008$.

SOBRAL, P.J.A. Influência da espessura sobre certas propriedades de biofilmes à base de proteínas miofibrilares. Pesquisa Agropecuária Brasileira, Rio de Janeiro, Brasil, v. 35, n. 6, p. 1251-1259, 2000.

SOBRAL, P.J.A. et al. Mechanical, water vapor barrier and thermal properties of gelatin based edible films. Food Hydrocolloids, Washington, DC, EUA, v. 15, n. 4-6, p. 423432, 2001.

SOBRAL, P.J.A.; HABITANTE, A.M.Q.B. Phase transitions of pigskin gelatin. Food Hydrocolloids, Washington, DC, EUA, v. 15, n. 4-6, p. 377-382, 2001.

SOBRAL, P.J.A. et al. Phase transitions in biodegradable films based on blends of gelatin and poly(vinyl alcohol). Ciência e Tecnologia de Alimentos, Campinas, Brasil, v. 31, n. 2, p. 372-379, 2011.

SOTHORNVIT, R.; KROCHTA, J.M. Plasticizer effect on mechanical properties of $\beta$ lactoglobulin films. Journal of Food Engineering, Londres, Inglaterra, v. 50, n. 3, p. 149-155, 2001.

SOUZA, A.C. et al. Cassava starch biodegradable films: Influence of glycerol and clay nanoparticles content on tensile and barrier properties and glass transition temperature. LWT - Food Science and Technology, Londres, Inglaterra, v. 46, n. 1, p. 110-117, 2012.

SOUZA, T.C.L.; SOUZA, H.A.L.; PENA, R.S. A rapid method to obtainning moisture sorption isotherms of a starchy product. Starch, Weinheim, Alemanha, v. 65, n. 5-6, p. 433-436, 2013.

STEIN, T.M; GORDON, S.H; GREENE, R.V. Amino acids as plasticizers: II. Use of quantitative structure-property relationships to predict the behavior of monoammoniummonocarboxylate plasticizers in starch-glycerol blends. Carbohydrate Polymers, Londres, Inglaterra, v. 39, n. 1, p. 7-16, 1999.

STYLIANOU, A. et al. Combined information from AFM imaging and SHG signal analysis of collagen thin films. Biomedical Signal Processing and Control, Oxford, Inglaterra, v. 6, p. 307-313, 2011.

STYLIANOU, A.; YOVA, D. Surface nanoscale imaging of collagen thin films by atomic force microscopy. Materials Science and Engineering C, Amsterdã, Países Baixos, v. 33, n. 5, p. 2947-2957, 2013. 
STYLIANOU, A.; YOVA, D.; ALEXANDRATOU, E. Investigation of the influence of UV irradiation on collagen thin films by AFM imaging. Materials Science and Engineering C, Amsterdã, Países Baixos, v. 45, p. 455-468, 2014.

TANG, X.; ALAVI, S. Structure and physical properties of starch/poly vinyl alcohol/laponite RD nanocomposites films. Journal of Agricultural and Food Chemistry, Washington, DC, EUA, v. 60, n. 8, p. 1954-1962, 2012.

TAPIA, M.S. et al. Use of alginate- and gellan-based coatings for improving barrier, texture and nutritional properties of fresh-cut papaya. Food Hydrocolloids, Washington, DC, EUA, v. 22, n. 8, p. 1493-1503, 2008.

TAPIA-BLÁCIDO, D. et al. Contribution of the protein and lipid fractions to the physical, thermal and structural properties of amaranth (Amaranthus caudatus) flour films. Journal of Food Science, Malden, EUA, v. 72, n. 5, p. 293-300, 2007.

TAWARI, S.L.; KOCH, D.L.; COHEN, C. Electrical double-layer effects on the Brownian diffusivity and aggregation rate of laponite clay particles. Journal of Colloid and Interface Science, Nova Iorque, EUA, v. 240, n. 1, p. 54-66, 2001.

TESTER, R.F.; KARKALAS, J.; QI, X. Starch-composition, fine structure and architecture. Journal of Cereal Science, Londres, Inglaterra, v. 39, n. 2, p. 151-165, 2004.

TEXEIRA, E.M. et al. Cassava bagasse cellulose nanofibrils reinforced thermoplastic cassava starch. Carbohydrate Polymers, Londres, Inglaterra, v. 78, n. 3, p. 422-431, 2009.

THARANATHAN, R.N. Biodegradable films and composite coatings: Past, present and future. Trends in Food Science \& Technology, Cambridge, Inglaterra, v.14, n. 3, p. 71-78, 2003.

TOUMEY, C. Reading Feynman Into Nanotechnology: A Text for a New Science. Techné, Santa Clara, EUA, v. 12, n. 3, p. 133-168, 2008.

TREZZA, T.A.; KROCHTA, J.M. The gloss of edible coatings as affected by surfactants, lipids, relative humidity, and time. Journal of Food Science, Malden, EUA, v. 65, n. 4, p. 658-662, 2000.

VALENCIA, G.A.; HENAO, A.C.A.; ZAPATA, R.A.V. Comparative study and characterization of starches isolated from unconventional tuber sources. Journal of Polymer Engineering, Londres, Inglaterra, v. 32, n 8-9, p. 531-537, 2012.

VANIN, F.M. et al. Effects of plasticizers and their concentrations on thermal and functional properties of gelatin-based films. Food Hydrocolloids, Washington, DC, EUA, v. 19, n. 5, p. 899-907, 2005.

VANIN, F.M. et al. Development of active gelatin-based nanocomposite films produced in an automatic spreader. Food Research International, Ottawa, Canadá, v. 63, p. 1624, 2014. 
VIEIRA, M.G.A. et al. Natural-based plasticizers and biopolymer films: a review. European Polymer Journal, Oxford, EUA, v. 47, n. 3, p. 254-263, 2011.

VILLALOBOS, R. et al. Gloss and transparency of hydroxypropil methycellulose films containing surfactants as affected by their microstructure. Food Hydrocolloids, Washington, DC, EUA, v. 19, n. 1, p. 53-61, 2005.

VOGLER, E.A. Structure and reactivity of water at biomaterial surfaces. Advances in Colloid and Interface Science, Amsterdã, Países Baixos, v. 74, n. 1-3, p. 69-117, 1998.

WANG, B. et al. Electrorheological properties of organically modified nanolayered laponite: influence of intercalation, adsorption and wettability. Journal of Materials Chemistry, Cambridge, Inglaterra, v. 19, n. 13, p. 1816-1828, 2009.

WANG, K. et al. Mechanical properties and solubility in water of corn starch-collagen composite films: Effect of starch type and concentrations. Food Chemistry, Barking, Inglaterra, v. 216, n. 1, p. 209-216, 2017.

WEI, D.; QUIAN, W. Facile synthesis of Ag and Au nanoparticles utilizing chitosan as a mediator agent. Colloids and Surface B: Biointerfaces, Amsterdã, Países Baixos, v. 62, n. 1, p. 136-142, 2008.

WOLF, K.L.; SOBRAL, P.J.A.; TELIS, V.R.N. Physicochemical characterization of collagen fibers and collagen powder for self-composite film production. Food Hydrocolloids, Washington, DC, EUA, v. 23, n. 7, p. 1886-1894, 2009.

WU, W. et al. Transparent cellulose/Laponite nanocomposite films. Journal of Material Science, Norwell, MA, EUA, v. 51, n. 8, p. 1-9, 2016.

YAKIMETS, I. et al. Effect of water content on the structural reorganization and elastic properties of biopolymers films: a comparative study. Biomacromolecules, Washington, DC, EUA, v. 8, n. 5, p. 1710-1722, 2007.

YUAN, Z. et al. Cross-linkage effect of cellulose/laponite hybrids in aqueous dispersions and solid films, Carbohydrate Polymers, Londres, Inglaterra, v. 102, n. 15, p. 431-437, 2014.

ZHANG, Y; HAN J.H. Mechanical and thermal characteristics of pea starch films plasticized with monosaccharides and polyols. Journal of Food Science, Malden, EUA, v. 71, n. 2, p. 109-18, 2006.

ZARAMA, O.M.A. et al. Barrier, mechanical and morpho-structural properties of gelatin films with carbon nanotubes addition. Journal of Food Engineering, Londres, Inglaterra, v. 120, n. 1, p. 223-232, 2014.

ZETASIZER NANO SERIES USER MANUAL. MAN 0317, 21, capítulo 16, 2004. Disponível 
<http://www.nbtc.cornell.edu/facilities/downloads/Zetasizer\%20Manual.pdf>. Acesso em: 27 de abril 2014. 


\section{APÊNDICE (APPENDIX)}

In the present appendix the research results obtained between June $1^{\text {st }}, 2015$, until May $31^{\text {th }}$, 2016, during a sandwich Doctorate; done at the "Ecole Supérieure de Physique et de Chimie Industrielles, ESPCI' in Paris, France, under the direction of the Prof. Dr. Madeleine Djabourov will be presented.

During the sandwich Doctorate, the granule and platelet structures of cassava starch and laponite, respectively, and their relationship with the water absorption were investigated. The results presented in this appendix served to understand some physicochemical properties of cassava starch films with laponite, as well as, the mechanism of exfoliation/intercalation of laponite platelets, both presented in section $\mathbf{6}$, in this thesis. 
A1. Water desorption of cassava starch granules: a study based on thermogravimetric analysis of aqueous suspensions and humid powders

The results about the starch characterization were published as a paper, as following:

Valencia, G.A., Djabourov, M., Sobral, P.J.A. Water desorption of cassava starch granules: a study based on thermogravimetric analysis of aqueous suspensions and humid powders. Carbohydrate Polymers, v. 147, n. 20, p. 533-541, 2016. 


\section{A2. Novel insights on swelling and dehydration of Laponite RD}

The results presented in this section are co-authored by Valencia, G.A., Djabourov, M., Carn, F., and Sobral, P.J.A.

\section{A2.1. Introduction}

Clay minerals are formed by the weathering and decomposition of igneous rocks. They are layered minerals, classified among the phyllosilicates, consisting of stacks of negatively charged two-dimensional aluminosilicate layers. Each layer is comprised of fused sheets of octahedra of $\mathrm{Al}^{3+}, \mathrm{Mg}^{2+}$ or $\mathrm{Fe}^{3+}$ oxides and sheets of tetrahedra of $\mathrm{Si}^{4+}$ oxides (Wyckoff, 1968; Anderson et al., 2010). Isomorphic substitution of metal atoms in the clay lattice can lead to an overall negative charge on individual clay layers. This charge is compensated by cations which exist in the region between the clay layers known as the interlayer region. The interlayer cations are exchangeable cations. Clay minerals containing two tetrahedral sheets which sandwich one central octahedral sheet are referred to as 2:1 clays. In naturally occurring clays there is variability in inorganic species, mainly $\mathrm{Na}^{+}$and $\mathrm{Ca}^{2+}$, cations which are the charge-balancing interlayer cations. Studies of clay swelling are most often focused upon 2:1 smectite $(\mathrm{Sm})$ due to their large swelling potential. The Sm group incorporates a variety of clays with the most common ones being montmorillonite $(\mathrm{Mt})$, hectorite $(\mathrm{Ht})$ and beidellite $(\mathrm{Bd})$ (Anderson et al., 2010).

Laponite (Lap) is a synthetic clay mineral that is mainly used to modify rheological properties of liquids in applications such as cosmetics, paints, and inks (Cummins, 2007). Lap (hydrous sodium lithium magnesium silicate) is a crystalline layered silicate colloid with structure and composition closely resembling the Sm (Cummins, 2007). The Lap nanoparticle has a disk-shape with a thickness of approximately $1 \mathrm{~nm}$, and a diameter of approximately $25 \mathrm{~nm}$, much smaller than raw clays (Cummins, 2007). Lap nanoparticles are also interesting for their potential to be used as nanobuilding basic units in the elaboration of hierarchically-organized materials by self-assembling processes (Bippus et al., 2009). Lap and surface modified Lap can be used for adsorption of dyes, surfactants and biomolecules (Clausen et al., 2009). Recently, it has been used to reinforce biopolymers based films (Valencia et al., 2016 ${ }^{\mathrm{a}}$ ). The potential for Lap to be used as an effective drug carrier was recently reported for in situ delivery of tetracycline (Bippus et al., 2009). 
Swelling of raw clays has been broadly studied in the context of catalysis, agriculture and environmental industries (Caturla, 1999; Karamanis et al., 2011; Prado \& Vyazovkin, 2011). In comparison, few studies have been devoted to Lap, which however presents the advantage over raw clays to have smaller particle size, lower polydispersity in dimension and charge, better stability and dispersion in water compared to Mt (Bippus et al., 2009; Cummins, 2007). The reverse process which is the release of water molecules is even less well known in Lap and may have implications in the stability of the hydrated composite materials.

In this paper Lap swelling was investigated by equilibration under different relative humidities $(\mathrm{RH})$ in desiccators. The isothermal adsorption and clay swelling were studied for the first time macroscopically by means of thermogravimetric analysis (TGA) (measure of the moisture content) and microscopically by $\mathrm{X}$ ray diffraction. The kinetics of desorption is analyzed and interpreted in relation with the Lap RD hydration using TGA under controlled gas flow (nitrogen) with isothermal treatments. Substantial differences appear in this investigation between Lap nanoparticles and raw clays. Lap RD also shows very unusual characteristics upon dehydration which are highlighted.

\section{A2.2. Materials and Methods}

The synthetic clay mineral used in the present research is Lap RD (Southerm Clay Products Inc. Reference number 23224) with molecular composition $\left(\mathrm{Si}_{8}\left[\mathrm{Mg}_{5.5} \mathrm{Li}_{0.4} \mathrm{H}_{4.0} \mathrm{O}_{24.0}\right]^{0.7-}\left[\mathrm{Na}_{0.7}\right]^{0.7+}\right)$ (Tawari et al., 2001). Lap RD initially stored at room conditions $\left(\mathrm{T}=23{ }^{\circ} \mathrm{C}\right.$ and $\left.\mathrm{RH}=52 \%\right)$ was disposed in desiccators containing silica gel with $\mathrm{RH}=0.1 \%, 3 \%$ and saturated salt solutions for $\mathrm{RH}$ values of $31 \%, 45 \%$, $71 \%, 89 \%$ and $94 \%$. Lap RD was conditioned after 4 days under each RH value, when powders reached a constant weight. The equilibrium water content (equilibrium moisture content) $w_{\text {equil }}$ is given by:

$w_{\text {equil }}=\frac{m_{\text {water }}}{m_{\text {dry clay }}}$

The mass of dry Lap RD is determined after heating the powders at $150{ }^{\circ} \mathrm{C}$ using thermogravimetric analysis.

Lap RD conditioned in desiccators was analyzed using an X-ray diffractometer (Panalytical Empyrean, $\mathrm{Cu} \mathrm{K} \alpha$ radiation) equipped with a multichannel detector a 
PIXcel 2D solid-state detector ( $255 \times 255$ pixels, each pixel is $55 \mu \mathrm{m} \times 55 \mu \mathrm{m})$. X-ray diffraction patterns were obtained in the $1.5-70^{\circ}$ range, with a $0.025^{\circ}$ step size and $30 \mathrm{~s}$ per step. XR diffraction patterns were analyzed using Panalytical HighScore Plus software. The $d_{001}$-value of basal reflection was calculated using Bragg law:

$\lambda=2 d \sin \theta$

where $\lambda$, is the wavelength of $\mathrm{Cu} \mathrm{K} \alpha$ radiation (1.54187 $\AA$ ), $d$, is the spacing between the Lap RD layers, and $\theta$, is the reflection angle. After equilibration in desiccators, the Lap RD powders were carefully collected and tightly wrapped into paraffin foils to avoid any loss or uptake of humidity and rapidly transferred onto the sample holder. The overall duration of a measurement is about $10 \mathrm{~min}$.

The water desorption rates of Lap RD with various hydrations was investigated by thermogravimetric analysis (TGA) methods. The thermogravimetric balance (TGA Q5000, TA Instruments, USA) with a precision of $0.1 \mu \mathrm{g}$ was used for all isothermal and non-isothermal modes, operating with a constant pure nitrogen gas flow, at a rate of $25 \mathrm{~mL} / \mathrm{min}$ and using an open Pt pan with $10 \mathrm{~mm}$ diameter and $2 \mathrm{~mm}$ height. The nitrogen gas flow was adjusted to the lowest possible value to eliminate the water vapor after desorption, imposing a dry atmosphere far from the surface of the sample, but keeping equilibrium at the surface of the powders, allowing dehydration in controlled and reproducible conditions. The value of the nitrogen flow rate were identical to the one used on previous experiments performed on humid powders with the same instrumental device (Agaciak et al., 2015; Valencia et al., 2016 ${ }^{\text {b }}$. The initial sample weight was approximately $50 \mathrm{mg}$. The protocol performed to evaluate the dehydration rates is based on isothermal conditions at $35^{\circ} \mathrm{C}$ and $45^{\circ} \mathrm{C}$ during $120 \mathrm{~min}$. These are the lowest possible temperatures; drying kinetics being slow the homogeneity of the sample can be preserved. Using a constant heating rate, $1{ }^{\circ} \mathrm{C} / \mathrm{min}$, from $20{ }^{\circ} \mathrm{C}$ to $150{ }^{\circ} \mathrm{C}$, continued by $60 \mathrm{~min}$ isothermal drying at $150{ }^{\circ} \mathrm{C}$ we were able to determine precisely the mass of dry Lap RD and establish the equilibrium adsorption diagram. Experiments were repeated at least two times for each sample and showed a very good reproducibility. 


\section{A2.3. Results and discussions}

\section{A2.3.1. Equilibrium water uptake}

Lap RD exhibits a type II isotherm (Fig. A2.1a), typical for the adsorption of gases on solid surfaces (Brunauer et al., 1938; Butt et al., 2000). The results are compared in Fig. 1a to those reported by Fripiat et al. (1982) at a temperature of $31{ }^{\circ} \mathrm{C}$. No other investigations have been published so far on Lap hydration to our knowledge.
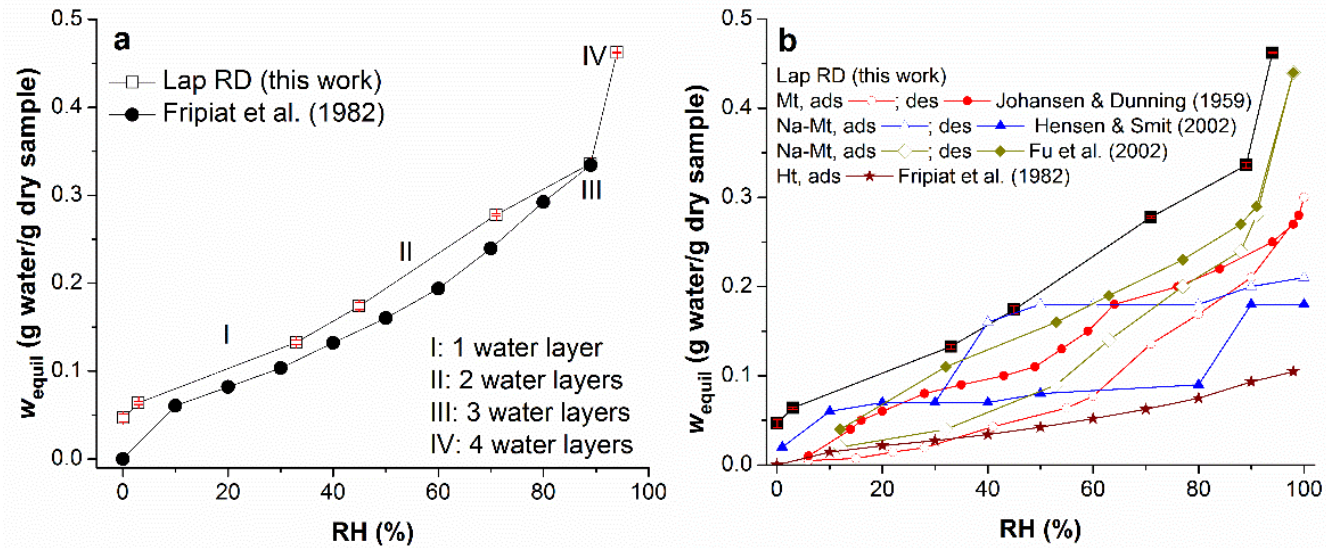

Figure A2.1. (a) Sorption isotherm of Lap RD conditioned under different relative humidities at $23^{\circ} \mathrm{C}$ and results from Fripiat et al. (1982) (b) Comparison between the sorption isotherms of Lap RD (this paper) and other natural clays: Mt (Johansen \& Dunning, 1959) solid and empty circle symbols, (Hensen \& Smit, 2002) solid and empty triangle symbols; (Fu et al., 2002) solid and empty diamond symbols; Ht (Fripiat et al., 1982) star symbols.

Fripiat et al. (1982) investigated in parallel water adsorption in Ht (which is raw clay similar to Lap) and they report lower adsorption compared to Lap in the same experimental conditions. The comparison between water adsorption of Lap $\mathrm{RD}$ and other raw clays is shown in Fig. A2.1b. Lap RD is much more hygroscopic and the adsorption isotherm is well reproducible compared to $\mathrm{Mt}$ and Na-Mt (Johansen \& Dunning, 1959; Fripiat et al., 1982; Fu et al., 2002). Clays expand with water adsorption through the hydration of interlayer cations, which balance the lattice negative electrical charges: $\mathrm{H}_{2} \mathrm{O}$ molecules adsorbed on the clay should be mainly confined into interlayer galleries and are initially positioned in the center of the interlayers. The water oxygen coordinates to a sodium counter ion, while the water hydrogen atoms hydrogen-bond to oxygen atoms at the clay surface. It is expected that crystal structure changes upon hydration of the layers and relaxation (Fu et al., 2002), 
depending on the nature of the cations. In general, substantial hysteresis is reported between water adsorption and desorption. The shape of the isotherms is also influenced by the nature of exchangeable cations and suggests complex adsorption/desorption mechanisms (Bérend et al., 1995). In raw clays, adsorption starts for a particular value of the relative pressure (RH), decreasing with increasing size of the exchangeable cation. One layer hydrate forms in the range $25 \%<\mathrm{RH}<70 \%$, whereas two layers are only observed in Li- and $\mathrm{Na}-\mathrm{Mt}$ and not reached in the other Mt.

Interpretation by Fripiat et al. (1982) of the adsorption isotherm of Lap, from the BET diagram locates the first hydration layer around $\mathrm{RH} \approx 20 \%$ and $w_{\text {equil }} \approx 0.11 \mathrm{~g} / \mathrm{g}$ dry Lap. The RH value where the 1rst layer forms in much higher in Mt clays than in Lap ( $\mathrm{RH} \approx 60 \%$ ) (Bérend et al., 1995). The second hydration layer in Lap builds between $20 \%<\mathrm{RH}<60 \%$, with $w_{\text {equil }}$ increasing between 0.11 and $0.23 \mathrm{~g}$ water/g dry sample and finally the third layer is completely filled around $\mathrm{RH} \approx 89 \%$. Adsorption still increases above the third water layer towards $0.46 \mathrm{~g}$ water/g dry sample at $\mathrm{RH}=94 \%$ (this work). The specific surface area of Lap RD to water is either $386.4 \mathrm{~m}^{2} / \mathrm{g}$ or 351 $\mathrm{m}^{2} / \mathrm{g}$ according to Fripiat et al. (1982) or Bippus et al. (2009). These values are larger than those reported for bentonite (Bent) $\left(164 \mathrm{~m}^{2} / \mathrm{g}\right)$, Sep $\left(149 \mathrm{~m}^{2} / \mathrm{g}\right)$ and Ht $\left(79 \mathrm{~m}^{2} / \mathrm{g}\right)$ (Johansen \& Dunning, 1959; Fripiat et al., 1982; Karamanis et al., 2011). Large specific surface areas can be interpreted as high proportion of active sites for water adsorption (Hellman \& Melvin, 1950). However, the estimated specific surface area of phyllosilicates from crystallographic determinations is much larger than measured on Lap, being $750 \mathrm{~m}^{2} / \mathrm{g}$ (Mooney et al., 1952; Fripiat et al., 1982).

In order to elucidate the water adsorption mechanisms in Lap RD, X-ray diffraction measurements were performed on the humid clays. X ray diffraction patterns reflect the changes of crystal structure with hydration of Lap RD after equilibration in desiccators.

\section{A2.3.2. X-ray diffraction patterns}

In X-ray diffractograms two distinct visible reflections appear (Fig. A2.2) at $3.7^{\circ} \leq 2 \theta \leq$ $7.7^{\circ}\left(d_{(001)}\right)$ and $2 \theta=60.8^{\circ}\left(d_{(060)}\right)$ which are related to the interlayer space and the trioctahedral character of Lap, respectively (Norrish, 1954; Bippus et al., 2009; Ghadiri et al., 2013). Reflections with $10^{\circ}<2 \theta<60^{\circ}$ are not influenced by the hydration of Lap, as also reported by Bippus et al. (2009) for nanobuilding blocks Lap/Brij58 surfactant. 
In the present results indeed only the reflection at the lowest angles is shifted to lower angles with increasing humidity. The peak positions are summarized in Table A2.1.

Thus, swelling of the clay is detected by means of alterations in the basal reflection $\left(d_{(001)}\right)$ related to the interlayer space. According to the early literature (Norrish, 1954), clay swelling can be classified as "crystalline" or "osmotic". The difference between the mechanisms is based on the quantity of water molecules adsorbed in interlayer positions; hence crystalline swelling is associated with low, whereas osmotic swelling is associated with high amounts of molecules adsorbed. Hensen \& Smit (2002) used the molecular dynamics and Monte Carlo sampling simulations to predict the theoretical swelling in Mt. Authors report that the crystalline swelling in clays corresponds to the range of interlayer spaces $10.3 \AA<d_{(001)}<14.25 \AA$ and osmotic swelling, to $d_{(001)}>$ 14.25 $\AA$. The two regimes are rigorously determined by the number of water molecules which enter the interlayers via the presence of the cation.

In Fig. A2.3, $d_{(001)}$ values are plotted versus $w_{\text {equil }}$ of Lap RD conditioned under different RH. The $d_{(001)}$ values increase linearly with $w_{\text {equil }}$, suggesting that water molecules adsorb in interlayer space progressively and as a consequence, produce of a physical swelling (Norrish, 1954). The relationship between $d_{(001)}$ values and $w_{\text {equil }}$ writes as (insert in Fig. A2.3):

$d_{(001)}(\AA)=21.86 * w_{\text {equil }}+10.21$

The distance extrapolated towards $w_{\text {equil }}=0$ is $d_{(001)}=10.21 \pm 0.2 \AA$ and predicts the interlayer space when Lap RD is completely dehydrated. The value $(10.21 \AA)$ is very close to that reported by Hensen \& Smit (2002) from numerical predictions in dehydrated Mt $\left(d_{(001)}=10.3 \AA\right)$. 


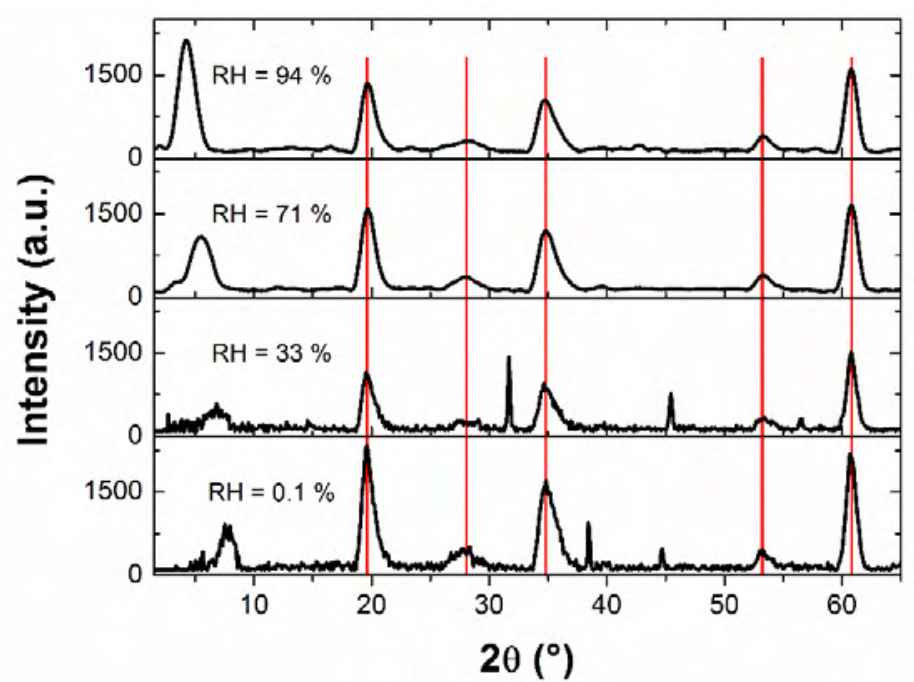

Figure A2.2. X-ray diffraction patterns of Lap RD conditioned under different relative humidities with $1.5^{\circ}<2 \theta<70^{\circ}$. The peak at the smaller scattering angle is related to the interlayer space which increases with water adsorption.

Table A2.1. Diffraction peak position vs. relative humidity (RH).

\begin{tabular}{ccccccc}
\hline RH & \multicolumn{5}{c}{ 20 Peak position $\left(^{\circ}\right)$} \\
\hline $0.1 \% *$ & 7.7 & 19.7 & 28.2 & 34.9 & 53.3 & 60.8 \\
$33 \% * *$ & 6.8 & 19.7 & 27.7 & 34.9 & 53.4 & 60.8 \\
$71 \%$ & 5.5 & 19.8 & 28.2 & 35 & 53.4 & 60.8 \\
$94 \%$ & 4.3 & 19.8 & 28.2 & 35 & 53.4 & 60.8 \\
\hline
\end{tabular}

* narrow peaks at $2 \theta=38.5$ and $44.7^{\circ}$ are probably due to impurities or sample contamination.

** narrow peaks at $2 \theta=29,31.7,45.5$ and $56.5^{\circ}$ are probably due to impurities or sample contamination.

Since water vapor adsorption and swelling are controlled by the cationic composition in $\mathrm{Mt}$, is it interesting to calculate the ratio $r=\mathrm{H}_{2} \mathrm{O} / \mathrm{Na}^{+}$for Lap equilibrated in desiccators.

With the chemical composition given by Tawari et al. (2001) the Lap RD unit cell contains $0.7 \mathrm{Na}^{+}$ions for a molar mass of $765.18 \mathrm{~g} / \mathrm{mol}$. From $w_{\text {equil }}$ measured at different $\mathrm{RH}$ values, the ratio $r$ is derived. The results are shown in Table A2.2. The lowest RH exhibit the lowest $r$ value which is about $r=2.2$ and the largest value is $r=$ 22. Hydration in Lap RD is very high compared to usual investigations of hydrates of Mt where this ratio is limited to the range $r<10$. Simulations by Hensen \& Smit (2002) of clay swelling show the presence of plateaus in layer spacing versus relative pressure. The dehydrated state corresponds to $d_{(001)}=10.3 \AA$, the one layer hydrate to $d_{(001)}=12.3$ 
$\AA$, and a less well defined state to $d_{(001)}=16-18 \AA$. $\mathrm{Na}^{+}$ions are assembled into complexes, water molecules are positioned initially in the center of the interlayer. With increasing water vapor pressure, in the simulations the complexes are preserved, their distance to the clay mineral surface remains almost constant. This forces the water molecules to form two layers or shells. Simulations show notably that the $\mathrm{Na}^{+}$ions move to the interlayer center for a ratio $r \approx 6$. The ratio $r \approx 6$ corresponds to the $\mathrm{Na}^{+}$ coordination number in concentrated $\mathrm{NaCl}$ aqueous solutions. Norrish (1954) observed experimentally for Na-Mt very large lattice expansions ( $d_{(001)}$ values), up to $70 \AA$, by equilibrium swelling of the clays in liquid water, after several months.

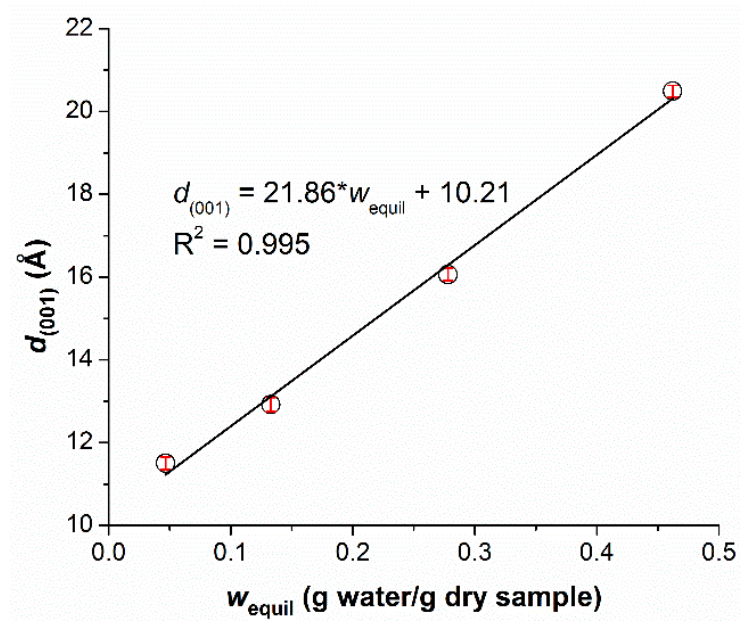

Figure A2.3. $d_{(001)}$ versus $w_{\text {equil }}$ of Lap RD conditioned under different relative humidities.

Table A2.2. The $w_{\text {equil }}, \mathrm{H}_{2} \mathrm{O} / \mathrm{Na}^{+}$and $d_{(001)}$ values $*$ in Lap $\mathrm{RD}$ conditioned under different relative humidities.

\begin{tabular}{cccc}
\hline RH (\%) & $\begin{array}{c}\boldsymbol{w}_{\text {equil }}(\mathbf{x 1 0})(\mathbf{g} \text { water/g dry } \\
\text { sample) }\end{array}$ & $\boldsymbol{R}=\mathbf{H}_{2} \mathbf{O} / \mathbf{N a}^{+}$ & $\boldsymbol{d}_{(\mathbf{0 0 1})}(\stackrel{\mathbf{A}}{)}$ \\
\hline 0.1 & $4.7 \pm 0.5$ & $2.2 \pm 0.2$ & $11.5 \pm 0.1$ \\
3 & $6.4 \pm 0.2$ & $3.0 \pm 0.1$ & \\
33 & $13.3 \pm 0.3$ & $6.3 \pm 0.1$ & $12.9 \pm 0.2$ \\
45 & $17.4 \pm 0.4$ & $8.3 \pm 0.2$ & \\
71 & $27.8 \pm 0.1$ & $13.2 \pm 0.1$ & $16.1 \pm 0.1$ \\
89 & $33.6 \pm 0.3$ & $16.0 \pm 0.1$ & \\
94 & $46.2 \pm 0.1$ & $22.0 \pm 0.0$ & $20.5 \pm 0.1$ \\
\hline
\end{tabular}

$\mathrm{RH}=$ relative humidity; $w_{\text {equil }}=$ equilibrium water; $d_{(001)}=$ basal reflection related to the interlayer space in Lap RD platelets. *All values are expressed as mean \pm standard error $(n=2)$. 


\section{A2.3.4. Discussion on Lap hydration}

These experiments highlight some specific features associated with Lap RD hydration. First of all, the Lap RD shows an equilibrium adsorption isotherm, while all other raw clays show lower adsorption and more scattered results (Fig. A2.1b). However most of the experimental work and numerical simulations were focused on raw clays. It is important therefore to examine the validity of conclusions based on raw clays by comparison with the synthetic clay, which should be considered as a reference. The relation between the ratio $r$ and the interlayer space $d_{(001)}$ measured by X-ray diffraction is shown in Table A2.2 and Fig. A2.4.

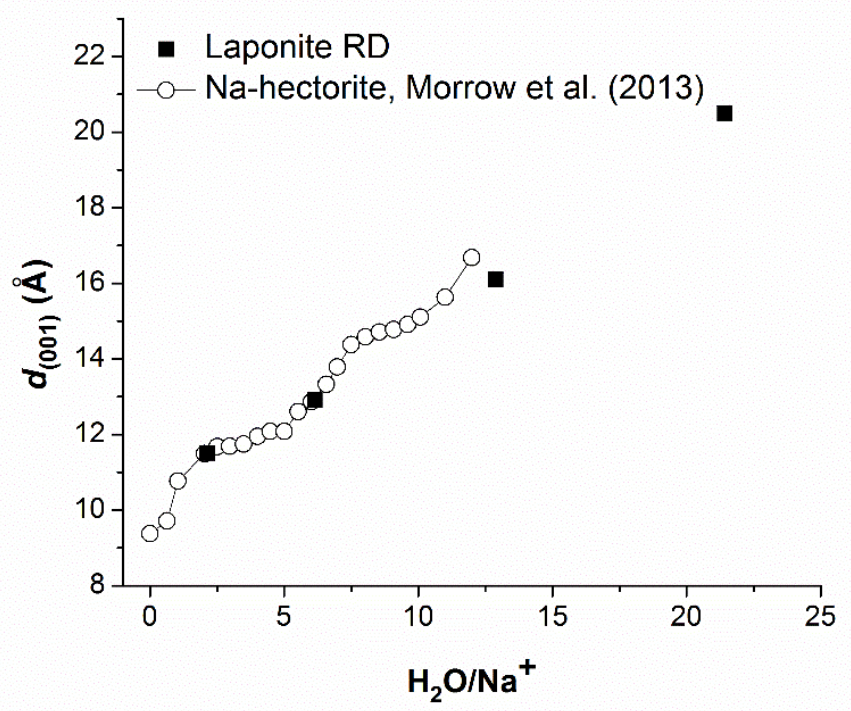

Figure A2.4. Interlayer space $(\AA)$ versus hydration level $\left(r=\mathrm{H}_{2} \mathrm{O} / \mathrm{Na}^{+}\right)$for Lap RD. Results on Na-Ht from simulations by Morrow et al. (2013) are also reported.

On Fig. A2.4 the $d_{(001)}$ values from X-ray diffraction measurements, are plotted together with the predicted values $\left(d_{(001)}\right)$ for Na-Ht by Morrow et al. (2013).

Experimental work on $\mathrm{Na}-\mathrm{Ht}$ determined the minimum hydration of the clay in very dry atmospheres $\left(\mathrm{P}_{2} \mathrm{O}_{5}\right)$ close to $r \approx 0.6$, while in the present research on Lap RD, the lowest hydration is close to $r \approx 2.2$. However, the measured interlayer space of Lap RD agrees very well with the molecular dynamics simulations of the first hydration plateau of $\mathrm{Na}-$ Ht which starts to form at $r \approx 2$ (Meleshyn \& Bunnenberg, 2005), the distance $d_{(001)}$ remaining constant $d_{(001)}=11.8 \AA$ until $r \approx 5$. Because Lap RD hydration is so favorable $r \approx 13$ is already reached with $\mathrm{RH}=71 \%$ with the interlayer $d_{(001)}=16.1 \AA$, while with $\mathrm{RH}=94 \%, d_{(001)}=20 \AA$. 
Besides, simulations by Hensen \& Smit (2002) on Na-Mt related the interlayer space to the relative pressure. The authors started simulations with the stable state corresponding to $\mathrm{RH}=30 \%$ with one-layer hydrate. When the equilibrium state was reached, the relative water vapor pressure was increased to $\mathrm{RH}=80 \%$, generating the two-layer hydrate. These simulations predict a hydration equilibrium diagram versus water activity (or water vapor pressure, $\mathrm{RH}$ ) which is completely different in Mt and in Lap, however the mechanisms of swelling seem to be well interpreted on basis of the $r$ parameter (simulations by Morrow et al., 2013). It is interesting to understand the origin of such discrepancies which need therefore a more refined analysis.

One important feature is the size of the platelets which is much smaller in synthetic clay (Lap) $25 \mathrm{~nm}$ than in any other Mt clays (Cummins, 2007).

Calculation from unit cell of Na-Mt evaluates specific surface area around $750 \mathrm{~m}^{2} / \mathrm{g}$. This suggests that, in the case of expanding clay lattices, the BET theory gives not the monolayer capacity on each surface of platelets, but the adsorption when only one layer of molecules occurs between each pair of platelets (plus the small contribution from a monolayer on edges and external surfaces), in agreement with the model based on complex formation between cations and water molecules. Lap hydration isotherm is in good agreement with this interpretation. It has also been reported in pioneer experiments by Norrish (1954) the existence of a gap between crystalline and osmotic swelling of Na-Mt. Recent Monte Carlo simulations of Na-Mt swelling by Meleshyn \& Bunnenberg (2005) found a chainlike structure consisting of $\mathrm{Na}$ cations, water molecules, and oxygen formed in Na-Mt at a layer space of $d \sim 19 \AA$, where experimental investigations showed "termination" of crystalline swelling. The authors suppose that such a persistent structure may "lock" the interlayer space, until excess water is able to break this chain by osmotic forces. This could be the reason for the existence of a gap in layer space between $\sim 19$ and $\sim 40 \AA$, which have been named "forbidden" layer space in experimental studies. The existence of this gap is reported by Norrish (1954) on clays which were let to swell in liquid water during several months with a water uptake in the range 0.5 to $1 \mathrm{~g}$ water/g sample. In the present work it was observed a continuous increase of the layer space, until $d_{(001)}=20 \AA$ and no gap. However, the available $2 \theta$ range of X-ray device should not be able to detect the coexistence of a second population with a larger gap and liquid water was not used. 


\section{A2.3.5. Kinetics of water desorption}

TGA experiments were carried out at constant temperature $\mathrm{T}=35{ }^{\circ} \mathrm{C}$ and $\mathrm{T}=45^{\circ} \mathrm{C}$ allowing to precisely follow the mass loss versus time for samples equilibrated in different humid atmospheres. The mass of water was calculated and normalized by the final mass of Lap RD measured at the same temperature after $120 \mathrm{~min}$. $x$ is the normalized mass of water by the final mass of Lap RD (moisture content):

$x(t)=\frac{m(t)-m_{\text {final }}}{m_{\text {final }}}$

where $m(t)$ is the sample mass (mg) at the time $t$ (min), and $m_{\text {final }}$ is the final mass (mg) of sample at $35{ }^{\circ} \mathrm{C}$ or $45{ }^{\circ} \mathrm{C}$. Samples analyzed with these isothermal protocols have a small amount of residual humidity approximately $0.01 \mathrm{~g}$ of water/g of dried sample determined by heating at $150^{\circ} \mathrm{C}$. It was considered that the "final mass" of the Lap RD after 120 min corresponds to “dry” Lap RD.

The normalized mass, $x$ versus time and the derivative of normalized mass, $|d x / d t|$ versus time for Lap RD samples conditioned initially under different $\mathrm{RH}$ are reported in Fig. A2.5a and 5b. At time 0 the initial values of $x$ vary between 0.45 and 0.05 . The $x$ values decrease versus time and the final mass is reached after $120 \mathrm{~min}$ (Fig. A2.5a). The plots versus time follow distinct curves depending on the initial humidity, but after $t=60 \mathrm{~min}$ they gather in almost a single curve. When $t=0 \mathrm{~min}$, the most humid samples exhibit large $|d x / d t|$ values (Fig. A2.5b). The evaporation rate is large because the difference between the water vapor concentration at the surface of the Lap RD and in (dry) nitrogen gas is large. A change of the slope of drying rate $|d x / d t|$ appears versus time (see insert arrows in Fig. A2.5b) for Lap RD conditioned at $\mathrm{RH}=71 \%$, $89 \%$ and $94 \%$ after $4.7 \mathrm{~min}, 5.49 \mathrm{~min}$ and $11.5 \mathrm{~min}$, respectively. The $x$ value associated to this particular moment is $0.15 \pm 0.02 \mathrm{~g}$ water/g dry sample. In contrast, Lap $\mathrm{RD}$ conditioned in $\mathrm{RH} \leq 45 \%$ shows no such a change because these samples have initial values $x \leq 0.14 \mathrm{~g}$ water/g dry sample. There is therefore an important change in the drying rate associated with the passage from high to low water contents. There is a formal analogy between dehydration and the desorption of gas from a solid surface or with decomposition reactions of solids, in particular analyzed by Kissinger (1957) and Adamson (1990). Although empirical orders of reaction can possibly be investigated 
with the help of more refined versions of these models, it was assumed here that desorption of water molecules previously adsorbed on Lap RD is a first order reaction and this assumption was validated with the experimental data.
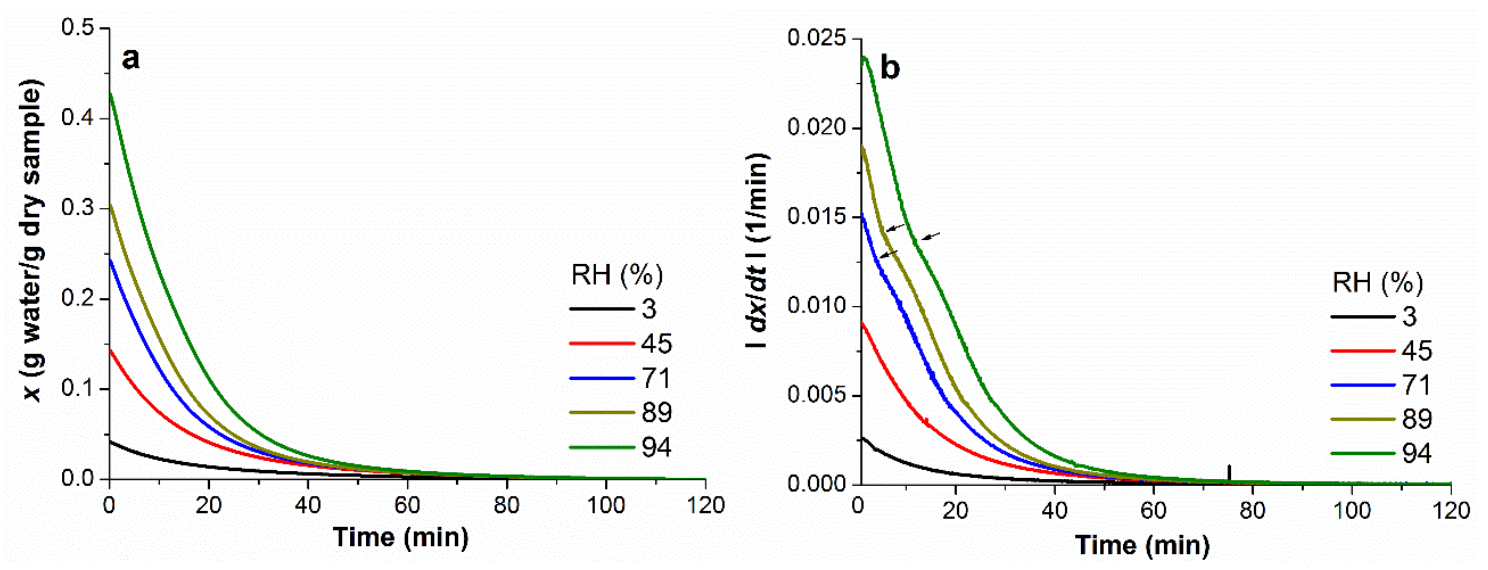

Figure A2.5. (a) Normalized mass of water $x$ versus time and (b) derivative of normalized mass, $|d x / d t|$ versus time of Lap RD conditioned under different relative humidities and analyzed by isothermal conditions at $35^{\circ} \mathrm{C}$.

In a general formulation of a desorption reaction from the surface of a solid, the variable $x$ is the fraction of occupied sites at the surface of the solid (or surface coverage), $d x / d t$ is the desorption rate. Assuming that there is no re-adsorption, the reaction rate for a first order reaction writes:

$-\frac{d x}{d t}=A x e^{-E / R T}$

where $A$, is a frequency factor $(1 / \mathrm{min}), E$ is the activation energy $(\mathrm{kJ} / \mathrm{mol}), R$ is the universal constant gas $(\mathrm{kJ} / \mathrm{mol} \cdot \mathrm{K})$, and $T$, is the temperature $(\mathrm{K})$.

From Eq. (A2.5) is possible to anticipate that desorption kinetics in isothermal conditions can be expressed as a potential function, where $|d x / d t|$ decreases as a function of time, following the decrease of $x$. In isothermal conditions, activation energy can be calculated by means of Eq. (A2.5); measuring the desorption rates at least at two constant temperatures allows determining both $A$ and $E$ values without any adjustable parameter. The plots of $|d x / d t|$ versus $x$ derived from several experiments on Lap RD conditioned at $\mathrm{RH}=3 \%, 45 \%$ and $94 \%$, dried in isothermal conditions, both at $35{ }^{\circ} \mathrm{C}$ and $45{ }^{\circ} \mathrm{C}$ are showed in Fig. A2.6. Interestingly, in each plot, at a fixed temperature, all desorption rates $|d x / d t|$ versus $\boldsymbol{x}$ are superposed on a single curve. As 
predicted by Eq. (A2.5) there is a linear dependence of the slope $|d x / d t|$ versus $x$ at a fixed temperature. However, it is observed distinctly two regimes according to the water content in Lap RD; the slope changes between the low and high values of $x$, when $x \approx$ $0.15 \pm 0.02 \mathrm{~g}$ water/g dry sample. Comparing desorption rates at different constant temperatures, one can see that they are larger when temperature increases in both regimes, which is expected from Eq. (A2.5). In the first regime, with $x<0.15$, the linear regression give respectively the slopes 0.074 and 0.137 at 35 and $45{ }^{\circ} \mathrm{C}$, from where the activation energy is calculated. The second regime, starts at $x \approx 0.15$ with an imposed initial rate and the slopes of the regression lines are 0.055 and 0.083 at 35 and $45{ }^{\circ} \mathrm{C}$. Extrapolation towards 0 desorption rate in this regime needs a shift of origin of the $x$ values. It was derived from these plots, using Eq. (A2.5), the following desorption energies and frequencies:

$$
\begin{gathered}
E_{1}=52 \pm 3 \mathrm{~kJ} / \mathrm{mol} \text {, when } x<0.15 \text {, and } A_{1}=1.410^{8} \pm 410^{7} \mathrm{~min}^{-1} \\
E_{2}=33 \pm 1.5 \mathrm{~kJ} / \mathrm{mol} \text {, when } 0.15<x \leq 0.4 \text {, and } A_{2}=4.610^{4} \pm 910^{2} \mathrm{~min}^{-1}
\end{gathered}
$$

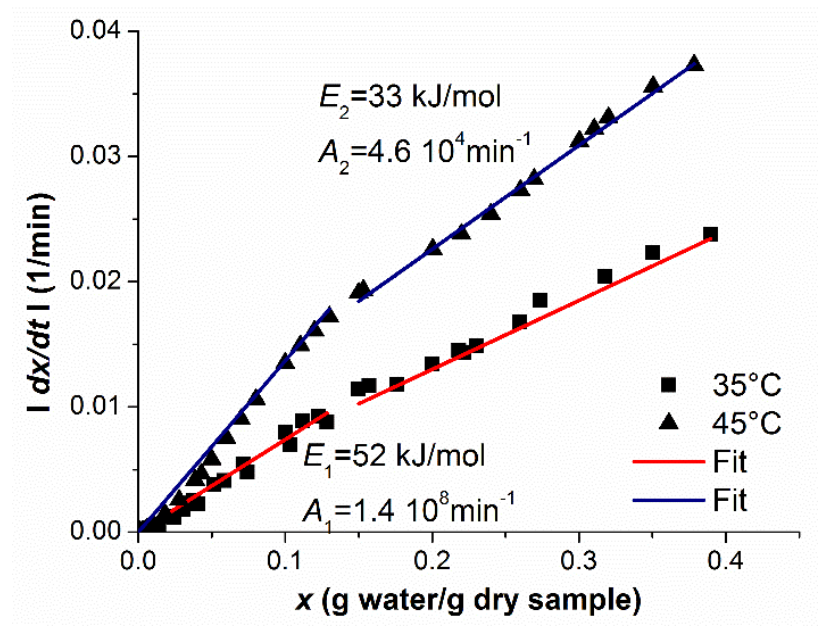

Figure A2.6. Derivative of normalized mass, $|d x / d t|$ versus normalized mass $x$ of Lap $\mathrm{RD}$ conditioned at $\mathrm{RH}=3 \%, 45 \%$ and $94 \%$, and analyzed in isothermal conditions at $35^{\circ} \mathrm{C}$ and $45^{\circ} \mathrm{C}$. Straight lines represent the fit by linear regressions.

The activation energies are of the order of magnitude to those reported for ionic and hydrogen bonds. At low $(x<0.15 \mathrm{~g}$ water/g dry sample) and high $(x>0.15 \mathrm{~g}$ water/g dry sample and $x<0.4 \mathrm{~g}$ water/g dry sample) water contents, desorption kinetics are different. When $x \approx 0.15 \pm 0.02 \mathrm{~g}$ water/g dry sample, $r=7.13 \pm 0.47$. This value is close to that predicted by Hensen \& Smit (2002) for Na-Mt $(r=6)$ and interpreted as the 
moment where $\mathrm{Na}^{+}$ions move to the interlayer center and corresponds also to $\mathrm{Na}^{+}$ coordination number of concentrated $\mathrm{NaCl}$ solutions.

It is observed a large difference in the frequency factors $(A)$ in the two ranges of water desorption. Frequency factors could be associated with the number of attempts by molecule per unit time to escape from the matrix (Adamson, 1990).

Two regimes according to the hydration level of the Lap RD are identified in TGA experiments:

i) When $0.15<x \leq 0.4$ the regime corresponds to the most hydrated samples, where the equilibrium interlayer space is larger $>14 \AA$ and water molecules form complexes around $\mathrm{Na}^{+}$ions. It was found a single activation energy 33 $\mathrm{kJ} / \mathrm{mol}$ and a small frequency factor $4.610^{4} \mathrm{~min}^{-1}$. It was suggested by Clausen et al. (2011) that the equilibrium desorption isotherm at high water contents of raw Na-Sm can be attributed to capillary adsorption of the water in the microstructure, corresponding to a liquid state of water, with a heat of vaporization of $44 \mathrm{~kJ} / \mathrm{mol}$. In their experiments, indeed, the initial rate of release of water molecules was close to the rate of evaporation of bulk water. However, these authors studied a raw Na-Sm with a granular structure prepared from slurry, which is very different from Lap RD sample. In the present work, no such effect can be suspected: the evaporation rate for pure water is $\approx 1 \mathrm{mg} / \mathrm{min}$ at $\mathrm{T}=40{ }^{\circ} \mathrm{C}$ (Valencia et al., 2016 ${ }^{\mathrm{b}}$ ) while for the most humid sample of Lap $\mathrm{RD}$ at $35{ }^{\circ} \mathrm{C}$, it is $0.60 \mathrm{mg} / \mathrm{min}$. A very small frequency factor $4.610^{4} \mathrm{~min}^{-1}$ is found.

ii) At $x<0.15 \mathrm{~g}$ water/g dry sample, it is observed a high activation energy 52 $\mathrm{kJ} / \mathrm{mol}$ and a high $A$ value $1.410^{8} \mathrm{~min}^{-1}$. In this range, water molecules are strongly bonded to $\mathrm{Na}^{+}$ions. The regime corresponds either to the end of the dehydration of the most humid samples or to the kinetics of dehydration of less humid ones, with $r<7$. As these samples are the less hydrated ones, the interlayer space should be smaller compared to hydrated samples. The activation energy is the same order of magnitude, but the frequency factor is increased by a factor $10^{4}$.

iii) In all cases, the diffusion coefficients of water vapor are configurational dependent: channel diameters, tortuosity, overall porosity (Xiao \& Wei, 
1992)... It is expected a small frequency factor in small channels. However hydration of Lap RD is due to a very specific mechanism which is well predicted in equilibrium configurations with the parameter $r$. During dehydration, it is possible that the structures are not in equilibrium. Numerical simulations, with $r<10$, show a plateau (constant) values the distance $d_{(001)}$ while the water content changes. It was also reported by Ferrage et al. (2007) in Ca-Mt that the interlayer space is not homogeneous during dehydration and several types of layers may coexist during the nonequilibrium process. In the present research, TGA experiments show that dehydration of Lap RD containing less water molecules than the coordination number of $\mathrm{Na}^{+}$ions proceeds with a very high rate.

To understand the mechanisms of desorption of water molecules in Lap RD it is necessary to investigate more closely the structure during the drying or de-swelling processes. Kinetics effects play a very important role in hydration of synthetic clay minerals and raw clays and it possible that Lap RD and raw clays do not follow the same paths. TGA experiments performed in similar conditions with Lap RD and raw clays may provide new insights on these aspects. The dehydration rates of nanoparticles of Lap RD reveal an unexpected tendency, which was not reported in experiments on raw clays. It is important therefore to establish protocols which are compatible with different experiments, by controlling in particular the environmental conditions. The mechanisms of dehydration of the clays are specific to these materials and may show many interesting and unique features.

\section{A2.4. Conclusions}

This investigation highlights the differences between $\mathrm{Sm}$ and the synthetic nanoparticle Lap RD with respect to their hydration, swelling and desorption properties. Lap RD is a model system for raw clays; however some properties have been less explored and should be important in applications and formulations where nanoscale objects, with organic and inorganic components are assembled and where the hydration level must be controlled. The present investigation reveals that physical swelling of Lap RD is fully controlled by water molecules that are adsorbed in interlayer space progressively and more precisely by the ratio $r=\mathrm{H}_{2} \mathrm{O} / \mathrm{Na}$. It is shown that the hydration proceeds towards very high levels 
unreached by raw clays. TGA and X-ray diffraction results support recent numerical simulations of complexes in the interlayer spaces of Sm. Desorption kinetics in isothermal conditions allow identifying two regimes according to the hydration of the Na cations, at high $(r>7)$ and low $(r<7)$ water contents. The activation energies associated to the desorption processes in these regimes are 33 $\mathrm{kJ} / \mathrm{mol}$ and $52 \mathrm{~kJ} / \mathrm{mol}$, respectively determined in the experimental conditions of this investigation. Unexpectedly, the frequency factors are totally different in the two regimes. It is suggested that the mechanisms of water desorption of Sm type clays and in particular Lap, may constitute a special case and bring interesting new features about the cation complex stability.

\section{A2.5. References}

Adamson, A.W., 1990. Physical chemistry surfaces. (5th Edition). Lewiston, NY (pp. 691-692).

Agaciak, P., Yahiaoui, S., Djabourov, M., Lasuye, T., 2015. Dehydration and drying poly(vinyl)chloride (PVC) porous grains: 2 . Thermogravimetric analysis and numerical simulations. Colloid Surface A. 470, 120-129.

Anderson, R.L., Ratcliffe, I., Greenwell, H.C., Williams, P.A., Cliffe, S., Coveney, P.V., 2010. Clay swelling - A challenge in the oilfield. Earth-Sci Rev. 98, 201-216.

Bérend, I., Cases, J.M., François, M., Uriot, J.P., Michot, L., Masion, A., Thomas, F., 1995. Mechanism of adsorption and desorption of water vapor by homoionic montmorillonites: 2. The $\mathrm{Li}^{+}, \mathrm{Na}^{+}, \mathrm{K}^{+}, \mathrm{Rb}^{+}$, and $\mathrm{Cs}^{+}$-exchanged forms. Clay Clay Miner. 43, 324-336.

Bippus, L., Jaber, M., Lebeau, B., 2009. Laponite and hybrid surfactant/laponite processed and spheres. New J. Chem. 33, 1116-1126.

Butt, H.J., Graf, K., Kappl, M., 2006, Physics and chemistry of interfaces (2nd Edition). Wiley-VCH (pp. 189-192).

Brunauer, S., Emmett, P.H., Teller, E., 1938. Adsorption of gases in multimolecular layers. J. Am Chem Soc. 60, 309-319.

Caturla, F., Sabio, M.M., Reinoso, F.R., 1999. Adsorption-desorption of water vapor by natural and heat-treated sepiolite in ambient air. Appl. Clay Sci. 15, 367-380.

Clausen, P., Signorelli, M., Schreiber, A., Hughes, E., Plummer, C.J.G., Fessas, D., Schiraldi, A., Månson, J.A.E., 2009. Equilibrium desorption isotherms of water, 
ethanol, ethyl acetate, and toluene on a sodium smectite clay. J. Therm. Anal. Calorim. 98, 833-841.

Clausen, P., Watzke, B., Hughes, E., Plummer, C.J.G., Månson, J.A.E., 2011. Evaporation kinetics of volatile liquids and release kinetics of water from a smectite clay: Comparison between experiments and finite element calculations. Int J Eng Sci. 49, 25-1140.

Cummins, H.Z., 2007. Liquid, glass, gel: The phases of colloidal Laponite. J. Non-Cryst Solids. 353, 3891-3905.

Ferrage, E., Kirk, C.A., Cressey, G., Cuadros, J., 2007. Dehydration of Camontmorillonite at the crystal scale. Part I: Structure evolution. Am Mineral. 92, 9941006.

Fripiat, J., Cases, J., Fracois, M., Letellier, M., 1982. Thermodynamic and Microdynamic behavior of water in clay suspensions and gels. J. Colloid Interf Sci. 89, $378-400$.

Fu, M.H., Zhang, Z.Z., Low, P.F., 1990. Changes in the properties of a montmorillonite-water system during the adsorption and desorption of water: hysteresis. Clay Clay Miner. 38, 485-492.

Ghadiri, M., Hau, H., Chrzanowski, W., Agus, H., Rohanizadeh, R., 2013. Laponite clay as a carrier for in situ delivery of tetracycline. RSC Adv. 3, 2019320201.

Hellman, N.N., Melvin, E.H., 1950. Surface area of starch and its role in water sorption. J. Am Chem Soc. 72, 5186-5188.

Hensen, E.J.M., Smit, B., 2002. Why clays swell. J. Phys Chem B. 106, 12664-12667. Johansen, R.T., Dunning, H.N., 1959. Water-vapor adsorption on clays. Clay Clay Miner. Ada Swineford, ed., Pergamon Press, New York, 249-258.

Karamanis, D., Ökte, A.N., Vardoulakis, E., Vaimakis, T., 2011. Water vapor adsorption and photocatalytic pollutant degradation with $\mathrm{TiO}_{2}$-sepiolite nanocomposites. Appl. Clay Sci. 53, 181-187.

Kissinger, H.E., 1957. Reaction kinetics in differential thermal analysis. Anal Chem. 29, 1702-1706.

Meleshyn, A., Bunnenberg, C., 2005. The gap between crystalline and osmotic swelling of Na-montmorillonite: a Monte Carlo study. J. Chem Phys. 122, 034705.

Mooney, R.W., Keenan, A.G., Wood, L.A., 1952. Adsorption of water vapor by montmorillonite. I. Heat of desorption and application of BET theory. J. Am Chem Soc. $22,1367-1371$. 
Morrow, C.P., Yazaydin, Ö., Krishnan, M., Bowers, G.M., Kalinichev, A.G., Kirkpatrick, R.J., 2013. Structure, energetics, and dynamics of smectite clay interlayer hydration: molecular dynamics and metadynamics investigation of Na-Hectorite. J. Phys Chem C. 117, 5172-5187.

Norrish, K., 1954. The swelling of montmorillonite. Discuss Faraday Soc. 18, 120-134.

Prado, J.R., Vyazovkin, S., 2011. Activation energies of water vaporization from the bulk and from laponite, montmorillonite, and chitosan powders. Thermochim. Acta. 524, 197-201.

Tawari, S.L., Koch, D.L., Cohen, C., 2001. Electrical double-layer effects on the Brownian diffusivity and aggregation rate of laponite clay particles. J. Colloid Interf Sci. 240, 54-66.

Valencia, G.A., Lourenço, R.V., Bittante, A.M.Q.B., Sobral, P.J.A., 2016 ${ }^{\text {a }}$ Physical and morphological properties of nanocomposite films based on gelatin and Laponite. Appl. Clay Sci. 124-125, 260-266.

Valencia, G.A., Djabourov, M., Sobral, P.J.A., 2016 ${ }^{\mathrm{b}}$. Water desorption of cassava starch granules: a study based on thermogravimetric analysis of aqueous suspensions and humid powders. Carbohyd Polym. 147, 533-541.

Wyckoff, R.W.G., 1968. Crystal Structures (4th Ed). (1968). John Wiley and Sons, New York, London.

Xiao, J., Wei, J., 1992. Diffusion mechanism of hydrocarbons in zeolites. I. Theory. Chem Eng Sci. 47, 1123-1141. 